\title{
A Structured Approach for Facilitating the Implementation of ISO 50001 Standard in Manufacturing Industry
}

Kartik Ramamoorthy

West Virginia University

Follow this and additional works at: https://researchrepository.wvu.edu/etd

\section{Recommended Citation}

Ramamoorthy, Kartik, "A Structured Approach for Facilitating the Implementation of ISO 50001 Standard in Manufacturing Industry" (2012). Graduate Theses, Dissertations, and Problem Reports. 3339.

https://researchrepository.wvu.edu/etd/3339

This Thesis is protected by copyright and/or related rights. It has been brought to you by the The Research Repository @ WVU with permission from the rights-holder(s). You are free to use this Thesis in any way that is permitted by the copyright and related rights legislation that applies to your use. For other uses you must obtain permission from the rights-holder(s) directly, unless additional rights are indicated by a Creative Commons license in the record and/ or on the work itself. This Thesis has been accepted for inclusion in WVU Graduate Theses, Dissertations, and Problem Reports collection by an authorized administrator of The Research Repository @ WVU. For more information, please contact researchrepository@mail.wvu.edu. 
A Structured Approach for Facilitating the Implementation of ISO 50001 Standard in

Manufacturing Industry

By

Kartik Ramamoorthy

Thesis submitted to the

Benjamin M. Statler College of Engineering and Mineral Resources at West Virginia University

in partial fulfillment of the requirements for the degree of

Master of Science

in

Industrial Engineering

Bhaskaran Gopalakrishnan, Ph.D., P.E

Edward Crowe, Ph.D., P.E

Majid Jaridi, Ph.D.

Industrial and Management Systems Engineering

Morgantown, West Virginia

2012

Keywords: ISO 50001, Superior Energy Performance (SEP), Energy Performance Indicator, Energy Planning, Implementation and Operations, ISO 50001 Analyzer software 


\section{Abstract \\ A Structured Approach for Facilitating the Implementation of ISO 50001 Standard in Manufacturing Industry}

\section{Kartik Ramamoorthy}

Technical solutions and technological changes alone cannot sustain energy saving improvements and promote continual improvement in an organization. Successful bridging between technical and management principles to implement an energy management system would lead to energy savings. To overcome the lack of availability of proper framework to implement an energy management system conforming to the ISO 50001, a standard methodology using flow charts and a software ISO 50001 Analyzer is developed to help facilities get certified by checking if their energy management system complies with the ISO 50001 standard. The major aim of the software is to reduce the degree of difficulty in implementing an energy management system in accordance with the ISO 50001 and hence help plants reap the benefits of managing energy which include cost benefits and increased business (due to certification). The software is also designed to be a guiding tool for energy consultants to help company managers understand the requirements of ISO 50001.

This research involves developing flow charts to identify steps to be followed by an organization to meet the requirements of the ISO 50001 standard and designing a software entitled "ISO 50001 Analyzer" which would help industries implement this management system. The software has code built into it containing all the requirements in the ISO 50001 standard. The user can follow the sequence of flow of the software and give inputs on the present working condition of their energy management system. The software will check if the organization satisfies all the requirements as per the ISO 50001 standard. This work also includes building a database in the software to store all the documents and records in an organized manner as required in the standard. This database would make the auditing process of documents and records simpler for both the auditor and organization. 


\section{Acknowledgement}

I would like to thank my advisor Dr. B. Gopalakrishnan for his continued support, guidance and encouragement during the course of this research. I also wish to thank Dr. Edward Crowe, Dr. Majid Jaridi and Mr. Sneh Kumar for their advice and support. I wish to extend my special thanks to Mr. Subodh Chaudhari and Mr. Maruthy Jakkam for their invaluable help and support for the success of this project.

Above all, I wish to thank God and my family for their constant support and blessings, enabling my success and happiness in all my pursuits and endeavors in life. 


\section{Nomenclature}

\begin{tabular}{|c|c|c|}
\hline EnMS - & - & Energy Management System \\
\hline ISO & - & International Organization for Standardization \\
\hline SEU & - & Significant Energy User \\
\hline KPI & - & Key Performance Indicator \\
\hline G20 & - & Group of Twenty Finance Ministers and Central Bank Governors \\
\hline IEA & - & International Energy Agency \\
\hline EnPI & - & Energy Performance Indicator \\
\hline SEP & - & Superior Energy Performance \\
\hline $\mathrm{NC}$ & - & Nonconformity \\
\hline PDCA - & - & Plan-Do-Check-Act \\
\hline LF & - & Load Factor \\
\hline UF & - & Utilization Factor \\
\hline Eff & - & Efficiency \\
\hline $\mathrm{R}^{2}$ & - & Coefficient of Correlation \\
\hline IRR & - & Internal Rate of Return \\
\hline MARR & & Minimum Acceptable Rate of Return \\
\hline
\end{tabular}




\section{Table of Contents}







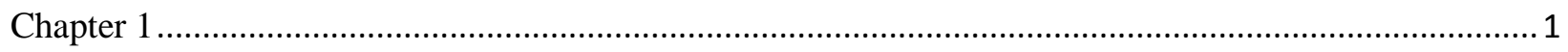

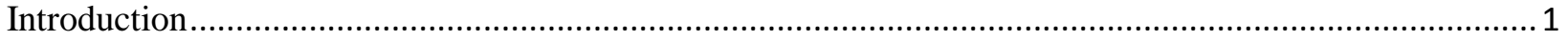

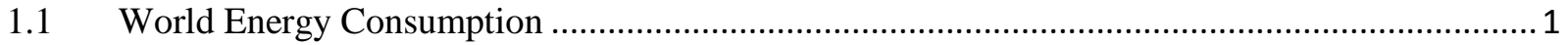

1.2 Requirement for Reduction in Energy Intensity .......................................................... 2

1.3 Arrival of Energy Management in Industries................................................................... 5

1.4 The Importance of Energy Management to Promote Energy Efficiency ................................... 6

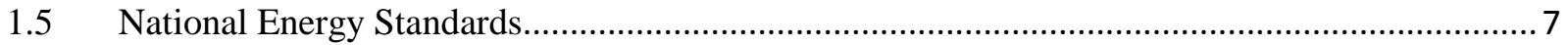



















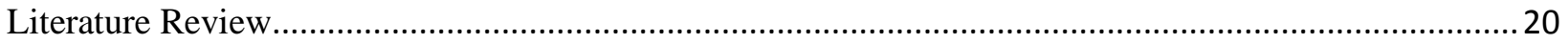



2.2 Implementation of ISO 50001 Energy Management System in Industries...............................21

2.2.1 Status Evaluation and Concept for Implementing Energy Consumption Data Monitoring





2.2.3 Measuring Energy Savings by Using Normalized Energy Intensity................................ 26














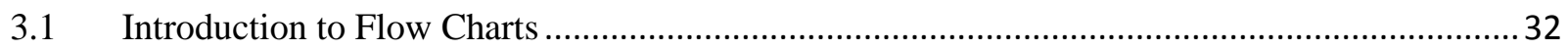

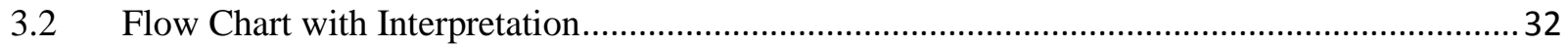

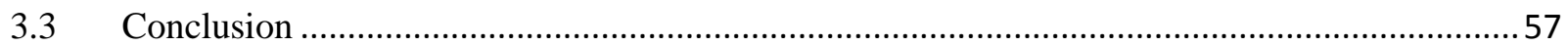

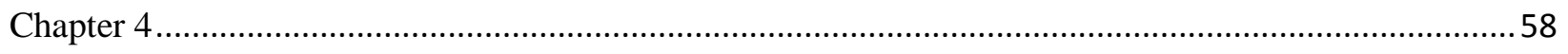

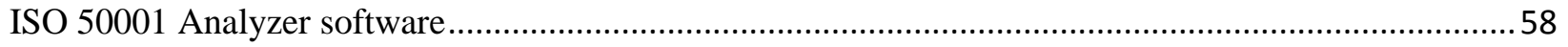

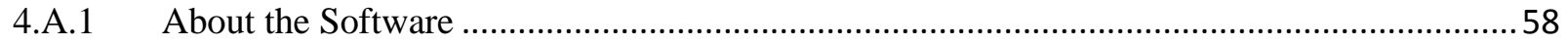



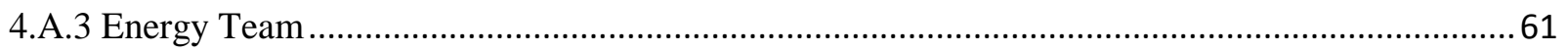

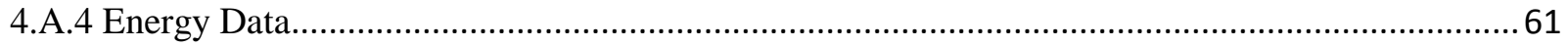

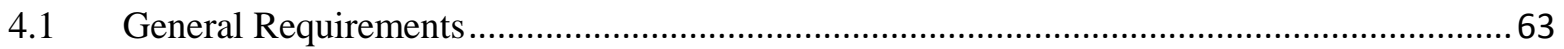

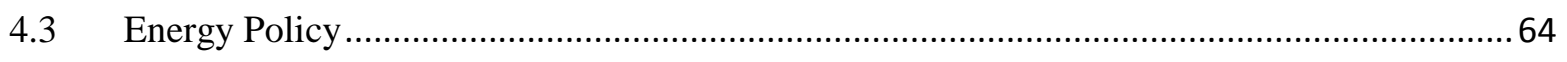

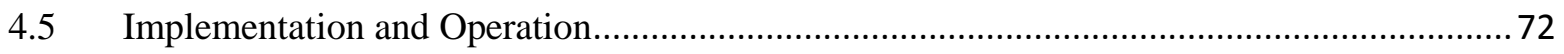

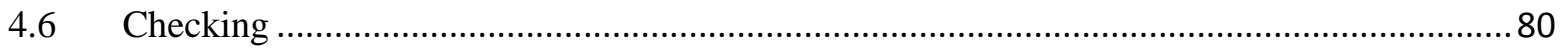



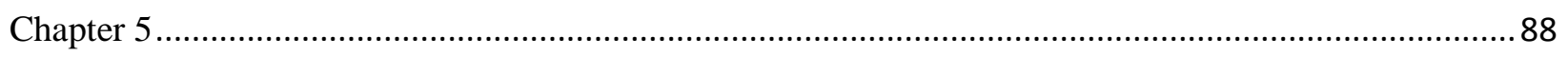

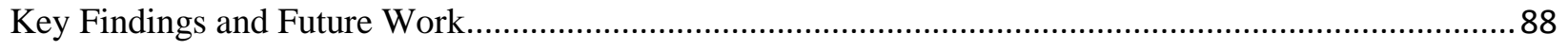

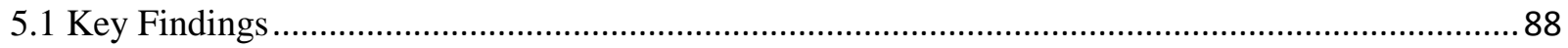

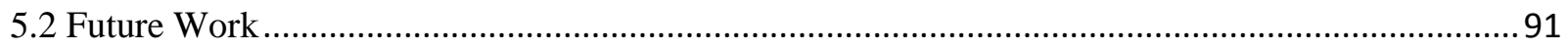

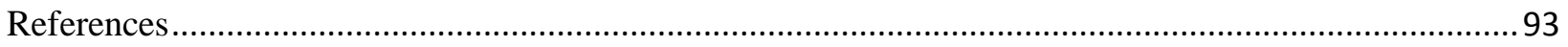




\section{List of Figures}

Figure 1.1.1: Energy consumption by major G20 countries $\quad 1$

Figure 1.1.2: Consumption of Energy Source in US - 2009

Figure 1.2.1: Total Global Cumulative Capacity of Wind Power from 1996 - 20104

Figure 1.6.1: Continual Improvement in Quality Management Cycle 9

Figure 1.6.2: Continual Improvement in Environmental Management Cycle 10

Figure 1.7.1: PDCA cycle $\quad 12$

Figure 1.10.1: Level of Increase in Energy Management Improvement 18

Figure 2.1.1: Framework for General Implementation of Energy Management 21

Figure 2.2.1: Status Evaluation by Checklist Methodology in ISO 50001

Figure 2.2.2: ISO 50001 Requirement Completion Score 23

Figure 2.2.3: Identification of Energy Sources and Consumers 24

Figure 2.2.4: Introduction of Energy Consumption Data Monitoring 24

Figure 2.2.5: Tool for Energy Consumption Data Monitoring 25

Figure 2.2.6: Framework for ISO 50001 27

Figure 2.3.1: Comparison between ISO 14001 and ISO 50001

Figure 3.1.1: Energy Policy $\quad 34$

Figure 3.1.2: Scope, boundary and management responsibilities 35

Figure 3.1.3: Legal and other requirements $\quad 37$

$\begin{array}{ll}\text { Figure 3.1.4: Energy review } & 38\end{array}$

Figure 3.1.5: Energy Review (ii) $\quad 40$

Figure 3.1.6: Energy Baseline $\quad 41$

Figure 3.1.7: Energy Performance Indicators 43

Figure 3.1.8: Objectives, targets and action plan 44

Figure 3.1.9: Competence, training and awareness 46

Figure 3.1.10: Control of documents $\quad 47$

$\begin{array}{ll}\text { Figure 3.1.11: Operational control } & 48\end{array}$ 
Figure 3.1.12: Design and procurement $\quad 50$

Figure 3.1.13: Procurement $\quad 51$

Figure 3.1.14: Energy Procurement $\quad 52$

Figure 3.1.15: Internal audit $\quad 54$

Figure 3.1.16: Nonconformities, correction, corrective and preventive action 55

Figure 3.1.17: Management Review 56

Figure 4.A.1 (a): Working of Java Language $\quad 59$

$\begin{array}{ll}\text { Figure 4.A.1 (b): Software Main Screen } & 60\end{array}$

Figure 4.A.2: Company Details Module 60

$\begin{array}{ll}\text { Figure 4.A.3: Energy Team } & 61\end{array}$

Figure 4.A.4 (a): Energy Data Collection Screen $\quad 62$

Figure 4.A.4 (b): Energy Data Collection Screen $\quad 62$

Figure 4.B.1: ISO 50001 Module Main Screen $\quad 63$

Figure 4.1.1: Screenshot of Scope and Boundary $\quad 64$

Figure 4.3.1 (a): Screenshot of Section of Guide to Energy Policy 65

Figure 4.3.1 (b): Screenshot of Post Defining Energy Policy 65

Figure 4.4.2: Screenshot of Legal and Other Requirements $\quad 67$

$\begin{array}{ll}\text { Figure 4.4.3 (a): Screenshot of Energy Review } & 68\end{array}$

Figure 4.4.3 (b): Screenshot of Energy Review (I) 69

Figure 4.4.3 (b): Screenshot of Energy Review (II) 71

Figure 4.4.5: Screenshot of Energy Objectives, Targets and Action Plan 72

Figure 4.5.1: Software Screenshot of Implementation and Operation 73

Figure 4.5.2(b): Screenshot of Competency and Training Requirement 74

Figure 4.5.2(c): Screenshot of Awareness Requirement $\quad 75$

Figure 4.5.3: Screenshot of Communication Section of the Software 75

Figure 4.5.4 (a): Screenshot of Document Approval Process 76 
Figure 4.5.4 (b): Screenshot of Document Collection Process

Figure 4.5.4 (c): Documents and Records Module of the Software

Figure 4.5.5: Screenshot of Operational Control Section of the Software

Figure 4.5.6: Screenshot of Design Module

Figure 4.5.7: Screenshot of Procurement of Equipment, Energy Service \& Module

Figure 4.6.A: Checking Performance Screen of the software

Figure 4.6.1 (a): Monitoring, Measurement and Analysis Screenshot

Figure 4.6.1 (b): Significant Deviation Screenshot

Figure 4.6.3: Internal Audit Section of the Software

Figure 4.6.4: Nonconformities, Correction, Corrective and Preventive Action Screenshot 83

Figure 4.6.5: Screenshot of Control of Records Section of the software

Figure 4.7.A: Management Review screen of the software

Figure 4.7.1: Management Review General Screenshot

Figure 4.7.2: Management Review Input Screenshot 86

Figure 4.7.3: Management Review Output Screenshot

Figure 5.1.1: Checklist showing Document and Record requirements 


\section{Chapter 1}

\section{Introduction}

\subsection{World Energy Consumption}

The consumption of energy sources has been increasing drastically over the past 30 years. Fossil fuels which are one of the major sources of energy are also the slowest growing energy source in the world. It is estimated that the world energy consumption would increase by $49 \%$ from 2007 to 2035 [1]. In 2009 the world energy consumption decreased by $1.1 \%$ in comparison with 2008 . This decrease in energy consumption was observed after 30 years and was the result of the economic crisis (average GDP drop across the world by $0.6 \%$ ). There was growth in energy consumption in several developing Asian countries $(+4 \%)$ as recession was comparatively least hit. In North America, Europe and Commonwealth of Independent States, consumptions shrank by $4.5 \%, 5 \%$ and $8.5 \%$ respectively due to the slowdown in economic activity [1]. Hence the energy consumption did not reduce in all parts of the world and was the net effect of highs and lows. As a result of gradual recovery from the economic crisis and further industrial dynamism shown by Asian countries energy consumption in 2010 increased by 5\% compared to 2009 [2].

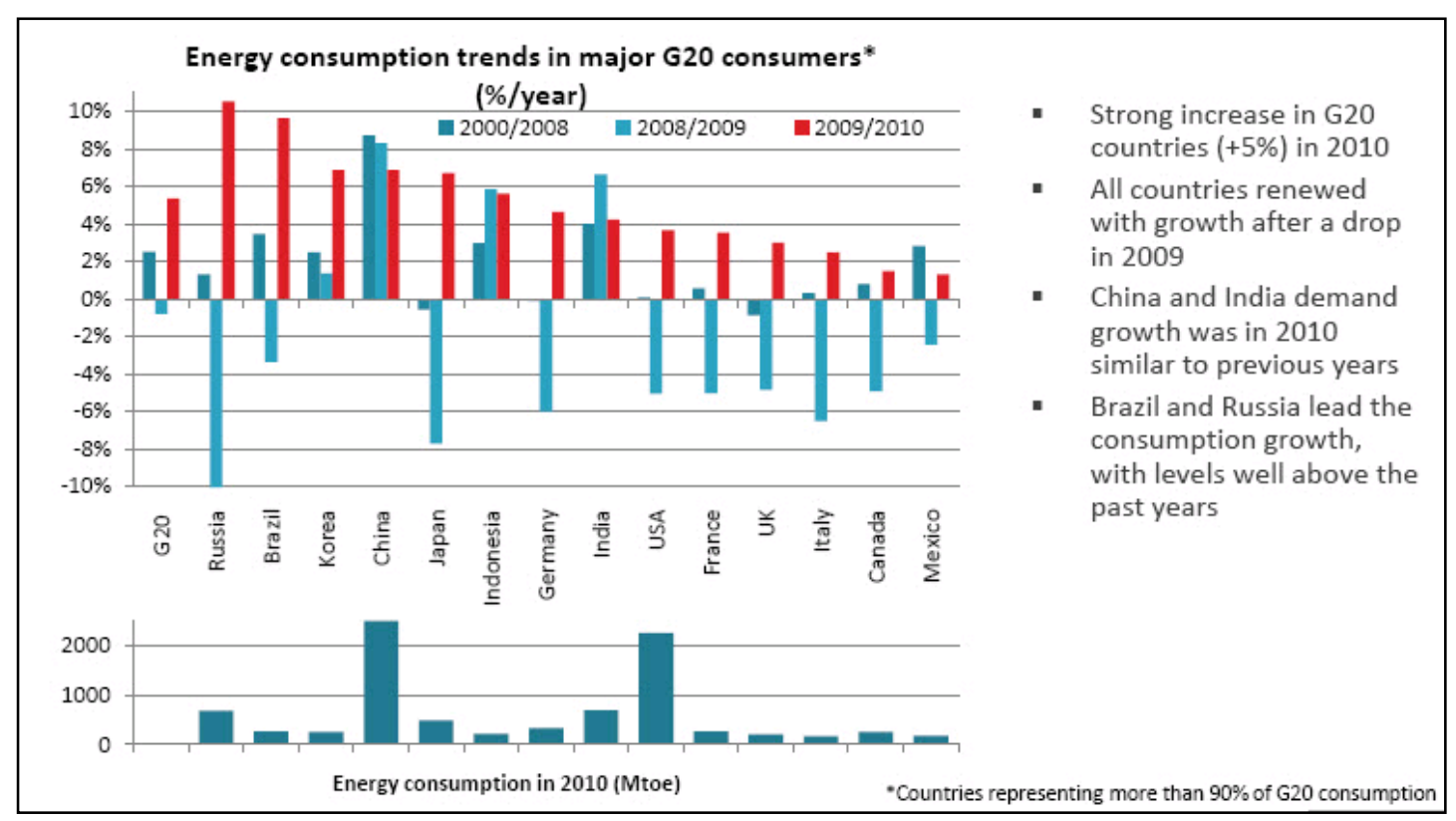

Figure 1.1.1: Energy consumption in major G20 countries [2] 
Figure 1.1.1 below shows the energy consumption in major G20 countries from 2008 - 2010 . According to the International Energy Agency (IEA), the world population increased by 5\%, annually $\mathrm{CO}_{2}$ emissions increased by $10 \%$ and the gross energy production increased $10 \%$ in four years (2004-2008) [2]. Despite advances in efficiency and sustainability, since the industrial revolution in the last two decades more than half of the world energy reserve has been consumed [2].

Though there has been technological advancement made to find several new renewable energy sources, oil remains to be the largest energy source followed by coal. In 2009 their shares as energy source were $35 \%$ and $30 \%$ respectively. The US consumes $25 \%$ of the world's energy with a share of global GDP at 22\% [1,2]. Figure 1.1.2 [3] shows the consumption of various energy sources in US in 2009.

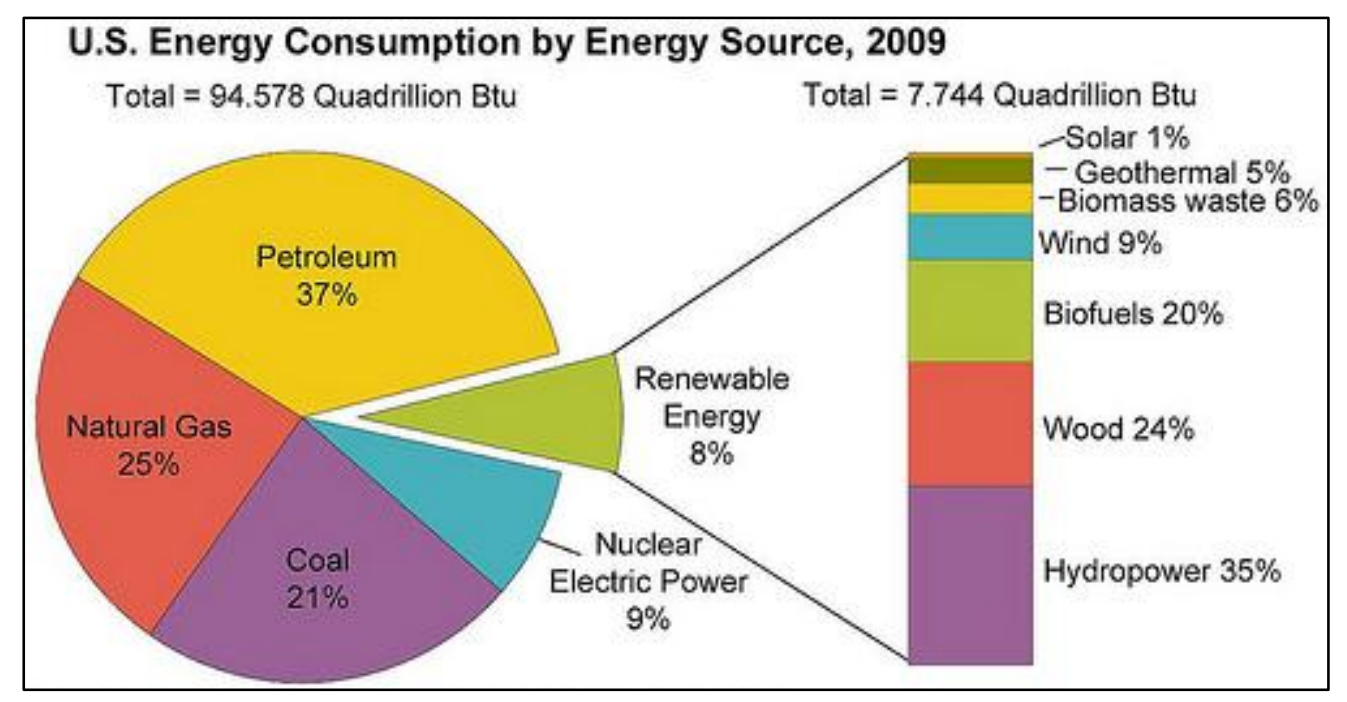

Figure 1.1.2: Consumption of Energy Source in US - 2009 [3]

\subsection{Requirement for Reduction in Energy Intensity}

Of the total energy consumption across the world about $31 \%$ is accounted for by industrial usage followed by transportation, residential and commercial with 28\%, 22\% and 19\% respectively [3]. About 60 percent of energy consumption in the industrial sector is used for manufacturing and the rest is used in mining, construction, agriculture and forestry. Most of the large scale manufacturing industries are large consumers of energy. Natural gas is one of the commonly 
used energy sources in manufacturing with end-uses such as process heating, driving machines and heating and ventilation [4].

Energy conservation can be thought of in several ways. The most common meanings include utilizing less energy in an individual operation and purchasing different forms of energy at lower cost. This is usually accomplished by negotiating with energy providers or by using energy under less costly conditions, shifting energy source by using a lower priced fuel, using "free" or "renewable" energy sources, shifting to energy sources that are considered to be eco-friendly with regard to non-efficiency concerns like pollution and conserving water, minerals and energy sources [5].

Energy Intensity reduction is a very important measure of energy efficiency improvement and can be defined as energy consumption per unit of production. The units for production can be in any output terms. For example, it can be tons of final production or number of pieces produced. It can also be work in progress in case a particular operation is very energy intensive. There are several important reasons why energy intensity has to be continuously monitored and improved including monetary benefits which will be discussed later. The important motive behind this reduction is to decrease the usage of non-renewable fuels and hence the emission of greenhouse gases which traps the infrared radiation in earth's atmosphere and increases the global average temperature causing global warming.

As the global competition for market share is on its peak, every industry is looking for ways to achieve a competitive advantage. Continuous cost reduction is a key factor for a business to sustain or increase their profitability. Energy costs are one of the crucial costs involved in making a product and this is generally referred to as a cost which cannot be altered for a constant volume of production. But if serious decisions and alternatives are made the energy usage can be lowered to a more efficient level. This may result in a considerable reduction in the total cost involved in producing a product [5]. Also, national energy certification programs give the organization recognition which helps in building up their market and also in getting more contracts (often government contracts are given to more reliable and certified parties).

Industrial energy efficiency is gaining importance in the view point of both public economy and business. Government has started several incentive programs to increase energy efficiency in 
industries, since it is one of the most efficient methods to reduce $\mathrm{CO}_{2}$ emissions resulting from the use of fossil fuels [6].

\section{Alternative energy paths}

The use of renewable energy requires heavy investment. Countries like Denmark, Germany, France, Brazil and Switzerland are setting an example for the alternate energy paths. Despite unfavorable geographic locations, Denmark and Germany have made huge investments in solar energy and Germany has now become the largest consumer of photovoltaic cells in the world. Also both these countries have installed a $3 \mathrm{GW}$ and $17 \mathrm{GW}$ of wind power respectively. To reduce the transportation fuel costs Brazil has invested in Ethanol production from sugar cane. Similarly France produces close to $75 \%$ of its electricity from nuclear power [2]. United Kingdom has started their working model towards zero energy building for all new housing by 2016. Switzerland is investing resources towards reducing its energy consumption by more than half by 2050 [2]. Figure 1.2.1 below shows the total global cumulative capacity of wind power from 1996 - 2010 [2]

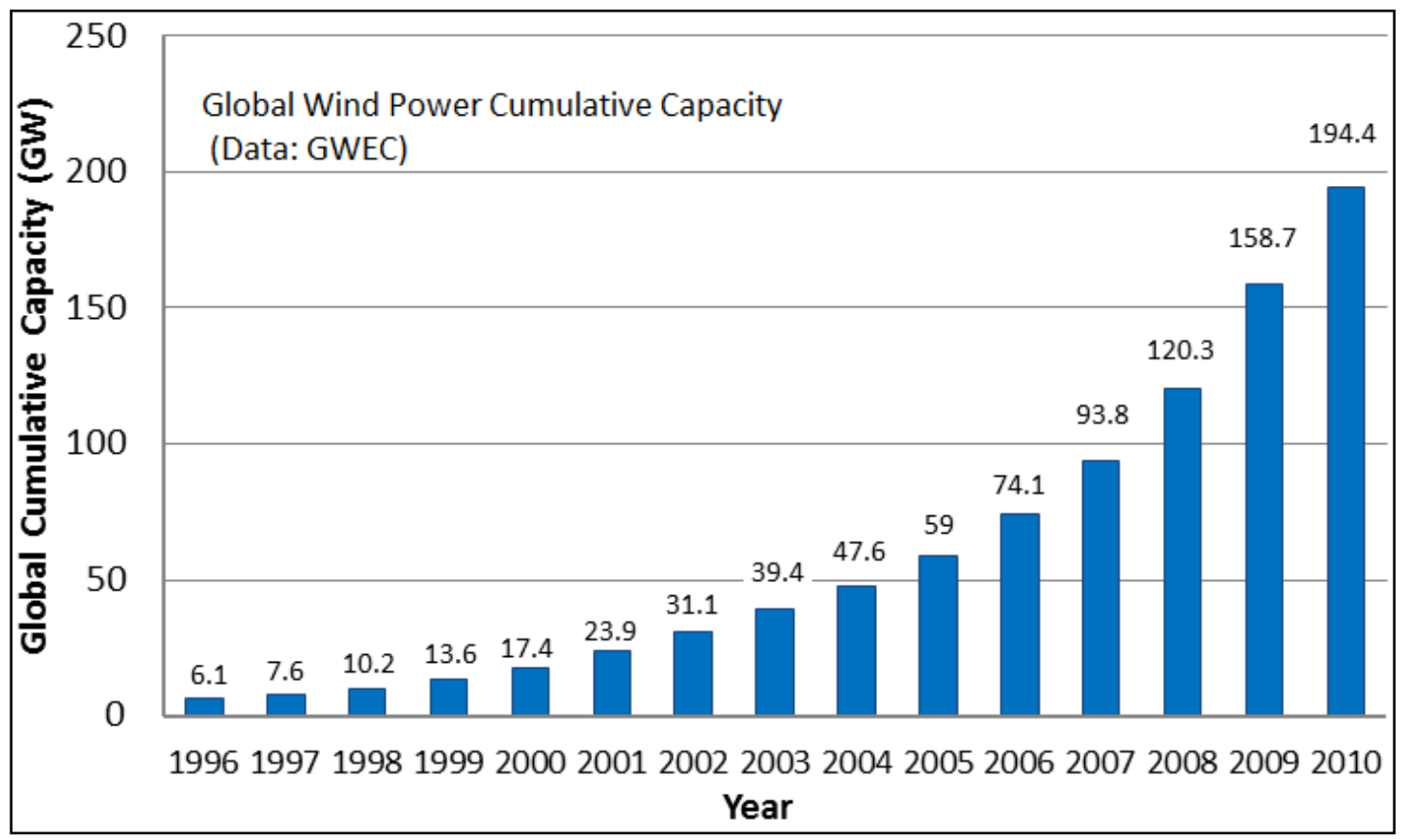

Figure 1.2.1: Total Global Cumulative Capacity of Wind Power from 1996 - 2010 [2]. 
Emission of greenhouse gases causes harmful environmental effect and these gases are released when energy is consumed (mainly fossil fuels). Greenhouse gases mainly consist of carbon dioxide, methane, and nitrous oxide. These gases block infrared radiation from escaping the Earth's atmosphere to space and hence retain the captured heat. In recent years, a rise in the global average temperature due to increase in energy consumption has been recorded, which causes harmful changes in the global eco balance. Carbon dioxide $\left(\mathrm{CO}_{2}\right)$ accounts for the largest share of combined human-caused greenhouse gas emissions. All sectors of the U.S. economy contribute to energy-related greenhouse gas emissions, especially $\mathrm{CO}_{2}$ [7].

\subsection{Arrival of Energy Management in Industries}

Growing concern over global warming, which results from the use of fossil fuels and lack of availability of new energy resources has led to the implementation of a number of policy instruments. Current and future policy instruments may result in higher energy prices and thus further increase the need for industrial energy efficiency [6].

As discussed above, every organization which strives for reduction in energy intensity gets rewarded directly or indirectly. Also an economic advantage due to cost reduction by decreasing energy intensity has been getting a lot of attention recently. It has been even more emphasized due to the recent recession effect which has got the sales to fall to a very low level in most countries.

It is interesting to know that the energy prices were in a decreasing trend in the 1800's and also in the early 1900's. It was in the 1970's that the energy crisis was recognized and the energy costs started climbing which led the organizations to start focusing on energy conservation methodologies [8]. Industries then started the use of energy efficient machines which consume least energy input to give the maximum possible output. The term energy management can be referred to in different ways. In general, energy management is "judicious and effective use of energy to maximize profits (minimize costs) and enhance competitive positions [5]."

Energy management and energy conservation may be used interchangeably. Energy conservation is a part of energy management and it does not completely define energy management. For example, some of the strategies like curtailment-contingency planning (energy input as required 
depending on demand), load shedding and power factor improvement are not essentially a primary part of energy conservation and they involve dedicated energy management practices $[5]$.

The above definition involves management of energy right from the entry of raw material in a facility throughout the product flow till the finished product is shipped out. Energy management involves both the product and the equipment handling the product. Energy management opportunities are also present in waste minimization and disposal [5]. A whole systems viewpoint to energy management is required to ensure that many important activities are examined and optimized [9].

\subsection{The Importance of Energy Management to Promote Energy Efficiency}

An energy assessment is a process used to understand the usage of energy in an industry along with finding opportunities for improvement and energy saving. Sometimes, energy audits are conducted to evaluate the effectiveness of an energy efficiency project or program. Energy management is defined as the process of establishing objectives and finding opportunities (consistent with the energy policy) for improvement in a continual manner. The main goals of energy management other than reducing energy cost and maximizing profits are to maximize energy efficiency, improving communication regarding energy throughout the plant between different groups, researching new technologies and ways to increase returns from best pactices and cultivating interest and dedication among all employees. Energy assessment does not breed continuous improvement. Continuous improvement is a recurring process which results in enhancement of energy performance and the energy management system.

Due to the presence of several other internal commitments, most of these energy savings improvement found in an assessment fade out. Hence, it is not just sufficient to have technical solutions and technological changes to sustain energy saving improvements, promote continual improvement and create a strategic energy management plan in an organization [10]. It is critical to have top level management commitment to change organizational culture. Successful bridging between technical and management principles would lead to sustained savings. Effective management is a crucial issue for the success of any business. Many industries are following 
Total Quality Management strategy for improving their working methodology. Energy management should be merged into TQM to reduce cost [5].

\subsection{National Energy Standards}

\section{A Management System for Energy ANSI/MSE 2000:2008}

ANSI/MSE is the first energy management standard compatible with the ANSI. It was developed by the Georgia Institute of Technology for industries in the year 2000. It was called the MSE 2000 (Management System for Energy 2000). The purpose of the MSE 2000 was to control and reduce an organization's energy cost and energy-related environmental impact [11]. This standard is intended for any organization that uses energy or water. It was later revised in the year 2008 and was used to manage energy supply, demand, reliability, purchase, storage, use and disposal in a systematic manner. It can be used to manage both primary and secondary energy sources.

Like any energy standard, ANSI/MSE 2000:2008 was developed to reduce energy use and hence decrease the energy cost of an organization. It was submitted as an input for the development of the ISO 50001 standard. The first pilot plants for Superior Energy Performance (SEP) certification (discussed later) were tested for compliance with ANSI/MSE 2000:2008 but once the ISO 50001 standard emerges every plant will have to comply with the ISO standard in order to get the SEP certification [12].

\section{European Standard for Energy Management EN 16001:2009}

The EN 16001:2009 is a European standard for efficient energy management. This standard was formally issued on July 1, 2009. EN 16001 can be applied both independently or integrated with other management systems such as quality and environment management. This European Standard is valid for all types and sizes of organization across the world. It specifies the requirements for an Energy Management System to develop and implement an energy policy, identify significant energy consumers and target energy reductions. The implementation of the standard helps in compliance with current and future legislation and regulations on greenhouse gas emissions. Pilot plants used for implementation of EN 16001 verified that the implementation of the standard reduces energy usage and related costs [13]. 


\subsection{ISO Standards for Quality and Environment}

International Organization for Standardization (ISO) is a non-governmental body which sets international standards. It consists of several members from different national standard organizations. It is headquartered in Geneva, Switzerland. The primary products of the ISO are International Standards, technical reports, technical specifications, publicly available specifications, technical corrigenda, and guides.

Some of the well-known standards made by the ISO are the ISO 9001 and ISO 14001.These two standards together have been implemented by more than a million organizations across the globe. ISO 9001 helps organizations to implement a quality management system whereas ISO 14001 helps organizations to implement an environmental management system [15].

\section{Quality Management Standard ISO 9001}

The term quality refers to the features of the product which are based on the requirements of the customer. Hence, quality management deals with the organization's efforts to ensure that its products or services satisfy the customer's needs and comply with regulations that are applicable. It also deals with the organization's strategy to enhance customer satisfaction, and achieve continual improvement of its performance [15].

There are 16 other standards in the ISO 9000 family which help an organization on other different aspects. ISO 9001 is the only standard that gives the requirements for a quality management system. The latest improved version of this standard is ISO 9001:2008. It is the only standard in the ISO 9000 family that can be used for certification [16]. Figure 1.6.1 shows the process of continual improvement in quality management system [14].

The Standard addresses the eight quality management principles as shown below.

- Customer focused organization

- Leadership

- Involvement of people

- Process approach

- Systematic approach to management 
- Continual improvement

- Factual approach to decision making

- Mutually beneficial supplier relationship

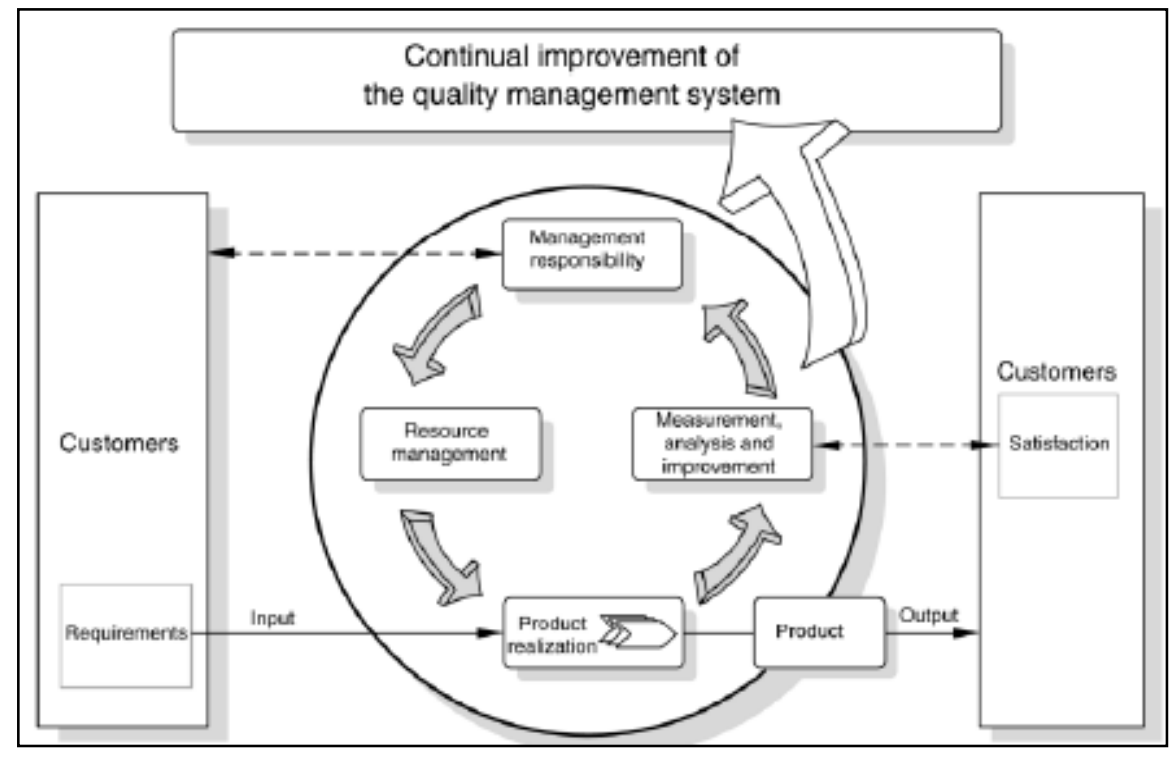

Figure 1.6.1: Continual Improvement in Quality Management Cycle [14]

\section{Environmental Management Standard ISO 14001}

Environmental management system deals with that organization's efforts to minimize harmful effects on the environment caused by its activities and conform to applicable regulatory requirements. It also deals with the organization's strategy to achieve continual improvement of its environmental performance.

ISO 14001 is a powerful management tool that can be utilized by an organization. Its benefits are not just applicable to the organization which adopts it. Adjacent property owners and environmental groups have the potential to benefit also. ISO 14001 can be integrated into an organization's strategic planning process [17]. Like the quality standard, the ISO 14001 is built on Plan, Do, Check and Act concepts with stress on continual improvement.

There are 21 other standards in the ISO 14000 family which deal with organization specific aspects and ISO 14001 is the standard that gives the requirements for an environmental 
management system. ISO 14001:2004 is the latest, improved version. It is the only standard in the ISO 14000 family that can be used for certification [18].

ISO 14001 is similar to the quality management standard as both these standards are based on the process by which the product is produced rather than the product itself. Certification for both standards is performed by third-party organizations rather than being awarded by ISO directly. Figure 1.6.2 shows the process of continual improvement in environmental management system [14].

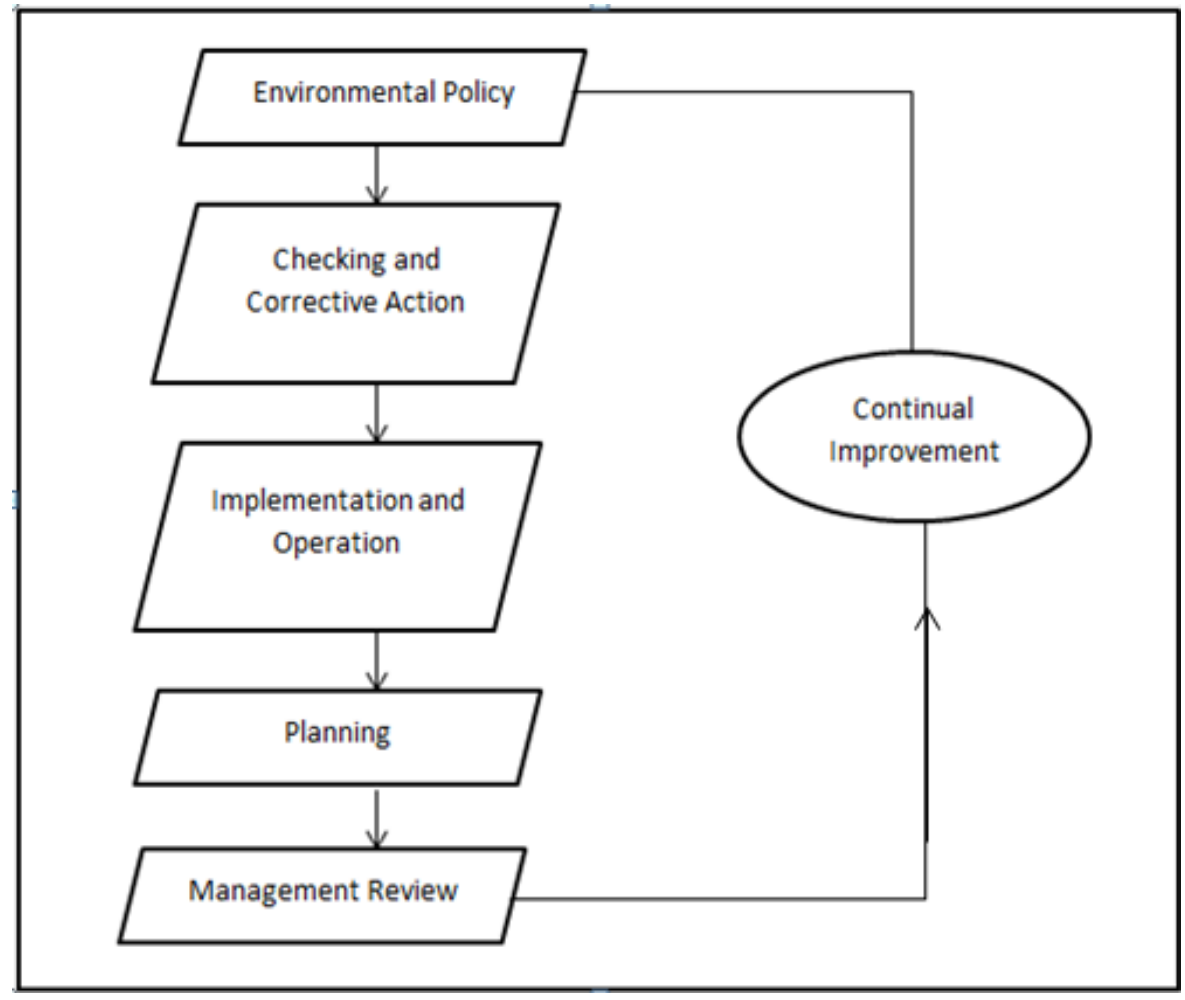

Figure 1.6.2: Continual Improvement in Environmental Management Cycle [14]

ISO 9001 and ISO 14001 are generic standards. Generic means that the same standards can be applied to any organization irrespective of its size and product type. These standards can be integrated into an organization's strategic planning process.

In general, a management system deals with the organization's strategy to manage its processes, or activities such that its products or services meet the organization's objectives, such as 
satisfying the customer's quality requirements, complying to regulations, or meeting environmental objectives $[17,18]$.

Large organizations or ones with complicated processes find it difficult to function properly without management systems. Companies in fields such as aerospace, automobiles, defense, or health care devices have been operating management systems for years. The ISO 9001 and ISO 14001 management system standards now make these successful practices available to all organizations $[17,18]$.

Some of the benefits of these standards are:

- A global and intellectual consensus on state-of-the-art practices for quality and environmental management can be obtained.

- They give a common mode of communication for dealing with customers and suppliers worldwide.

- Increase efficiency and effectiveness.

- Continual improvement model.

- Customers and other stakeholder's satisfaction.

- Quality can be fed into products and services from design onwards.

- Helps comply with government regulations.

- Merge with global economy.

- Qualify suppliers for supply chains

- Technical support for the latest regulations

\subsection{Plan-Do-Check-Act (PDCA cycle)}

The concept of PDCA was first introduced by Walter Shewhart and was further developed and popularized by Edwards Deming. The cycle presented in the Figure 1.7.1 below can be used as an effective continuous improvement tool [14]. 


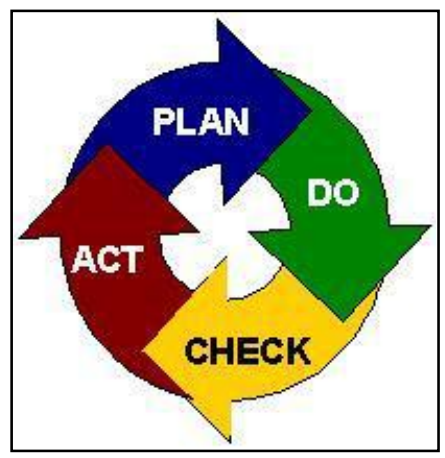

Figure 1.7.1: PDCA cycle [14]

The PDCA cycle consists of 4 stages which can be used in systems to assist facilities in addressing processes from problem facing to problem solving situations. The cycle consists of:

- Plan: Planning of system, process and resource allocation to achieve the objective.

- Do: Executing required actions in accordance with the plan.

- Check: Measuring, monitoring and verifying results, conforming to a pre-defined criteria

- Act: Analyzing the results and important changes required to improve the process.

After the completion of the Act stage the cycle moves back again to the Plan stage, giving PDCA cycle the characteristics of continuous improvement [14].

\subsection{New ISO Standard for Energy}

Due to the enormous consumption of non-renewable energy sources and high potential to conserve energy and reduce greenhouse gas emissions the International Organization for Standardization (ISO) has determined energy management as a priority. ISO 50001 is expected to potentially influence up to $60 \%$ of the world's energy use [19].

The implementation of ISO 50001 in an industry would address effective organizational management of energy usage and performance with respect to global standards. An international framework would be established for industrial plants to manage all aspects of energy, including procurement and use. The standard would give industries technical and management strategies to increase energy efficiency, reduce energy costs, and improve environmental performance. The 
standard also relates to relevant monitoring, measurement and metrics including measuring and reporting on their carbon emissions [14].

The ISO standard majorly addresses the following:

- It gives a framework which integrates energy efficiency into management practices.

- It talks about use of existing energy-consuming assets.

- It gives lot of information regarding benchmarking, measuring, documenting, and reporting energy intensity improvements and their projected impact on reductions in greenhouse gas (GHG) emissions.

- Transparency and communication on the management of energy resources.

- Energy management best practices and good energy management behaviors.

- It gives guidelines to evaluate and prioritize the implementation of new energy-efficient technologies.

- A framework to promote energy efficiency throughout the supply chain.

- Energy management improvements with regards to GHG emission reduction projects.

The standard is meant to assist industries by providing them with a framework for management of energy which leads to enhancing energy efficiency, cost cuts and reduction in greenhouse gas (GHG) emissions. This would give plants, commercial facilities and organizations competitive advantage [20].

The ISO 50001 standard is built upon the existing national standards such as the US ANSI/ MSE 2000:2008 and the European Union EN 16001:2009 [20]. It is considered as the latest best energy management practice. The standard specifies an organization to develop and implement a policy, identify significant areas of energy consumption and commit to energy reductions. The standard in general does not specify by itself any specific performance criteria but it is performance based requiring continuous improvement in energy performance just like any other management system standard published by the ISO.

It is also a generic standard and can be applied to all types and sizes of organizations as do the expected benefits. Any organization wanting to conform to their energy policy and wishing to demonstrate conformity to others can commit to this standard. However, it is more important for energy intensive industry or industries facing greenhouse gas emission legislation to commit and 
conform to the standard. Conformity to the standard can be verified by self-evaluation \& selfdeclaration or by certification by an external auditor. The ISO 50001 is structured around the Plan-Do-Check-Act cycle of continual improvement just like the other two ISO standards (14001 $\&$ 9001).

This standard can be integrated into already existing ISO management standards like the ISO 14001, OHSAS 18001, ISO 9001, or Responsible Care® Management System. An organization that already has one of the above standards can integrate ISO 50001 into a management system. To ensure this compatibility, the ISO 50001 standard is based on common elements like management commitment, operational control, nonconformity, corrective and preventive action, and management review.

\subsection{Need for research}

In general, energy management procedures followed by facilities are not sequential or in an orderly manner making the EnMS less accountable. Also for efficient working of the EnMS the system must be well communicated within the organization. These complications make continuous implementation of energy management strategies very difficult to manage as the preliminary job of every employee in the industry is to get the product produced in the most effective manner and with the specified requirements. The other tasks including energy management become just an additional work on the employees. Also during rough times these tasks are completely omitted and the concentration is majorly focused onto the production output. Hence slowly the energy management strategies start getting eliminated and finally get dissolved.

Energy management certification in accordance with ISO 50001 requires several tasks to be done including documentation, monitoring and measurements of significant energy users and many other such requirements. The written standard tells about the mandatory requirements necessary but does not provide a roadmap for the steps or procedures that have to be followed. The standard also mentions the need for documentation but does not discuss the exact amount of documentation. Excess documentation leads to waste of resources and it can also sometimes prove to be harmful. Also, less documentation may make a firm ineligible for the certification program. Criteria and metrics have to be developed for resource allocation and planning on 
major energy consumers in the plant. Priorities have to be made to look at the major users of energy. Hence, a standardized methodology is essential to the implementation of the International Standard.

A step by step approach to energy management will help a facility perform the required tasks in forming an energy management system by allocating their resources efficiently. Also, the work allocation on every individual employee can be fixed and responsibility can be shared equally. This may also help facilities during crisis to concentrate on their major requirements and then shifting back systematically to their additional energy management tasks.

\subsection{Requirements in the Standard}

The International Standard specifies mandatory requirements to be followed by an industry to form an Energy Management System (EnMS) by developing an energy policy, energy objectives, targets and action plan on major energy consuming users. It also specifies criteria on the legal requirements and other requirements to be satisfied while formation of Energy Management System (EnMS) [21]. The standard can be flexibly used by all industries depending on the complexity of their processes, degree of documentation possible and resources that can be allotted for the purpose.

Successful implementation of the energy management system requires high level of commitment from all the parts of the organization. The top management has to play the most important role of showing highest level of interest and commitment towards the EnMS. Though implementation of the ISO 50001 requires to the improvement of energy performance, the certification process does not deal with the level of energy intensity reduction that must be obtained.

ISO 50001 is considered as a fundamental tool to manage energy and can be interpreted as a tool which initiates energy management in an organization and makes necessary changes in the organization by getting all the required components set in order to achieve significant energy improvement as desired. The basic components of the management system are baseline, policy, plan and team. The list is not exhaustive and is dealt with in depth in Chapter 3. Presently, there exists other certification programs which deal with quantifying energy intensity improvement and are discussed later in the chapter. 


\section{Regression Model Development for Energy Baseline}

Energy Management Standard ISO 50001 requires industries to build a baseline model as reference and against which they could quantify improvement in energy intensity. In some cases expected energy savings from a lighting upgrade can be easily verified by measuring the power draw of lighting fixtures before and after a lighting upgrade. In other cases involving retrofitting on a larger component, the energy use may be difficult or impossible to measure. Also, the energy consumed may be a function of several factors involving weather and/or amount of production, which varies frequently. In such cases, it is difficult to measure energy savings and hence savings are seldom verified.

A tool for modeling and analyzing several variables with focus on obtaining a relationship between a dependent variable and one or more independent variables is called regression analysis. This tool helps one to analyze and understand how the value of the dependent variable changes when any one of the independent variables is varied, while the other independent variables are held fixed. It is important to know that regression analysis gives only the estimate of the dependent variable for the given independent variables - that is, the average value of the dependent variable when the independent variables are held fixed [22].

According to "Guide to Energy Management" by W.C.Turner [5], in many instances linear regression of energy consumption against single variable (production or temperature related variable) generates a valid energy model if only one of these variables affect the energy consumption. Else, in some cases multivariate linear regression containing degree days and production for plant where there is significant dependence on production is a better representation of energy model.

\subsection{Other Certification Programs}

\section{Superior Energy Performance}

Superior Energy Performance is a plant certification program which provides industrial facilities with a roadmap for achieving continual improvement in energy efficiency and hence enhancing their competitiveness. Its major goals are to drive continual improvement to reduce energy intensity by developing a transparent system to validate energy intensity improvements and 
management practices and to build efficiency market and workforce by encouraging broad participation throughout industry [23].

The U.S. Department of Energy (DOE) mandates the use of ISO 50001 as the organizing framework for the Superior Energy Performance (SEP) energy management certification program. The requirements for SEP certification are Energy Management System conformity with ISO 50001 Energy Management Standard and Energy Performance Improvement. The plant can choose to pursue this program from two different pathways depending on the duration of plant's energy management system. The two pathways are Energy Performance Pathway and Mature Energy Pathway. Depending on the type of validation, the certification has 2 tiers. They are partner self-declaration and certified partner ANSI accredited certification. Also depending on the energy Performance Improvement the Certified Partners are eligible for 3 levels of certification. They are silver, gold and platinum. An ANSI - accredited certification body will conduct a third party audit to verify that SEP requirements are met [24].

\section{Better Buildings, Better Plants}

Better Buildings, Better Plants program is a national initiative for the industrial sector to achieve the goals mandated by the Energy Policy Act of 2005 (EPAct) to drive 25\% reduction in industrial energy intensity by in 10 years by 2020. This program encourages industries to voluntarily reduce their energy usage in a period of volatile energy prices and uncertain supplies. The program also creates momentum to significantly improve energy efficiency practices throughout the industrial sector.

Some of the requirements of this program are to sign a pledge to adopt a goal to reduce energy intensity by $25 \%$ or more over 10 years, to designate an energy manager, to develop an energy intensity baseline, to develop an energy management plan, to implement actions for reducing energy intensity, to reduce carbon emissions, and to annually report energy intensity data and achievements to DOE and assess operational and financial feasibility.

The features of SEP and Better Buildings, Better Plants provides the tools, training, and technical resources that enable actual progress toward energy efficiency goals. These tools and guidance will empower companies to implement the ISO 50001 standard and achieve significant and 
sustained energy savings, greenhouse gas reductions in their plants [25]. Figure 1.10.1 shows level of increasing energy management improvement [32].

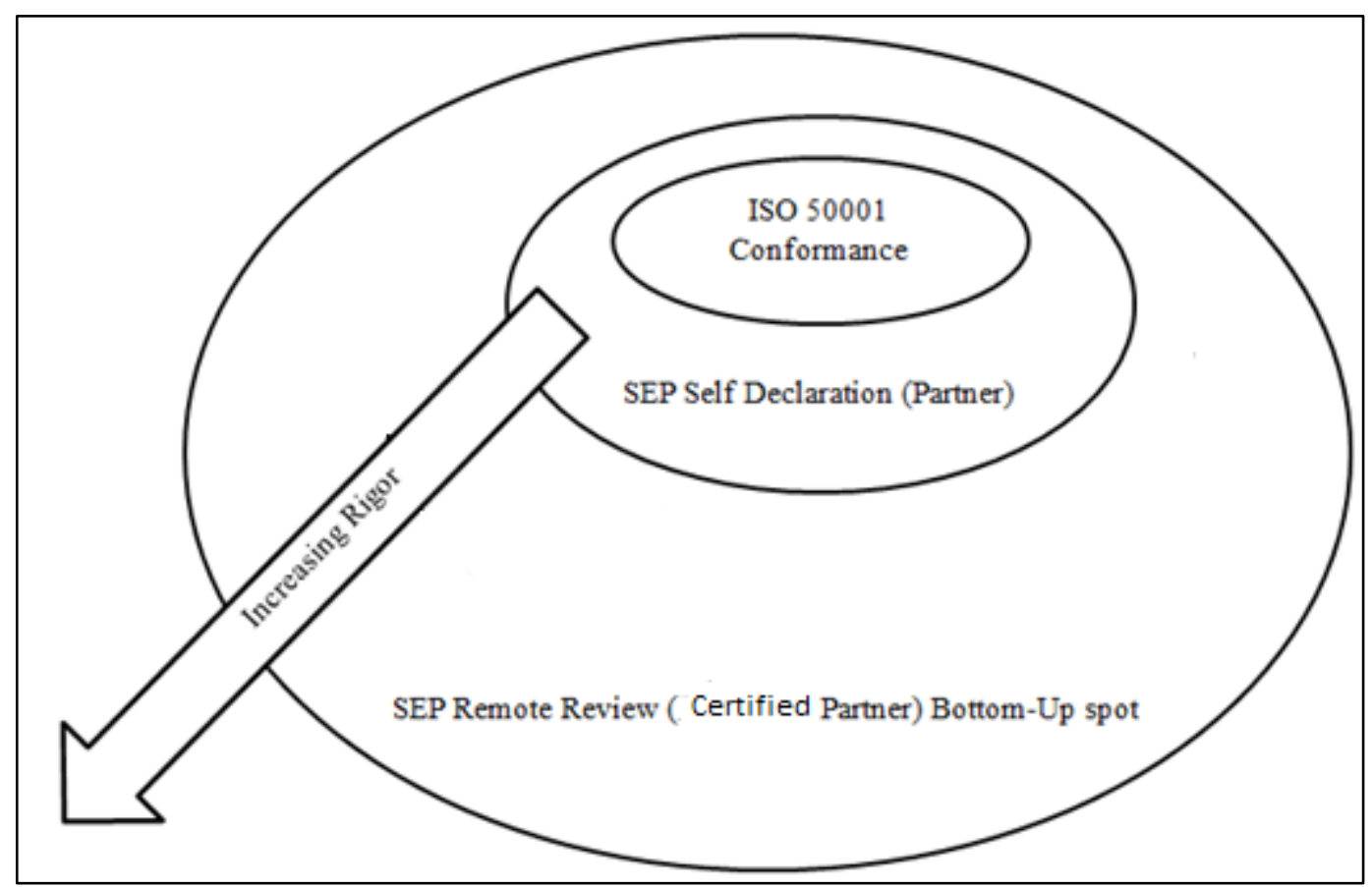

Figure 1.10.1: Level of Increase in Energy Management Improvement [32]

\subsection{Research Objectives}

The objectives of the current study are to develop ISO 50001 Analyzer software which assists an organization to implement an energy management system by conforming to the ISO 50001 requirements and eventually get certified. This software is built by initially developing a step by step algorithm using flow charts in forming a standardized methodology. Contributing to the enormous tasks to be performed it becomes very challenging without a standard approach to implement an energy management system in a firm and conform to every individual requirement in the standard. Hence, having a standardized methodology will help plants to focus on significant tasks that need to be done and not waste their resources on insignificant areas. In addition, the software may also eliminate the requirement of hiring an energy management consultant (ISO 50001) as the mandatory requirements, documentation, record maintenance and other objective specific tasks are addressed in this software.

The specific objectives of the research are listed below: 
1. Develop flow charts showing logical sequence of tasks to be performed for facilitating manufacturing facilities* obtain ISO 50001 certification.

2. Develop software using the flow charts to help facilities implement an energy management system in accordance with the ISO 50001.

*Since buildings and service industries do not have any tangible product which is manufactured, the energy planning module must be tailored to suit them. Though buildings and service industries can use these flowcharts and software for guidance towards energy management implementation in accordance with ISO 50001, the present work is more inclined to help manufacturing industries.

\section{Advantages of Flow Charts and ISO 50001 Analyzer software}

- Helps industry understand requirements in the ISO 50001 standard

- Reduces complexity to implement ISO 50001 as the framework of the system is built

- Allocating tasks to employees in the organization to implement ISO 50001

- Helps consultant store multiple organization's data and hence utilize strategies from other organization's EnMS

- Makes transferring of energy management system to sister plants easier

Database allows for storage of documents and records in an organized manner hence making auditing simpler for the auditor.

\subsection{Conclusion}

This chapter helps understand the present energy consumption across the world and the need for an energy management system similar to the quality and environmental management system in a manufacturing facility. It also helps understand the different national and international management standards and certification programs. To overcome the lack of availability of proper framework to implement an energy management system conforming to the ISO 50001 standard, a standard methodology using flow charts and ISO 50001 Analyzer software is required to be developed which can help perform tasks to realize the best possible results. 


\section{Chapter 2}

\section{Literature Review}

\subsection{Energy Management Practices}

Energy management can be considered as a comprehensive and systematic approach for energy conservation efforts in an organization. An energy management system (EnMS) is built to continuously reduce an organization's energy costs by forming a set of well-planned procedures. An energy management system (EnMS) is a documented structure which defines the goals, policies, procedures and the processes by which they are maintained and improved. This management system is more effective when the policies and procedures are reviewed in a specified interval. An energy management policy states the commitment or decision of an organization to manage energy consumption. Until recent times, energy savings was viewed as an issue only during the modification of a production plant or when replacement investments are made, or when bottle-neck arises. But when the problems are solved, energy saving is put aside again [26].

Also, energy management practices primarily are thought as a procedure to replace inefficient equipment with energy efficient ones. It is seen that the gains made from these energy efficiency improvements are decreased over time. Significant efforts have been made to develop standards to implement energy management systems which in turn would help in increasing and maintaining energy savings [27].

A procedure to develop an energy management system in a metal working industry was formed in a Serbian car company "Zastava" [26]. Management of the factory together with the research team consisting of faculty of Mechanical Engineering from the University of Kragujevac initiated a project to introduce energy management system in the factory. An algorithm for implementing an energy management system was developed by the team which can be applied to other factories with minor modifications. This framework is shown below in Figure 2.1.1 as it can serve as a guideline for entrepreneurs to implement energy management strategies. 


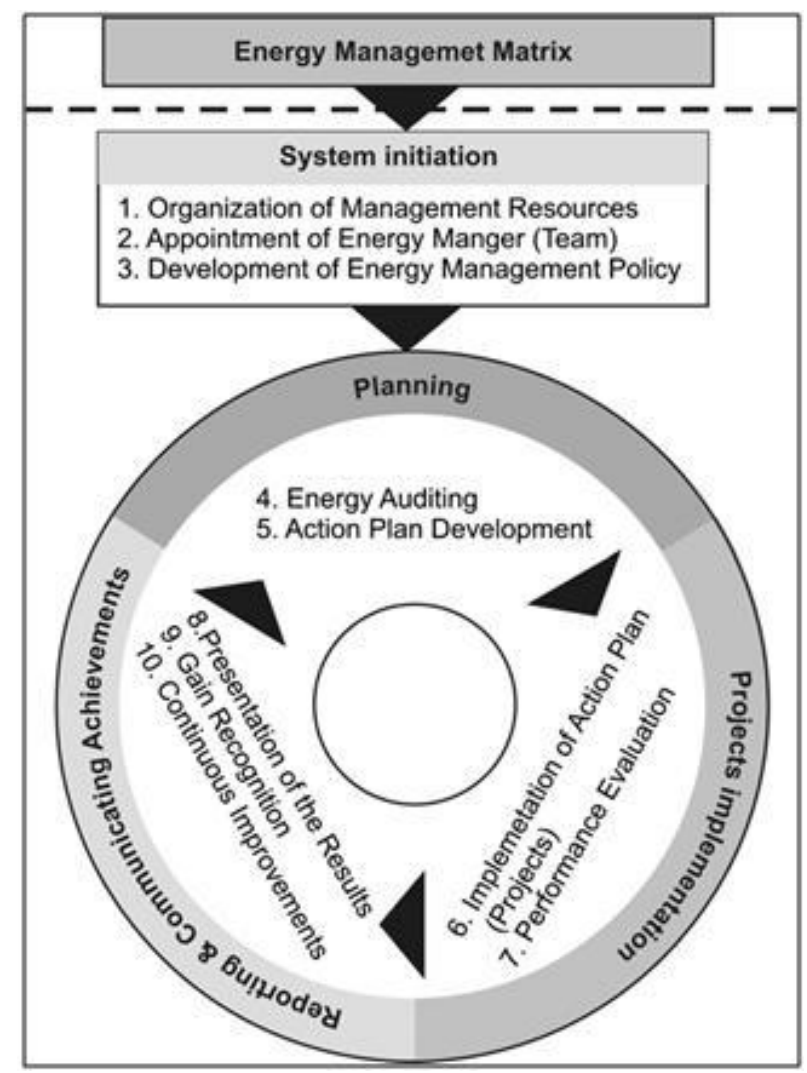

Figure 2.1.1: Framework for General Implementation of Energy Management

\subsection{Implementation of ISO 50001 Energy Management System in Industries}

ISO 50001 has different elements added to the management system compared to the other ISO standards like energy planning, continuous energy performance. Due to lack of hands on expertise with this system, industries are looking for potential tools, tips and resources which would help them implement this management system. This section talks about some tools which have been developed to assist such industries.

\subsubsection{Status Evaluation and Concept for Implementing Energy Consumption Data Monitoring Instruments}

A thesis done by Daiane Pandolfo at Politecnico Di Milano on "Implementing an Energy Management System” involved creating checklist tool for assisting organizations evaluate their status on the energy management system [14]. Figure 2.2.1 below shows the checklist methodology to check status towards implementing ISO 50001. 


\begin{tabular}{|c|c|c|c|c|c|c|c|}
\hline \multirow[b]{2}{*}{$\begin{array}{l}\text { Req. } \\
\text { No }\end{array}$} & \multirow[b]{2}{*}{ Element Requirement } & \multicolumn{4}{|c|}{ Evaluation } & \multirow[b]{2}{*}{ Comments to explain the evaluation i.e. evidences } & \multirow{2}{*}{$\begin{array}{c}\text { rating } \\
\text { score } \\
\text { and inter } \\
\text { mediate } \\
\text { results } \\
(\%) \\
\end{array}$} \\
\hline & & 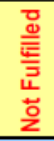 & 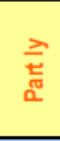 & 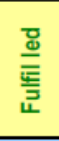 & 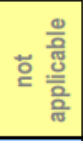 & & \\
\hline 4.1 & General requirements & & & & & & $0 \%$ \\
\hline 1 & $\begin{array}{l}\text { Has the organization defined an Energy Management System } \\
\text { accordingly to ISO 50001? }\end{array}$ & & & & & & 0 \\
\hline 4.2 & Management responsibility $(4.2 .1 / 4.2 .2)$ & & & & & & $0 \%$ \\
\hline 1 & $\begin{array}{l}\text { Has the organization defined an energy management representative } \\
\text { (energy manager) and defined their roles, responsibilities and } \\
\text { authorities? }\end{array}$ & & & & & & 0 \\
\hline 2 & $\begin{array}{l}\text { Are the specialized skills, human, financial and technological } \\
\text { resources necessary for energy management identified and provided } \\
\text { by the board? }\end{array}$ & & & & & & 0 \\
\hline 4.3 & Energy policy & & & & & & $0 \%$ \\
\hline 1 & $\begin{array}{l}\text { Has the board defined in writing a policy, which includes also a } \\
\text { commitment to continuous improvement of energy efficiency? }\end{array}$ & & & & & & 0 \\
\hline 2 & $\begin{array}{l}\text { Does the policy show a commitment to achieve the energy } \\
\text { management objectives and to reduce energy related emissions? }\end{array}$ & & & & & & 0 \\
\hline 3 & Is the policy available to internal and external public? & & & & & & 0 \\
\hline
\end{tabular}

\section{Figure 2.2.1: Status Evaluation by Checklist Methodology in ISO 50001}

The checklist is built using the draft version of the ISO 50001 and the questions are framed directly from the requirements mentioned in the standard. The user is required to click on one of the 5 'Evaluation' options shown in the Figure above followed by providing comments to explain the evaluation and the tool calculates percentage of completion of the requirement. Figure 2.2.2 shows the percentage completion of every individual requirement in the ISO 50001. The last column in the histogram showing $70 \%$ is the average completion of the entire system. 


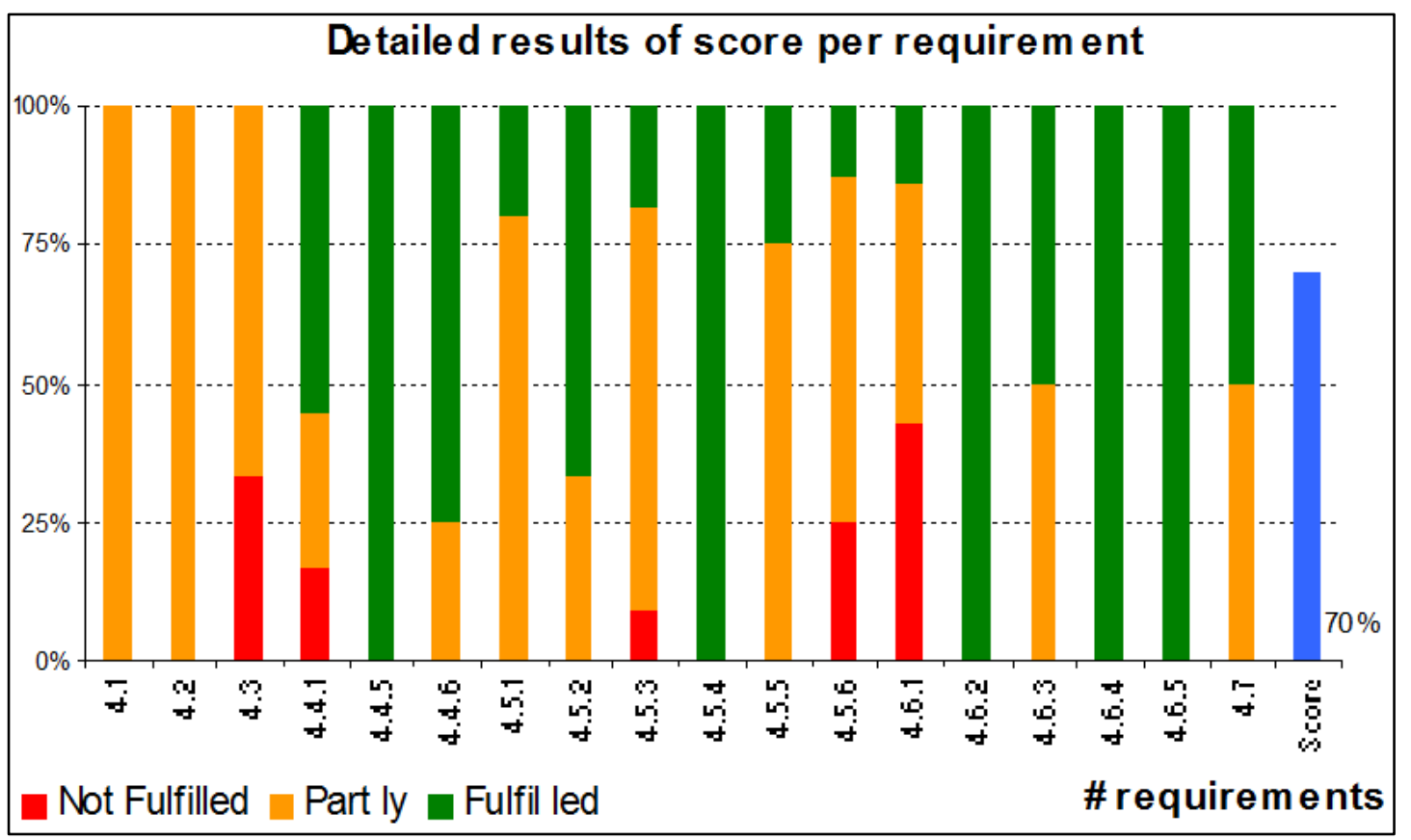

Figure 2.2.2: ISO 50001 Requirement Completion Score

Data collection and monitoring is a critical aspect of the development of energy baseline and measurement of energy savings. Research on implementing or improving instruments for energy consumption data monitoring has been done which can be used by organizations in deciding when to invest in energy consumption monitoring instruments. Since it is hard to manage what cannot be measured it is better to have more accurate data for good results. This can be done by investing in equipment for measuring energy consumption. With organizations having a strict return on investment policies it gets hard to estimate the exact kind of instruments to purchase nd time to invest due to the limited funds available. Additionally this work also deals with helping organizations determine plan for implementing or improving energy consumption data monitoring schemes that can be gradually and continuously upgraded.

The Figures 2.2.3 and 2.2.4 show a tool developed to help industries split and calculate the energy consumption of every area or equipment of the plant. The user is required entering the names of all equipment and areas of the plant followed by checking the energy source utilized by them (both input and output). Next the user needs to input the energy consumption units and the type of metering present which is used for calculation of consumption. If there is no metering in the plant the software opens a sheet which the user needs to input regarding cost of metering and type of metering to be installed as shown in Figure 2.2.5. These sheets make decision making to 
buy energy consumption metering easier as the user knows the present energy consumption and the importance of installing meters.

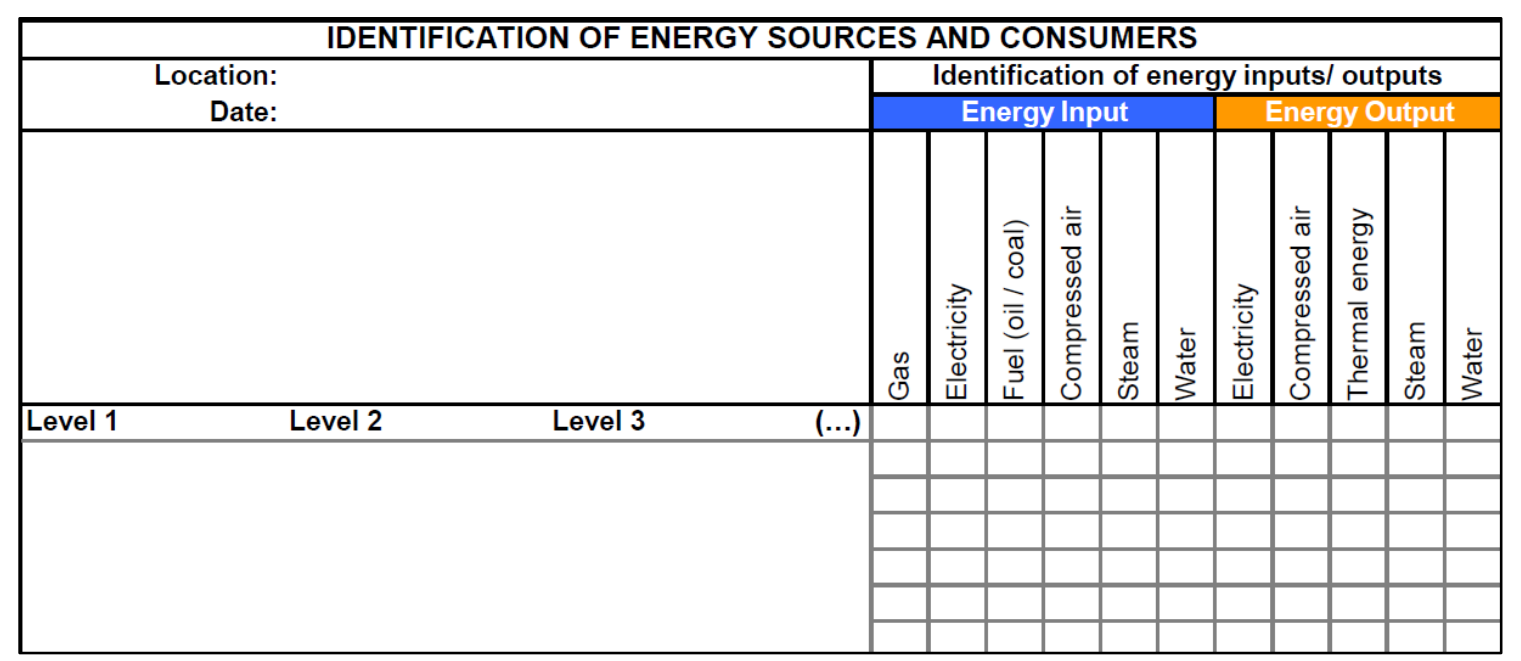

Figure 2.2.3: Identification of Energy Sources and Consumers [14]

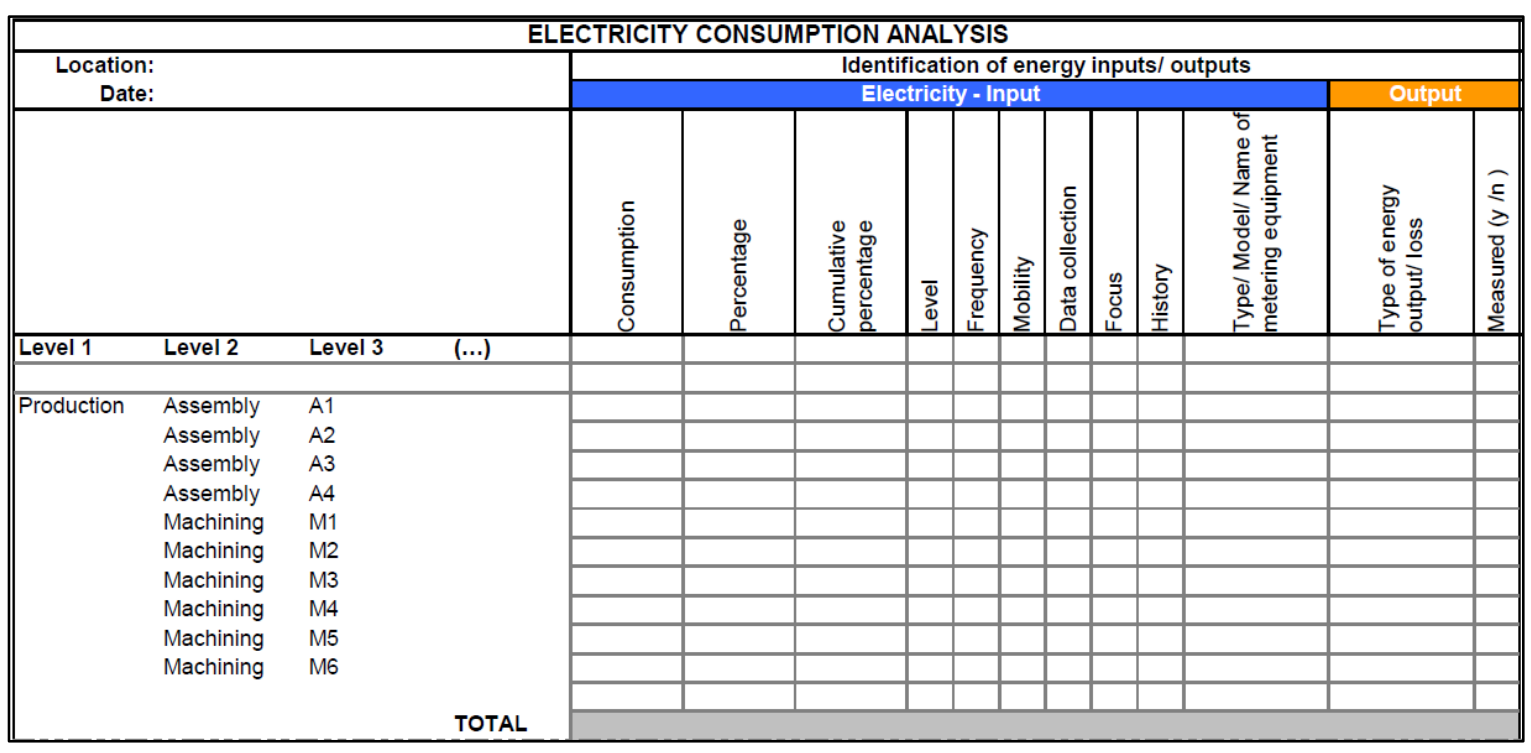

Figure 2.2.4: Introduction of Energy Consumption Data Monitoring [14] 


\begin{tabular}{|c|c|c|c|c|c|}
\hline \multicolumn{6}{|c|}{ Plan: Introduction of Instruments for Energy Consumption Data Monitoring } \\
\hline Reference & \multicolumn{5}{|c|}{ Production - Truck } \\
\hline Action & \multicolumn{5}{|c|}{ Study of saving potentials } \\
\hline Budget (€) & \multicolumn{5}{|c|}{$€ 9.533,30$} \\
\hline \multicolumn{6}{|l|}{ Resources } \\
\hline Current situation & \multicolumn{5}{|c|}{ No meter, just estimations } \\
\hline Indicators & \multicolumn{5}{|c|}{ (will be defined in phase 6) } \\
\hline Saving potentials & \multicolumn{5}{|c|}{ Main part of this plan } \\
\hline Approval \& completion & \multicolumn{5}{|c|}{ Industrial Engine ering Manager } \\
\hline Task & Priority & Responsible & Start date & End date & Comments \\
\hline 1. Outsourcing or internal & 2 & Internal & $\operatorname{Jan} .2010$ & $\operatorname{Jan} 2010$ & \\
\hline $\begin{array}{l}\text { 2. Research of suitable } \\
\text { equipment }\end{array}$ & 2 & To be defined & $(\ldots)$ & $(\ldots)$ & \\
\hline 3. Verification with budget & 1 & To be defined & $(\ldots)$ & $(\ldots)$ & \\
\hline $\begin{array}{l}\text { 4. Identification of saving } \\
\text { potentials }\end{array}$ & 1 & To be defined & $(\ldots)$ & $(\ldots)$ & \\
\hline 5. Definition of new baselines & 1 & To be defined & $(\ldots)$ & $(\ldots)$ & \\
\hline 6. Definition of targets & 1 & To be defined & $(\ldots)$ & $(\ldots)$ & \\
\hline $\begin{array}{l}\text { 7. Definition of responsible for } \\
\text { achievement of targets }\end{array}$ & 2 & To be defined & $(\ldots)$ & $(\ldots)$ & \\
\hline 8. Definition of next phase & 1 & $\begin{array}{l}\text { Industrial } \\
\text { Engineering Mgr }\end{array}$ & Dec.2010 & Dec.2010 & \\
\hline
\end{tabular}

Figure 2.2.5: Tool for Energy Consumption Data Monitoring

\subsubsection{Key Performance Indicator (KPI)}

Management systems which rely heavily on information systems have led to generation of huge volume of data which needs to be processed by the energy managers. For effective output it is essential to summarize the data into a few critical actionable information. A KPI is used to provide both the metrics which would determine success of a project and also provide periodic information to the managers to track performance. The journal article [28] deals with selection and breakdown of key performance indicator depending on requirement and energy objective of an organization. One of the effective ways to breakdown the KPI is by separating indicators based on energy type and usage of energy at different equipment. 


\subsubsection{Measuring Energy Savings by Using Normalized Energy Intensity}

For certification ISO 50001 Management System requires industries to quantify energy intensity improvement. Due to the possibility of large variation of production and weather data, the quantification of energy intensity becomes tough, hence a new method which removes these effects is required to accurately calculate the energy intensity improvement. This is a four step method which starts by developing a three parameter change point regression model using actual bills, weather and production data followed by running the model with TMY 2 weather data and historical production data. This energy consumption is called Normalized Annual Consumption (NAC). The next step involves making sliding NAC's for sequential 12 month data (creating sequential 3 parameter change point model for 12 month data by eliminating the first month of the last model). Following generation of sliding NAC's this consumption is to be divided by the typical production data. This paper is also shows an example case study of quantification of savings of an industry with varying production [32].

\subsubsection{Framework for Implementation of ISO 50001}

Work has been done in developing the structure and functionality of a computer aided framework according to the requirements of ISO 50001. Specifically, a task centered framework which includes task descriptions, instructions, processes, tools, drawings etc has been employed to develop the web based interface. The section of flowchart shown in Figure 2.2.6 integrates entities such as training material, data collecting tools, project management etc with the various steps involved in a logical manner thereby yielding a single unified framework. Implementation of the framework into an industrial organization which is one of the largest manufacturers in power and automation has also been discussed. The framework was initially planned to be implemented as a pilot project involving one unit of its business operations which includes 62 sites worldwide. The instutionalization of the framework which will strictly follow ISO 50001 will adapt the organization based on assessments of lighting, occupational sensors, insulation for old equipment etc which is estimated to result in a cost savings of the order of $\$ 50$ to $\$ 100$ million every year. Once the energy savings are proven they will be copied, improved and implemented in other divisions of the organization [30]. 


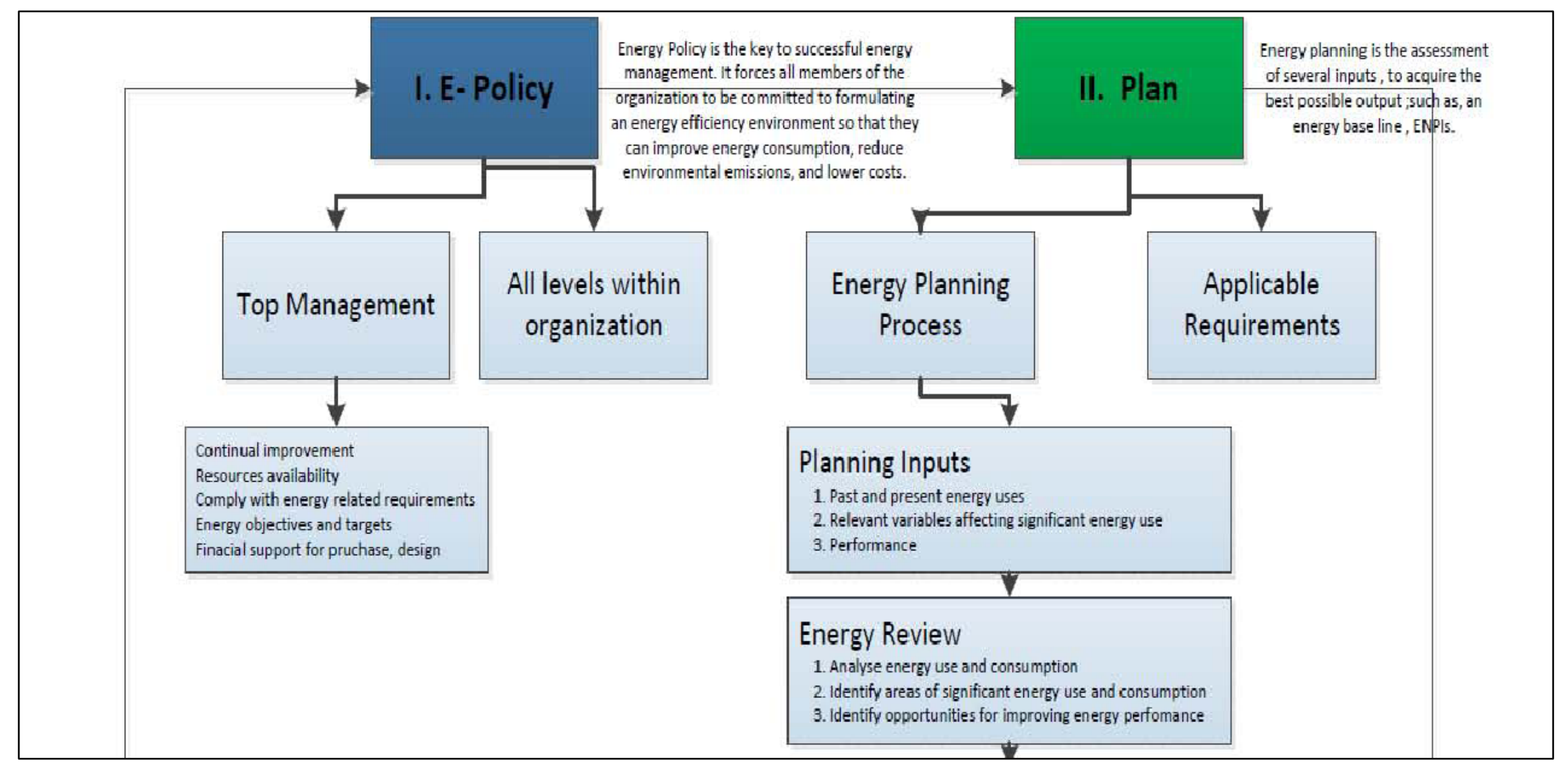

Figure 2.2.6: Section of Framework for ISO 50001 [30] 


\subsubsection{Obstacles in Implementation of Energy Management System}

Some of the large scale manufacturers of ferrous, nonferrous, metallurgy and petrochemical products in Russia started to implement ISO 50001[31]. This article deals with reviewing the difficulties and challenges faced by such industries that they had to overcome. Some of the difficulties which are discussed are:

- Importance of energy policy as perceived by the company stock holders, program developer and higher level officials

- Insufficient personnel motivation

- Shortcoming of the energy efficiency planning

- Uncertainty and untimely establishment of energy management structures

- Lack of energy consumption data and data analysis equipment

- Documentation of energy management system

\subsubsection{Financial Decision}

\section{Making through Energy Balance Spreadsheet}

It is always hard to decide on the type of project to invest, hence making financial decisions by using energy balance spreadsheet is helpful. The energy balance spreadsheet is nothing but a mathematical analysis of energy consumption throughout the organization. This can be done by data collection about equipment rating, usage hours, and measurement of load and estimation of efficiency for all the equipment. A spreadsheet can be made which would indicate the present energy usage of the equipment. Following this an estimated proposed consumption can be calculated based on improvement possible and then energy savings can be found by subtracting current energy usage and proposed energy usage. Once the energy balance sheet is completed, the financial analysis can be done by gathering information such as expected savings, project MARR, expected project cost and expected project life [29].

Following this the organization should calculate simple payback, Internal Rate of Return (IRR), Savings to Investment Ratio and Net-Present Value for every project. The organization can then 
have a cut off score for each of these criteria and select project which cross the cut off. This method can help organization make a selection on which project to implement.

\subsection{Merging Existing ISO Systems into ISO 50001}

The similarity between the Quality, Environmental and Energy Management Standard helps industries with already existing management systems to implement the energy standard with lesser effort. With increasing concern to reduce energy intensity and environmental emissions the importance of energy management cannot be more over emphasized. As the ISO 50001 standard has just been released there has not been a lot of research done to create tools which would help industries to implement this Energy Management System (EnMS). In one such research, comparison between the international environmental and energy management standards has been made to assist industries in reviewing the energy standard and accurately determine the resources that would be required to implement an Energy Management System (EnMS). The comparison made between the two standards is logical as the two exhibit several similarities when compared to other standards. Comparison between ISO 50001:2011 draft standard and the ISO 14001:2009 is shown in Figure 2.3.1 [21].

\begin{tabular}{|c|c|}
\hline ISO 50001:2011 Energy Management & $\begin{array}{c}\text { ISO 14001:2009 Environmental } \\
\text { Management }\end{array}$ \\
\hline 4.1 General Requirements & 4.1 General Requirements \\
\hline \multicolumn{2}{|l|}{ 4.2 Management Responsibility } \\
\hline 4.2.1 Top Management & $\begin{array}{r}\text { 4.4.1 Resources, Roles, Responsibility and } \\
\text { Authority }\end{array}$ \\
\hline 4.2.2 Management Representative & $\begin{array}{r}\text { 4.4.1 Resources, Roles, Responsibility and } \\
\text { Authority }\end{array}$ \\
\hline 4.3 Energy Policy & 4.2 Environmental Policy \\
\hline 4.4 Energy Planning & 4.3 Planning \\
\hline 4.4.1 General & 4.3 Planning \\
\hline 4.4.2 Legal and Other Requirements & 4.3.2 Legal and Other Requirements \\
\hline 4.4.3 Energy Review & 4.3.1 Environmental Aspects \\
\hline \\
\hline 4.4.5 Energy Performance Indicators & \\
\hline $\begin{array}{r}\text { 4.4.6 Energy Objectives, Energy Targets and } \\
\text { Energy Management Action Plans }\end{array}$ & $\begin{array}{r}4.3 .3 \text { Objectives, Targets and } \\
\text { Programme(s) }\end{array}$ \\
\hline 4.5 Implementation and Operation & 4.4 Implementation and Operation \\
\hline $\begin{array}{ll}4.5 .1 \text { General } \\
\end{array}$ & 4.4.6 Operational Control \\
\hline
\end{tabular}




\begin{tabular}{|c|c|}
\hline ISO 50001:2011 Energy Management & $\begin{array}{c}\text { ISO 14001:2009 Environmental } \\
\text { Management }\end{array}$ \\
\hline 4.5.2 Competence, Training and Awareness & $\begin{array}{r}\text { 4.4.2 Competence, Training and } \\
\text { Awareness }\end{array}$ \\
\hline 4.5.3 Communication & 4.4.3 Communication \\
\hline ISO 50001:2011 Energy Management & $\begin{array}{c}\text { ISO 14001:2009 Environmental } \\
\text { Management }\end{array}$ \\
\hline \multicolumn{2}{|l|}{ 4.5.4 Documentation } \\
\hline 4.5.4.1 Documentation Requirements & 4.4.4 Documentation \\
\hline 4.5.4.2 Control of Documents & 4.4.5 Control of Documents \\
\hline 4.5.5 Operational Control & 4.4.6 Operational Control \\
\hline \multicolumn{2}{|l|}{4.5 .6 Design } \\
\hline \multicolumn{2}{|l|}{$\begin{array}{l}\text { 4.5.7 Procurement of Energy Services, } \\
\text { Products, Equipment and Energy }\end{array}$} \\
\hline 4.6 Checking & 4.5 Checking \\
\hline 4.6.1 Monitoring, Measurement and Analysis & 4.5.1 Monitoring and Measurement \\
\hline $\begin{array}{r}\text { 4.6.2 Evaluation of Legall Requirements } \\
\text { and Other Requirements }\end{array}$ & 4.5.2 Evaluation of Compliance \\
\hline 4.6.3 Internal Audit of the EnMS & 4.5.5 Internal Audit \\
\hline $\begin{array}{l}\text { 4.6.4 Non Conformities, Correction, } \\
\text { Corrective and Preventive Action } \\
\end{array}$ & $\begin{array}{r}\text { 4.5.3 Nonconformity, corrective action } \\
\text { and preventive action }\end{array}$ \\
\hline 4.6.5 Control of Records & 4.5.4 Control of Records \\
\hline 4.7 Management Review & 4.6 Management Review \\
\hline 4.7.1 General & 4.6 Management Review \\
\hline 4.7.2 Input to Management Review & 4.6 Management Review \\
\hline 4.7.3 Output from Management Review & 4.6 Management Review \\
\hline
\end{tabular}

Figure 2.3.1: Comparison between ISO 14001 and ISO 50001 [14]

There are lots of similarities between the ISO 14001 and the ISO 50001. It is possible to include energy as a significant aspect in the existing environmental management system (EMS) ISO 14001 but doing this does not equalize the ISO 14001 with the 50001 standard. There are several advantages of the ISO 50001 as it can assist organizations to improve efficiency of their existing energy-consuming activities and help in benchmarking, measuring, documenting, and reporting energy intensity improvements and their projected impact on reductions in greenhouse gas emissions. Also ISO 50001 promotes energy management best practices and helps emphasize good energy management behaviors. The standard also helps firms to evaluate and prioritize the implementation of new energy-efficient technologies. 
There are several topics which the ISO 50001 dominates and emphasizes excessively compared to the ISO 14001 like energy review, awareness, training and competence, monitoring and measurement, operational control and several others. Also ISO 50001 provides a framework for promoting energy efficiency throughout the supply chain. ISO 14001 has very high requirements which make it very challenging for small and mid-size organizations to conform. ISO 50001 has less complication and hence has attracted a wider audience.

\subsection{Enerit Software}

Enerit Ltd is the first company that provides software for large energy users to implement the ISO 50001 standard. The software has been designed for users who manage manufacturing plants and building stocks (such as supermarkets and office buildings). The framework developed addresses critical day-to-day operational issues which overshadow efforts to reduce energy costs. The major focus of the software is to manage energy costs systematically on a continuous basis, delegate responsibility and accountability throughout the organization and obtain significant savings by changing employee behavior. Instead of manual process this software uses excel spreadsheets and access databases. Enerit can integrate Monitoring and Targeting (M\&T), Building Management Systems (BMS), ISO 9001/14001, Enterprise Resource Planning (ERP). The software is sold based on a fixed monthly cost [33].

\subsection{Conclusion}

The literature review gives an idea about the growing importance of implementing an energy management system in an organization and the complications involved in implementing and sustaining the system. This chapter also gives inputs to make the framework for the ISO 50001 Analyzer software which would assist the industries to implement the energy standard. It can be seen that not many research work has been carried out in this area. The status checklist and the energy management algorithm from Zastava are very general framework and cannot be used as a full-fledged guidance towards implementing an energy management standard via ISO 50001. Thus, research in this area will be of immense help to industries to implement the EnMS according to ISO 50001. 


\section{Chapter3}

\section{Development of Process Flow Charts}

\subsection{Introduction to Flow Charts}

The flow charts developed in this chapter are used as the logic for the development of the ISO 50001 Analyzer software which aims to help facilities to implement energy management system in accordance with ISO 50001.

This chapter shows 17 flow charts which merges the ISO 50001 standard and the procedure to be followed to meet the standards. All the flow charts shown in this chapter are linked to each other and for the ease of understanding the explanation of flowcharts are done after every two to three charts.

The 17 flow charts shown next are:

- Energy Policy

- Scope, boundary and management responsibilities

- Legal and other requirements

- Energy review

- Energy Review (ii)

- Energy Baseline

- Energy Performance Indicators

- Objectives, targets and action plan

- Competence, training and awareness

- Control of documents

- Operational control

- Design and procurement

- Procurement

- Energy Procurement

- Internal audit

- Nonconformities, correction, corrective and preventive action

- Management Review

\subsection{Flow Chart with Interpretation}

As discussed, it is critical to have top level management commitment to change the behavioral aspect of the organization. The top management of any organization implementing an energy management system has to perform several tasks. The organization has to define an energy 
policy which expresses their commitment towards continual energy improvement. It also should provide a framework for setting targets and objectives. The energy policy should be defined by considering several factors like resource availability, long term goals like Save Energy Now Leader, corporate, environmental and sustainability goals. The policy should be available to all levels within the organization and has to be documented and, any changes to the policy should be updated. It is sometimes preferred by the organization to share the policy with external source. Figure 3.1.1 shows the requirements for defining an energy policy.

The organization has to identify the scope and boundary of its energy management system. This involves identifying the physical boundary or limit, operations, processes which would be involved in the energy management system. The scope and boundaries need to be documented and updated when changed. The top management has to appoint a management representative who would be the source of contact between the organization's management and the employees. The top management has to approve and help in creating an energy team consisting of inter departmental or cross functional employees. They also have to periodically perform management review at a specified interval. The management has to introduce energy management and the requirements to be followed to the team and also employees within the organization. An initial task of collecting production data from respective departments has to be assigned which would require processing in later stages. The energy team along with the management representative has to gather information regarding the legal and other requirements that the organization subscribes presently which may affect energy sources. These policies need to be documented and updated when changed. Figure 3.1.2 shows the requirements for defining scope, boundary and the formation of the energy management team. 


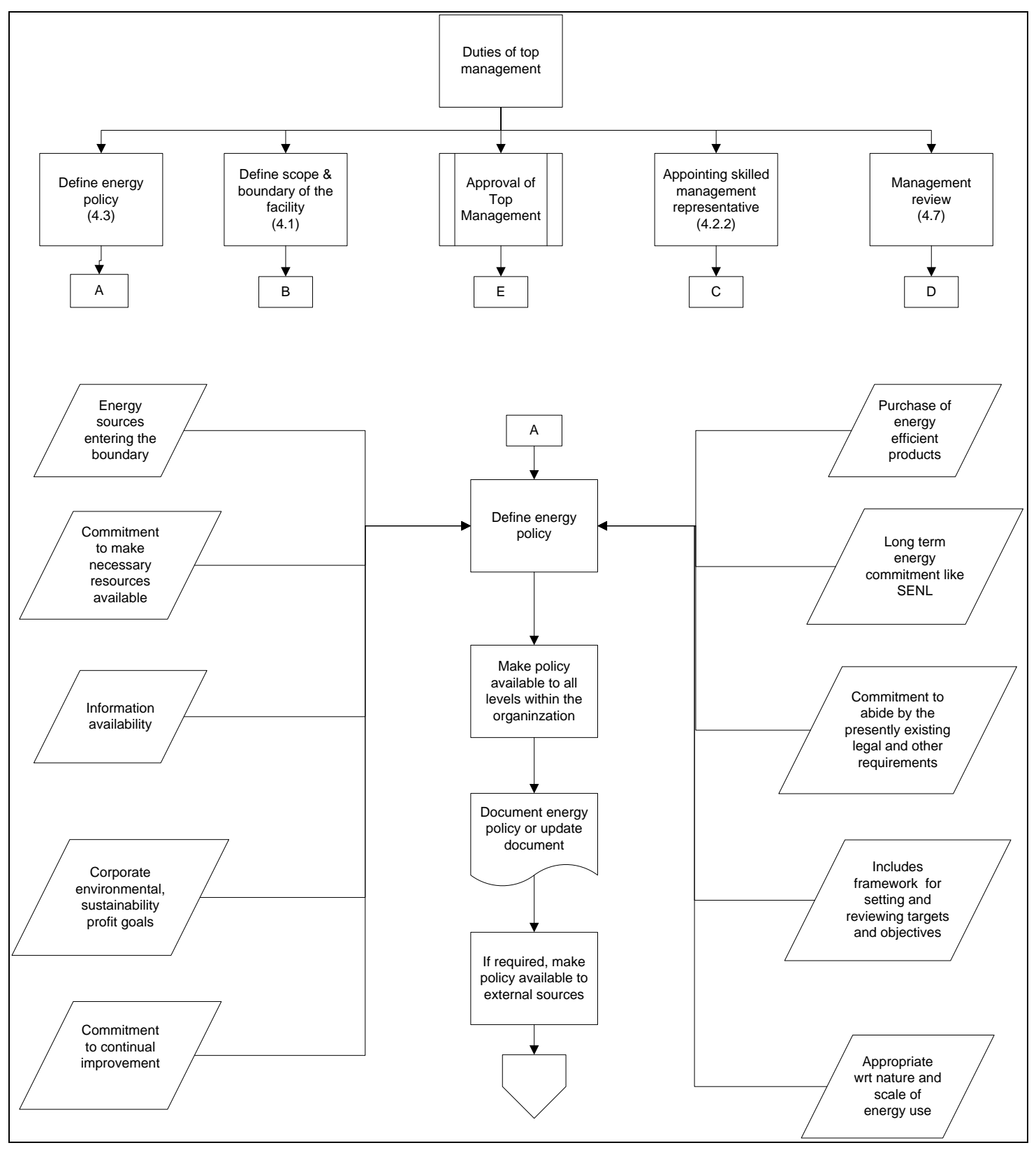

Figure 3.1.1: Energy Policy 


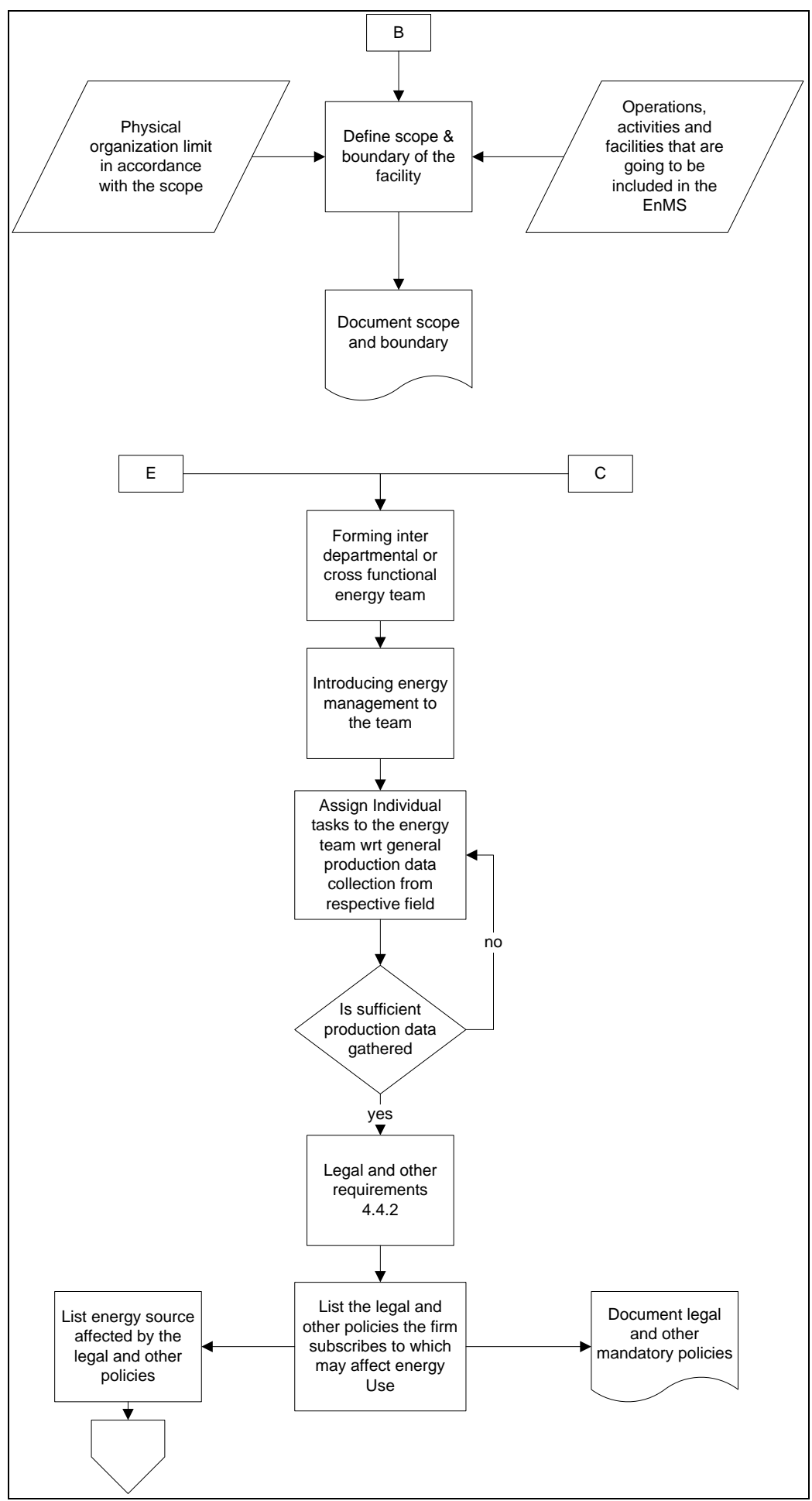

Figure 3.1.2: Scope, boundary and management responsibilities 
The energy policy should be in agreement with the legal and other requirements that the organization presently subscribes. The other requirements are special policies which the firm follows like Energy Star. The energy policy must include a commitment to comply with legal and other requirements. Any deviations would require notification to the management review which would be discussed later. The firm must have direct access to these requirements which should get updated if any change occurs. The firm must record their compliance to these requirements and update it when change occurs. These legal and other requirements can be identified from any of the following:
a) Existing permits, licenses, manuals, records
b) Discussion with personnel throughout organization about requirements
c) Federal, state and local regulatory agencies
d) Code of federal regulations
e) Trade periodicals
f) Electronic Newsletter

This section is shown in Figure 3.1.3.

The firm must identify the energy source which crosses the documented boundary. According to SEP requirements (not required by the ISO 50001), industries must account for $95 \%$ of its energy sources. The energy consumption data for each energy source must be collected for the past and present usage. Other important information to be gathered involve collection of utility bills, utility tariffs, production data, weather data, operating hours for each equipment, equipment rating. The data should be gathered from a genuine source with calibration certification. The energy usage must then be roughly analyzed with respect to the production quantity and the weather data and hence future energy requirements must be roughly estimated. From the energy bills, operating hours and the rating of equipment average utilization and load factor must be estimated. Using the above data a Pareto chart can be made which will show the energy consumed by individual equipment in the process. Figure 3.1.4 shows the first part of energy review. 


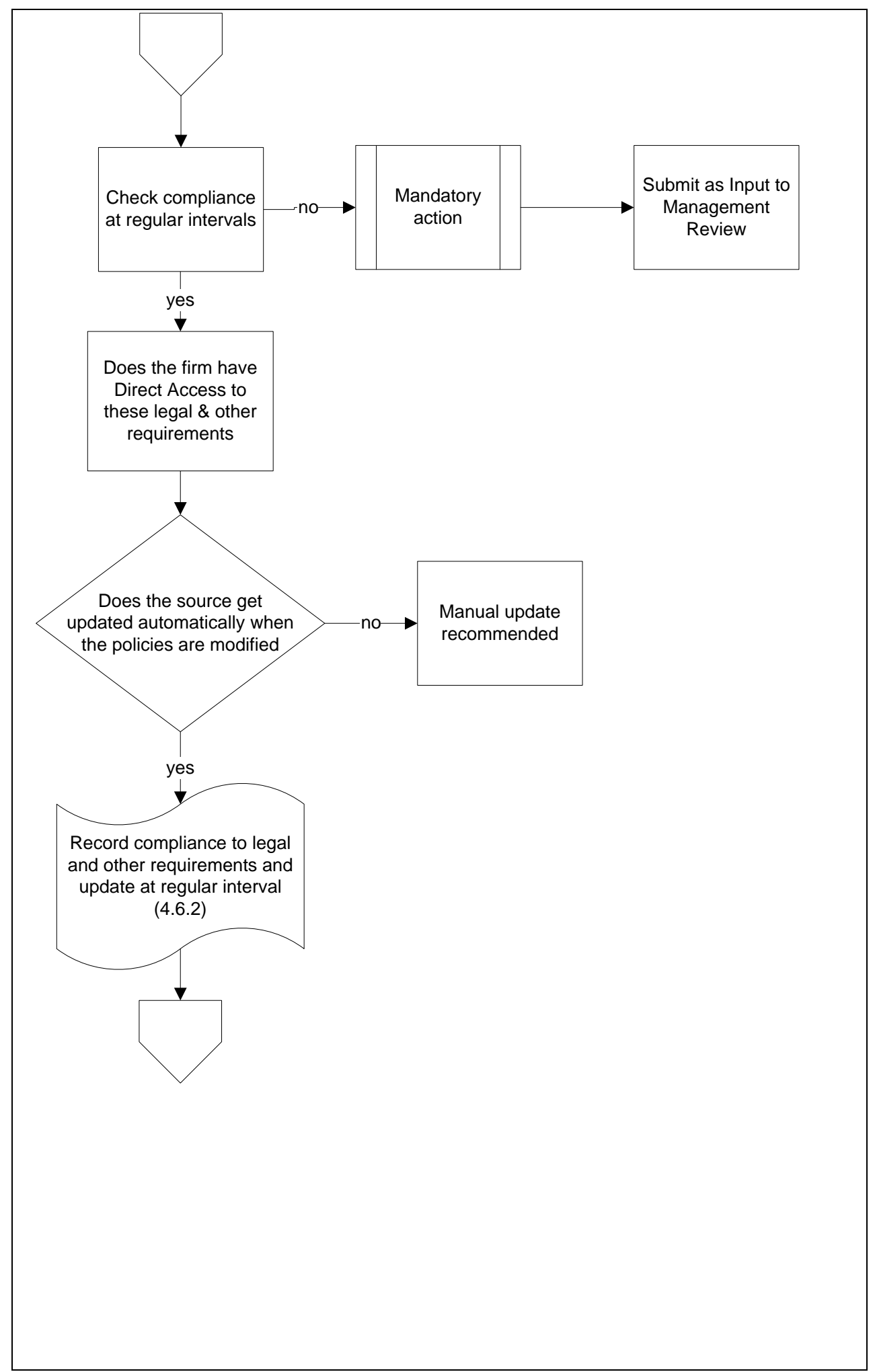

Figure 3.1.3: Legal and other requirements 


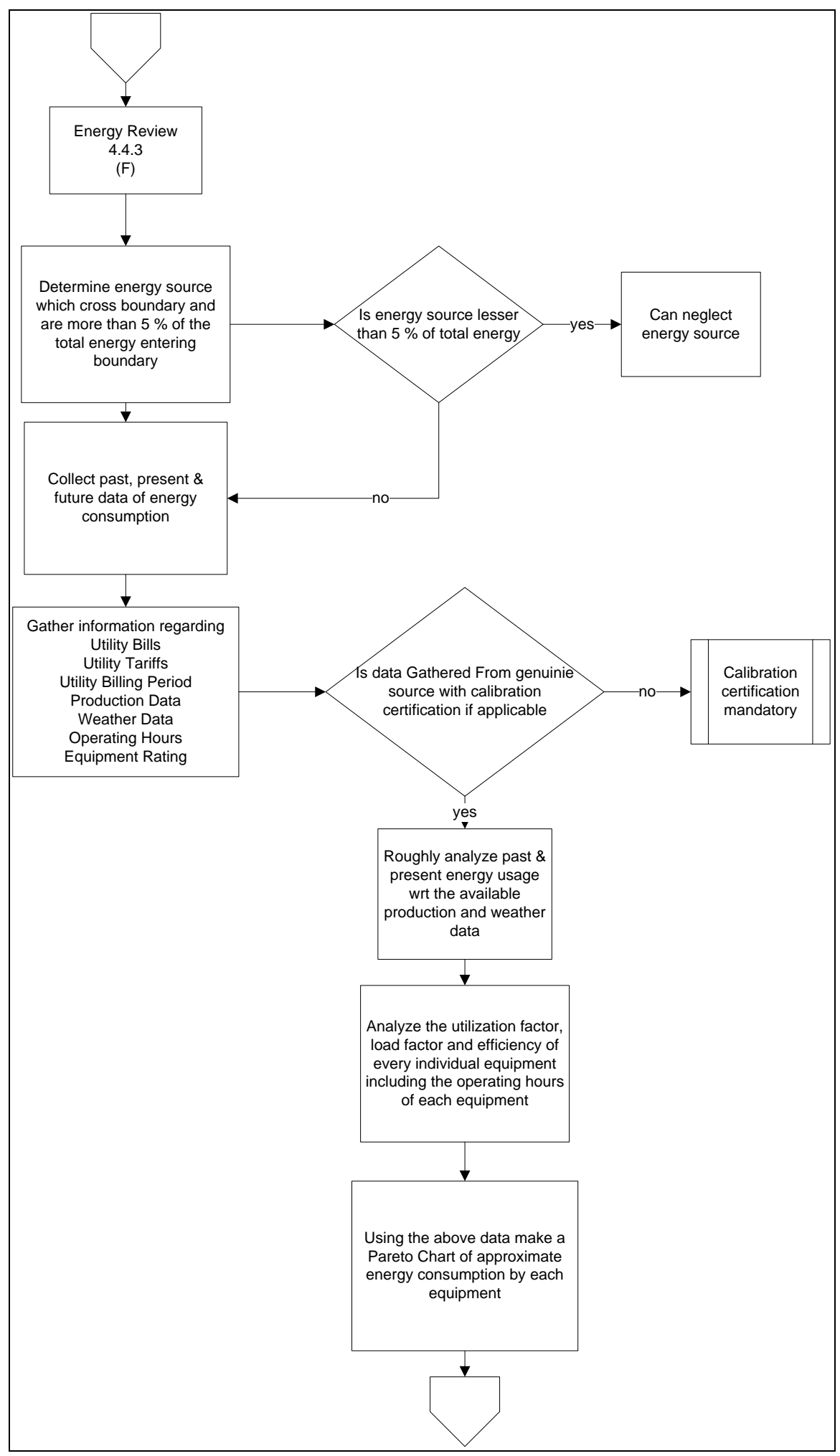

* The energy source elimination $5 \%$ is a part of the SEP requirement and is not required for the ISO 50001

Figure 3.1.4: Energy review 
From the Pareto chart the highest energy consumers can be identified. Information then needs to be gathered about the input and output variables for this equipment/process. Energy conservation measures need to be identified for each of these major energy consumers. This can be done by using US DOE services, private audits, webinars, experience from other industries etc. There are several rebates and incentive programs offered by the state, federal and a local utility board. It is beneficial for the industry to identify these rebates and incentives and utilize them to implement energy efficiency measures. It is also essential to identify the top management's criteria for implementation of recommendation. The criteria may involve the payback period, capital cost incurred, energy cost savings, etc. The recommendations can be prioritized based on management criteria. The entire energy review methodology and process of identification of significant energy users have to be documented. This completes the energy review and is shown in Figure 3.1.5.

An energy baseline has to be built to help the firm quantify energy savings after implementation of energy projects. The baseline year selection depends on the availability of all the required production and energy information and the planned certification time. To build a baseline the firm must determine production variables for the main and secondary product and weather data if it influences energy usage. A regression model can be built using one of the commercial software available in the market. For simplicity the EnPI tool developed by the Georgia Tech Research Corporation is used in the ISO 50001 Analyzer software. Regression building may also involve using several transformations for variables to satisfy the final requirement. According to the Measurement and Verification Protocol, the baseline regression model is acceptable only if the F-test for the overall model has a P-value of less than 0.1 and at least one of the variables has a P-value of less than 0.1. The baseline building process is shown in Figure 3.1.6. 


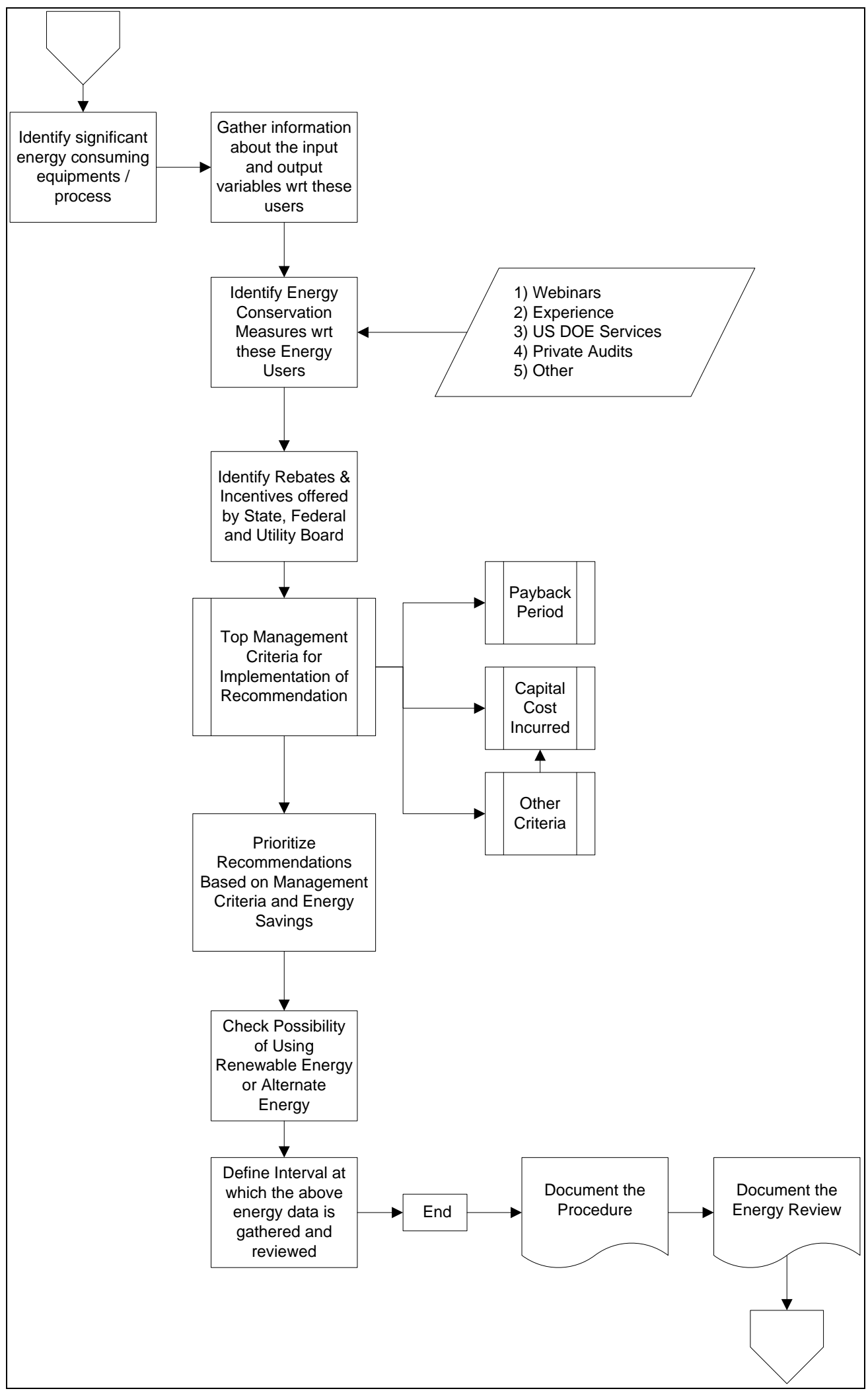

Figure 3.1.5: Energy Review (ii) 




Figure 3.1.6: Energy Baseline 
Once the final model is built for the baseline year which satisfies all the above conditions it must be recorded. The baseline model must be modified if any major change occurs to the process, facility or production or the model is not valid for the future years. The record should be updated in case any change to the baseline is made. The organization should require the identification of the Energy Performance Indicator (EnPI) which is a measure of the energy performance. It can be calculated as energy consumed per production variable. The production variable can be the independent variable used in the regression model or any other significant factor. If the EnPI does not show the correct trend that the organization expects, it can be changed to a different variable and if none of the output variables prove a good fit, it may be useful to use terms involving input raw material bought by the manufacturing facility terms to check the trend. If none of these works, sub-metering may be required to differentiate between different energy consumers followed by rebuilding the baseline. EnPI's need to be recorded, reviewed, and updated. The procedure for determining EnPI's should be documented. The EnPI determination process is shown is Figure 3.1.7.

The firm must make individual objectives focusing towards major energy consuming areas and equipment. These objectives have to be subdivided into smaller timeframe targets. These objectives and targets should satisfy the legal and other requirements of the plant and comply with the energy policy. The objectives and targets should be documented and reviewed in a specified interval. The firm should also develop an action plan to achieve the targets. The action plan includes identifying resources, assigning individual responsibilities, identifying procedure to verify results of action plan and energy performance improvement. The data about the employees working with the significant energy users like educational background, experience, skill level and training given should be recorded and validated. The process of making objectives, targets and action plan is shown in Figure 3.1.8. 


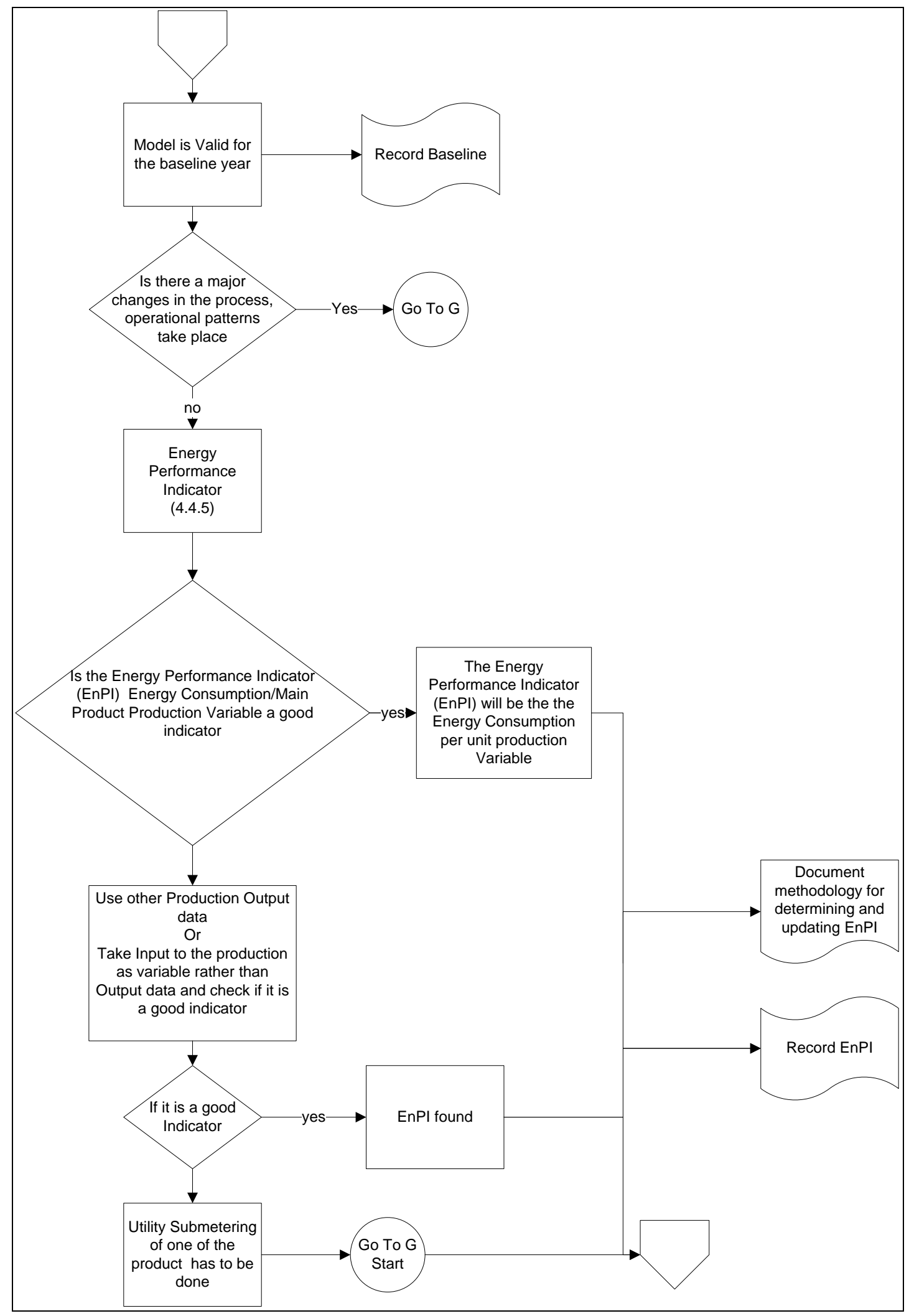

Figure 3.1.7: Energy Performance Indicators 


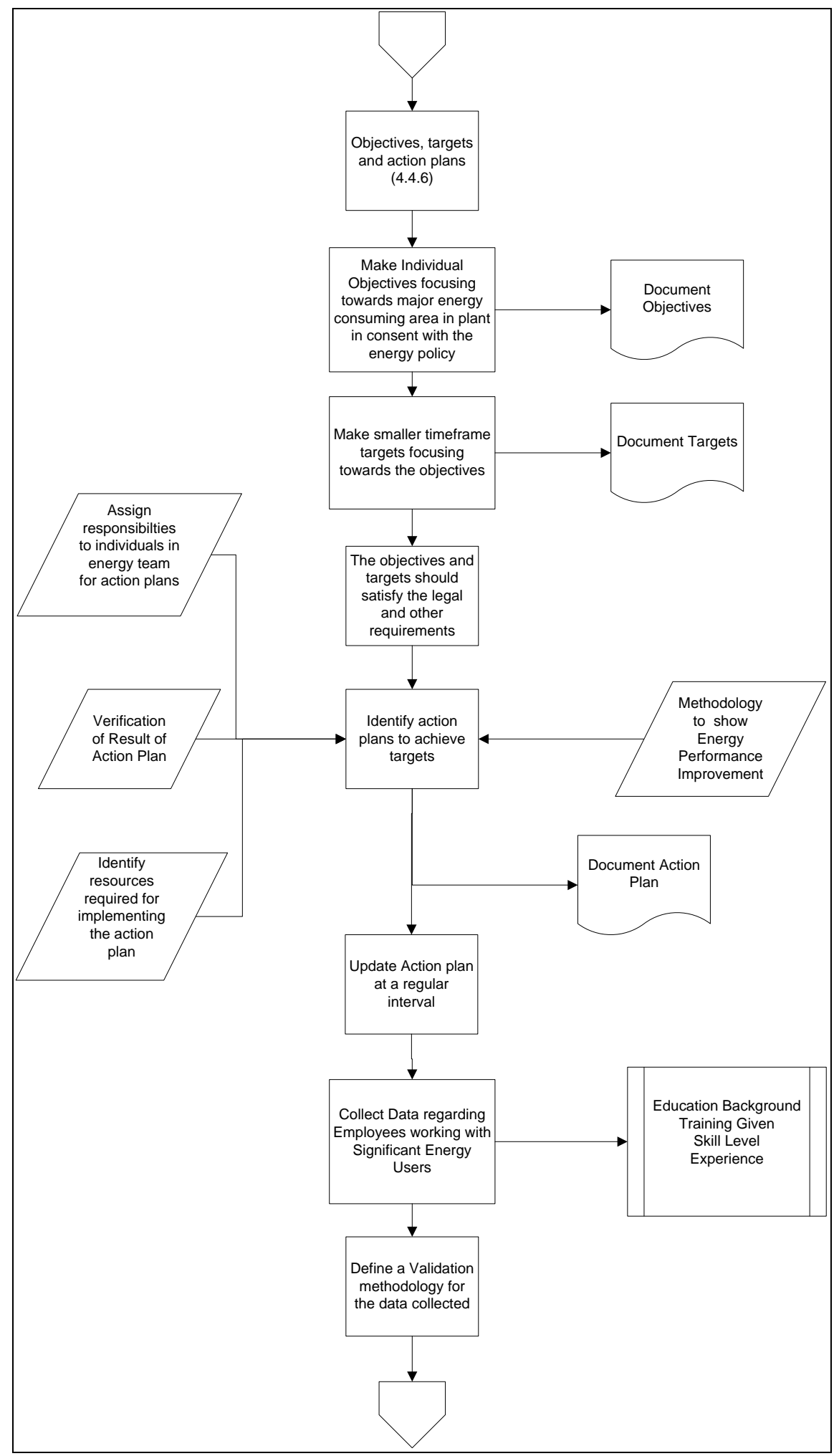

Figure 3.1.8: Objectives, targets and action plan 
The employees working with SEU's need to demonstrate competence else must be trained on the efficient use of the equipment, energy management and importance of reduction of energy intensity. Training can be given by webinars, conferences, certification exams etc. The workers should be made to realize their responsibilities in achieving the energy targets, objectives and hence abiding to the energy policy. Records for training and competence of workers should be made and updated whenever required. Procedure for training new employee or change in employee must be defined. This process is shown in Figure 3.1.9.

It is required to review, verify and update all the documents at a specified interval. The documents can be maintained as a soft or hard copy. A written procedure to control the documents should be made which describes the document approval criteria, changes and revision status, prevent the use of obsolete information. All documents should be legible and identifiable. The firm should also consider identifying other documents considered important for the proper running and operation of the EnMS which need to be documented. If an external agent is involved in the working of the energy management system, required documentation should be made to show his involvement in the management systems implementation. The control of document procedure is shown in Figure 3.1.10.

The organization should make strategic plans to operate and maintain equipment/process and hence running them in an efficient manner. The operating and maintaining criteria for the equipment should be documented. The above needs should be communicated effectively to the workers working with the significant energy users. It is advisable to follow best practices from DOE webinars and conduct training to emphasize the best practices. It is required to create an internal communication methodology which would help in transferring information throughout the firm. If there is requirement for external communication a procedure has to be defined to address it and has to be documented. It is also required to define information that would be communicated externally like existence of energy management system, energy performance improvement etc. The operational plan and communication methodology is shown in Figure 3.1.11. 


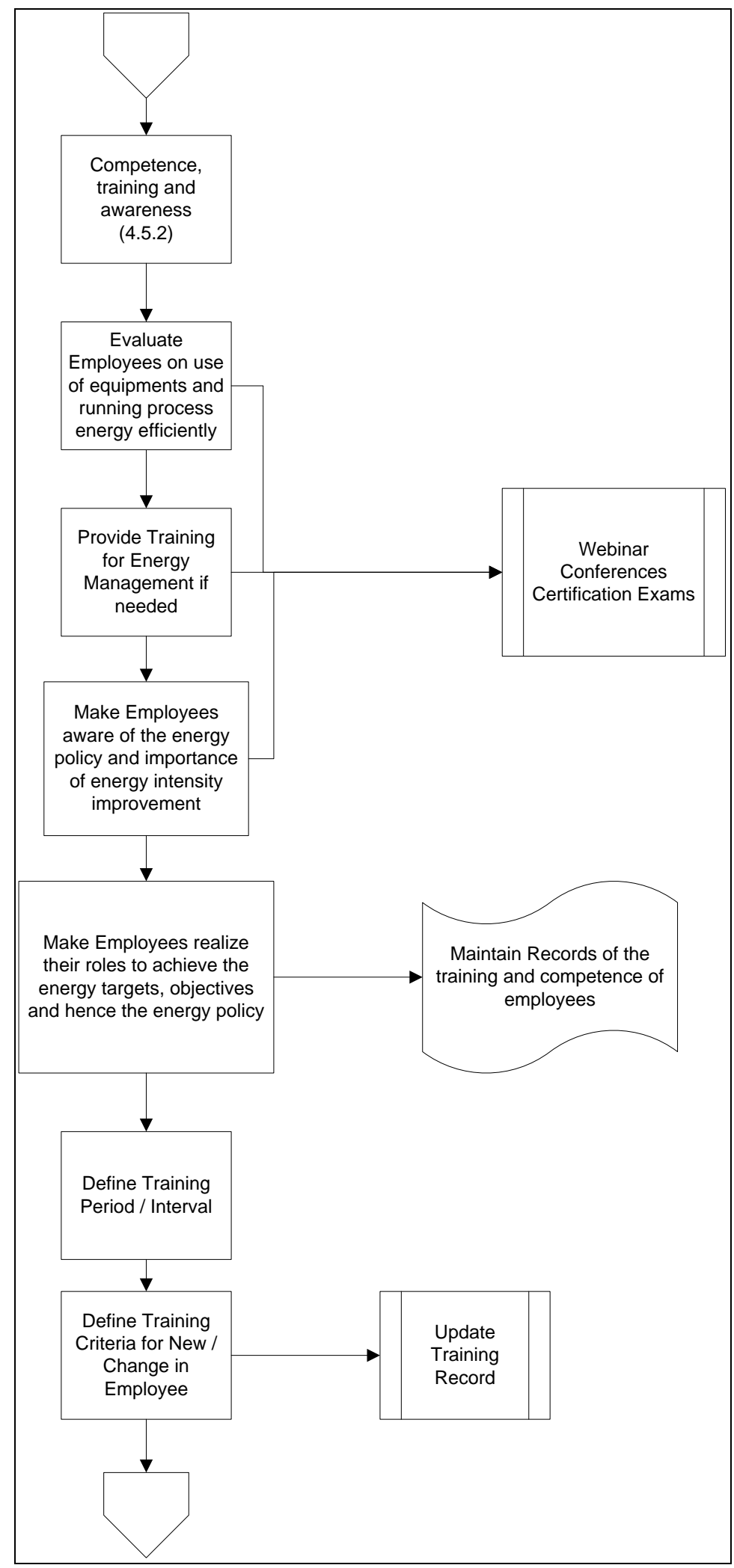

Figure 3.1.9: Competence, training and awareness 


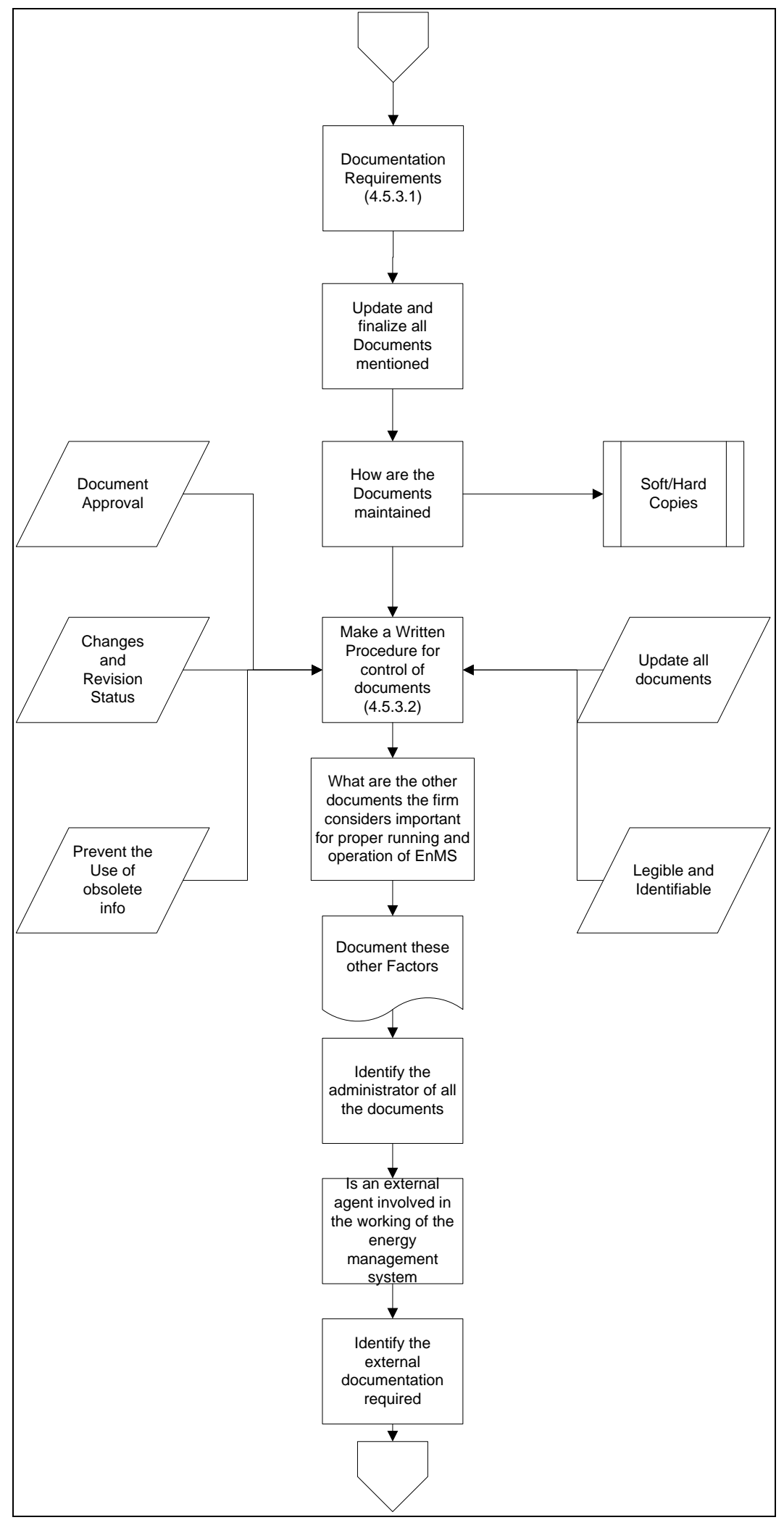

Figure 3.1.10: Control of documents 


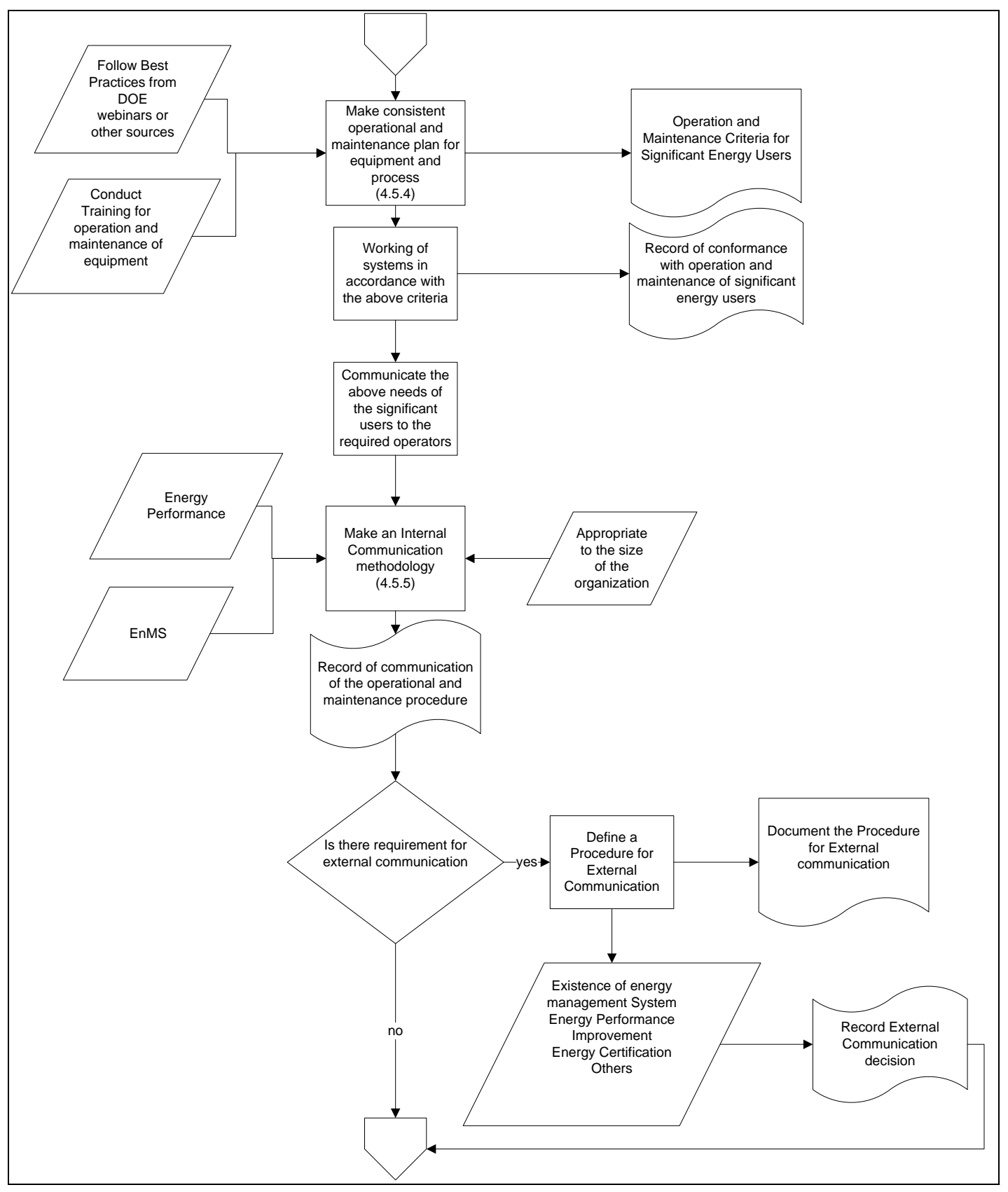

Figure 3.1.11: Operational control 
The firm must consider energy efficiency improvement changes that need to be made if the organization is changing/modifying equipment. The firm must also consider factors like process requirement, losses, and future expansion and retrofit needs. This process needs to be recorded. The organization is required to check if the procurement department has existing criteria on energy efficiency for procurement of new equipment. If there is no existing energy efficiency criteria the procurement department must create a new criteria which must be informed to the suppliers for efficient procurement and the notification given to the suppliers should be recorded. The energy usage of the equipment should be calculated over the life time by analysis which includes the maintenance cost, disposal cost and additional labor cost. The procedure involved to make this analysis must be documented along with the energy criteria used for procurement of equipment. Then the quality of energy source required for efficient production must be determined and the specification documented along with any other existing criteria like cost terms. The design and procurement process is shown in Figures 3.1.12 and 3.1.13.

It should be checked if the current energy supplier satisfies the above conditions. Several times the selection of the supplier is done only based on cost and the quality factors are not considered. If the present supplier does not satisfy the conditions, the firm must notify the management in the management review and if approved, the firm should consider changing their present energy provider with an efficient one. All the key characteristics must be documented. The key characteristics are energy review, EnPI, objectives, targets and action plan. They should be continuously monitored and measured. The procedure used for measurement must be documented. Calibrated equipment with certification must be used for measurement and the calibration should be recorded. Energy performance should then be checked for significant deviations and, if any, the firm should determine reasons for non-compliance and record these deviations. If there are no significant deviations the firm must record compliance towards the standard specification. This is shown in Figure 3.1.14. 


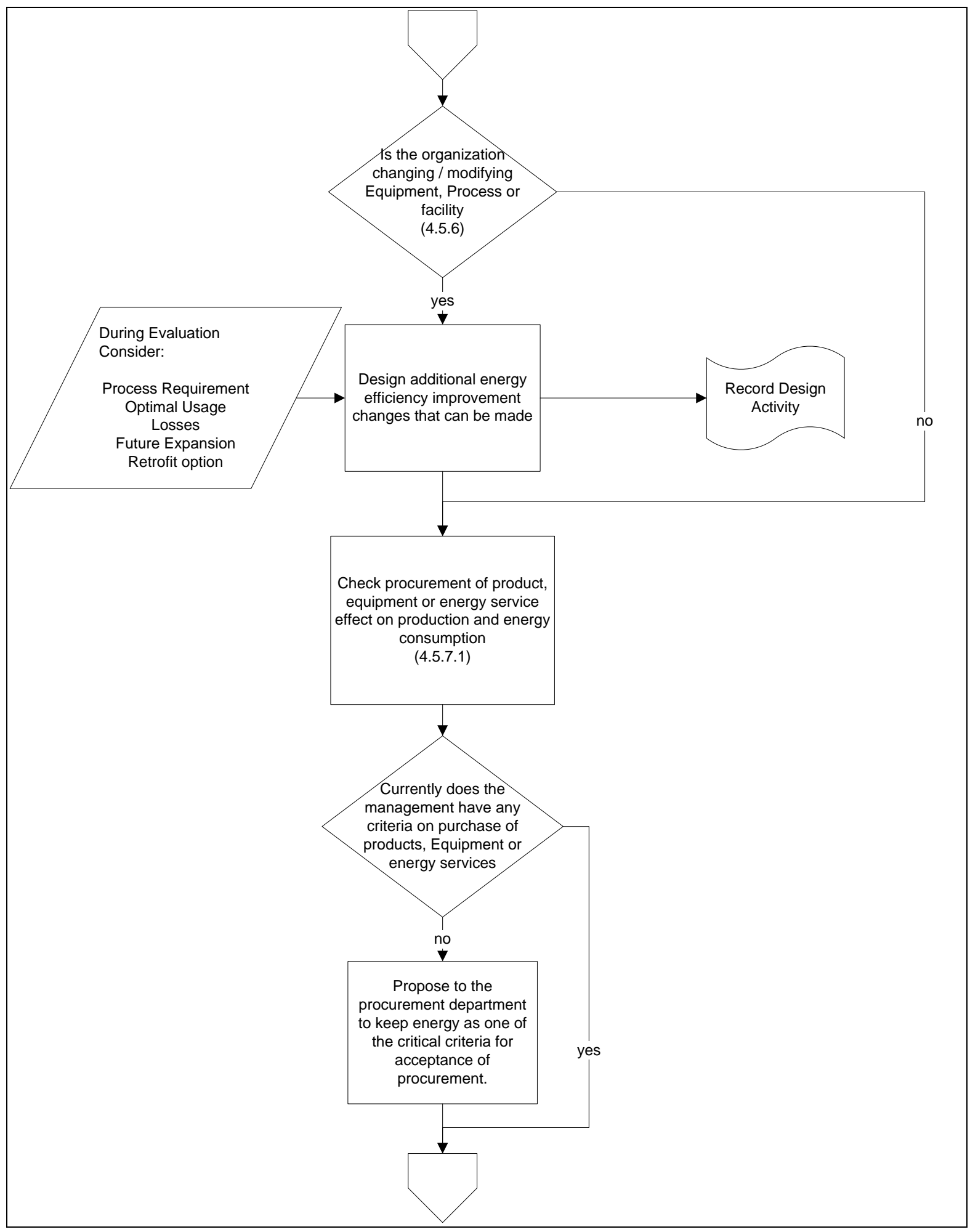

Figure 3.1.12: Design and procurement 


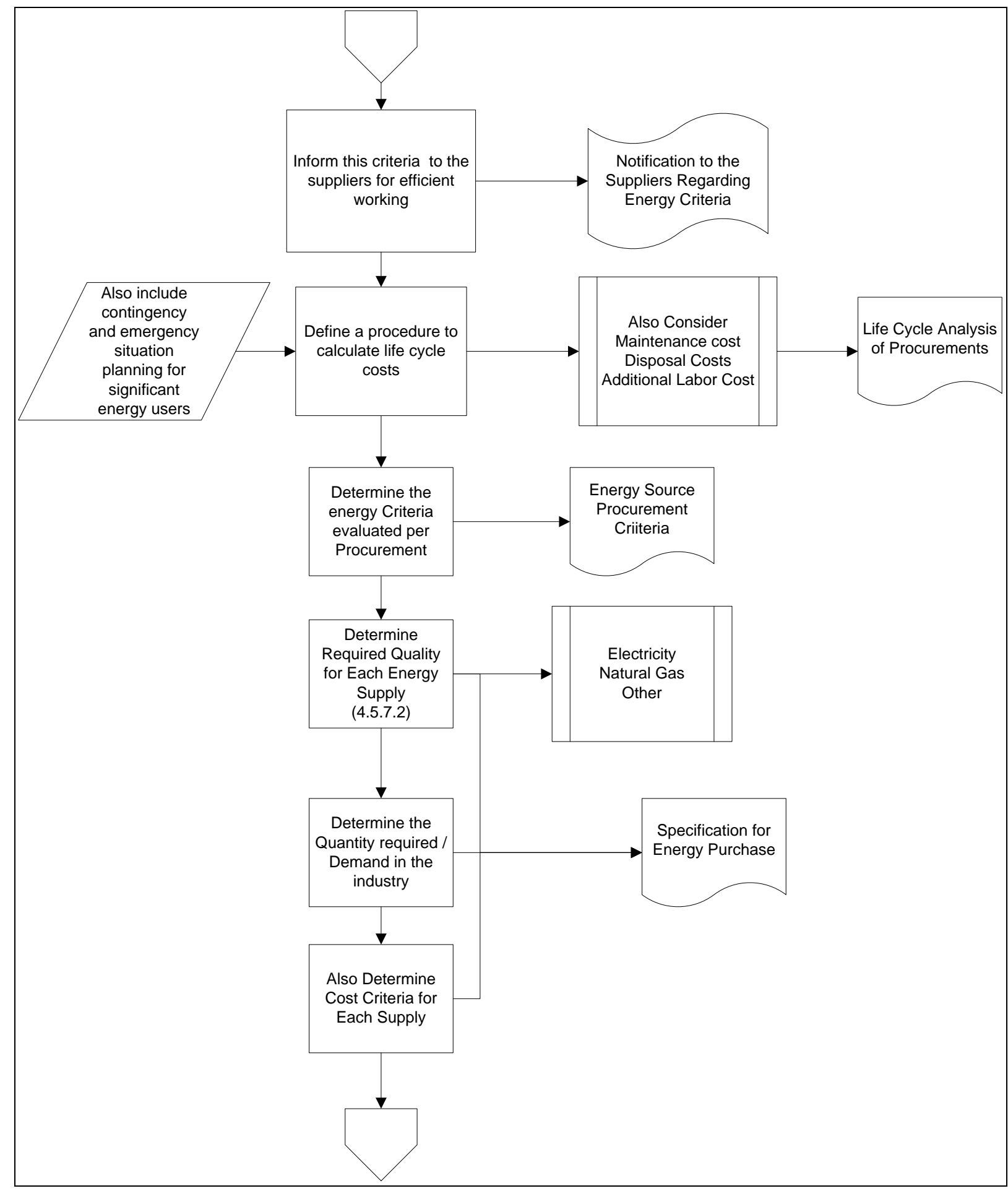

Figure 3.1.13: Procurement 


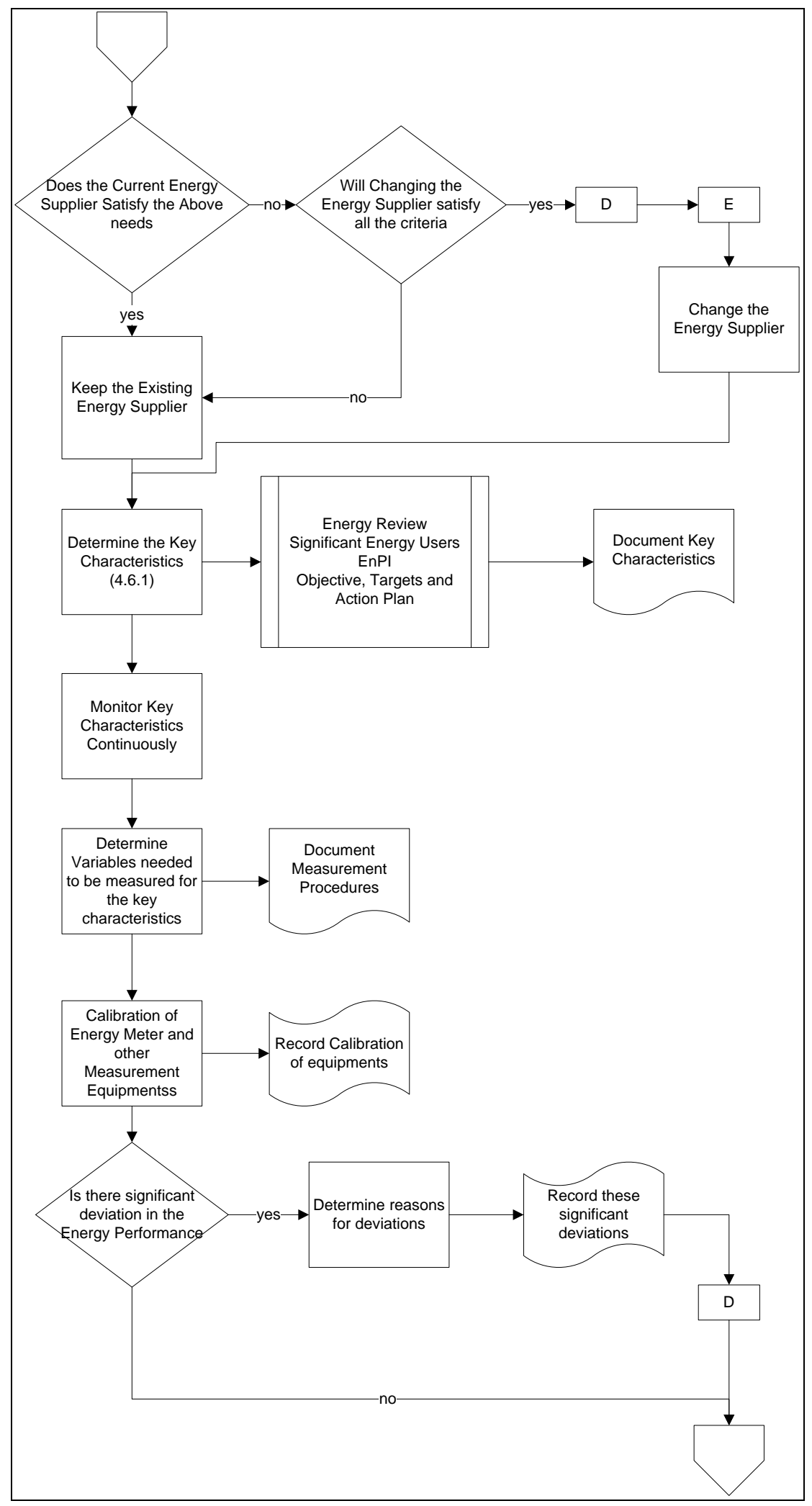

Figure 3.1.14: Energy Procurement 
Once all the above requirements are met, the top management of the organization needs to select an internal auditor to inspect the compliance to the standard. It is advisable to select an auditor by determining some criteria for selection. The auditor must have specific goals and an action plan to follow. If an internal audit had been performed earlier, the output of the previous audit must be considered for the present audit. The auditor must check for compliance towards the standards along with the mandatory documentation and records for the ISO 50001. The final report of the internal auditor must be recorded and sent to the top management for review. Also if the auditor concludes some unmet requirement mentioned in the standard, the firm must determine reasons for such non-compliance and take corrective actions to rectify the errors and hence, meet the required compliance towards the standard. This procedure must be recorded. The firm then must also come up with preventive action plans to avoid future occurrence of similar non-compliance. These preventive actions must also be recorded and reviewed periodically. All records must be maintained and updated at a regular interval. Similar procedure like maintenance of documents should be used to control records. This procedure is shown in Figures 3.1.15 and 3.1.16. Finally, after the internal audit, the top management must review the progress of the organization towards the EnMS. The procedure used for management review along with the schedule must be documented. The management should be given all the inputs used for implementing the energy management system. The inputs provided to the management for review and their outputs must be independently recorded. The organization should make the required changes to the EnMS as mandated by the top management.

Some of the inputs are:

- Energy Policy

- Energy Performance Indicators

- Legal and Other Requirements

- Compliance of Legal and Other Requirements

- Energy Objectives and Targets

- Achieved Objectives and Targets

- Internal Audit Results

- Non Conformities, Corrective and Preventive Actions 
- New Ideas for Improvements

- Previous Management Review Conclusions and Inputs

- Status Check on the Previous Inputs

- Resource Allocation Requirements

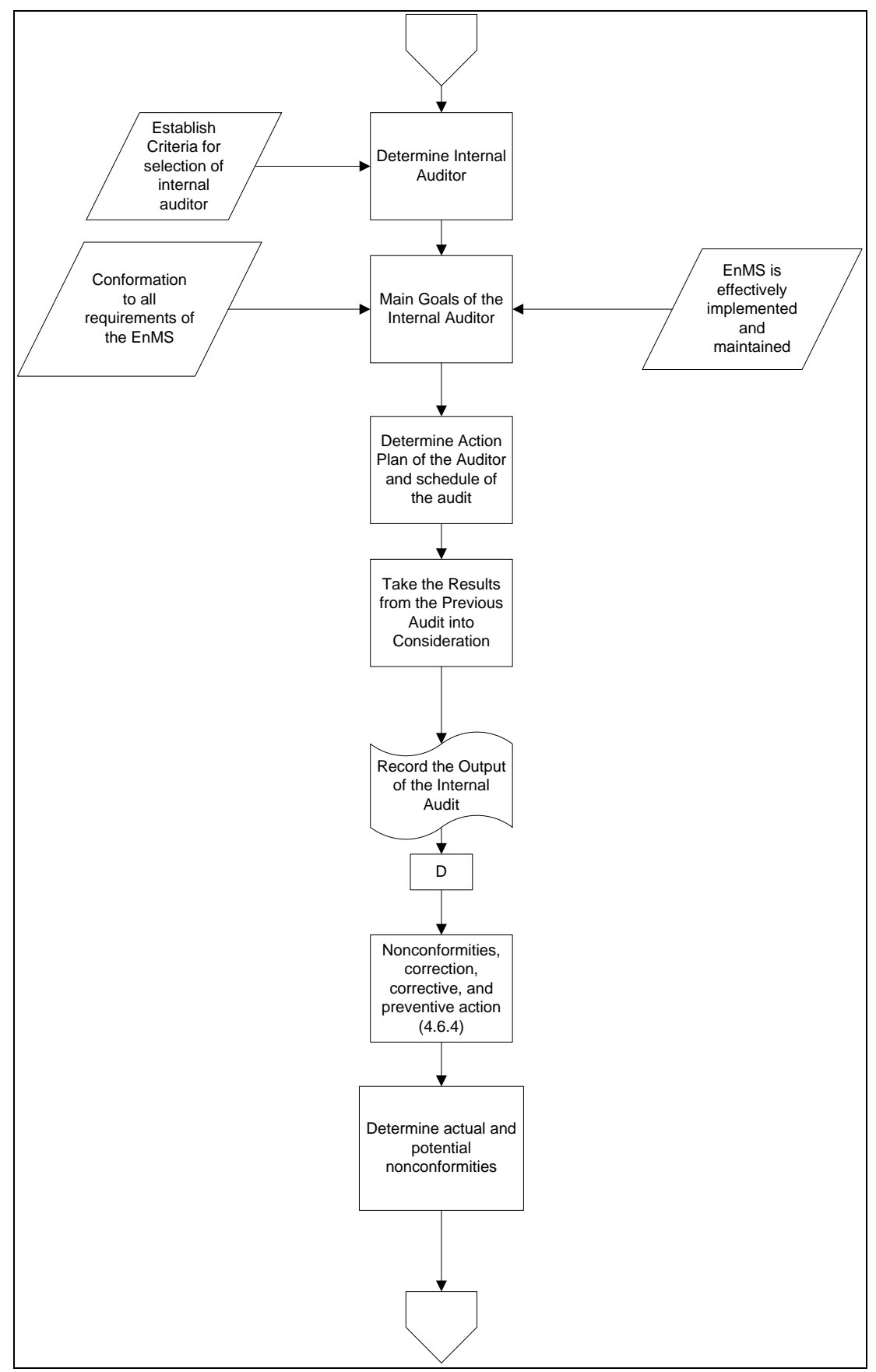

Figure 3.1.15: Internal audit 


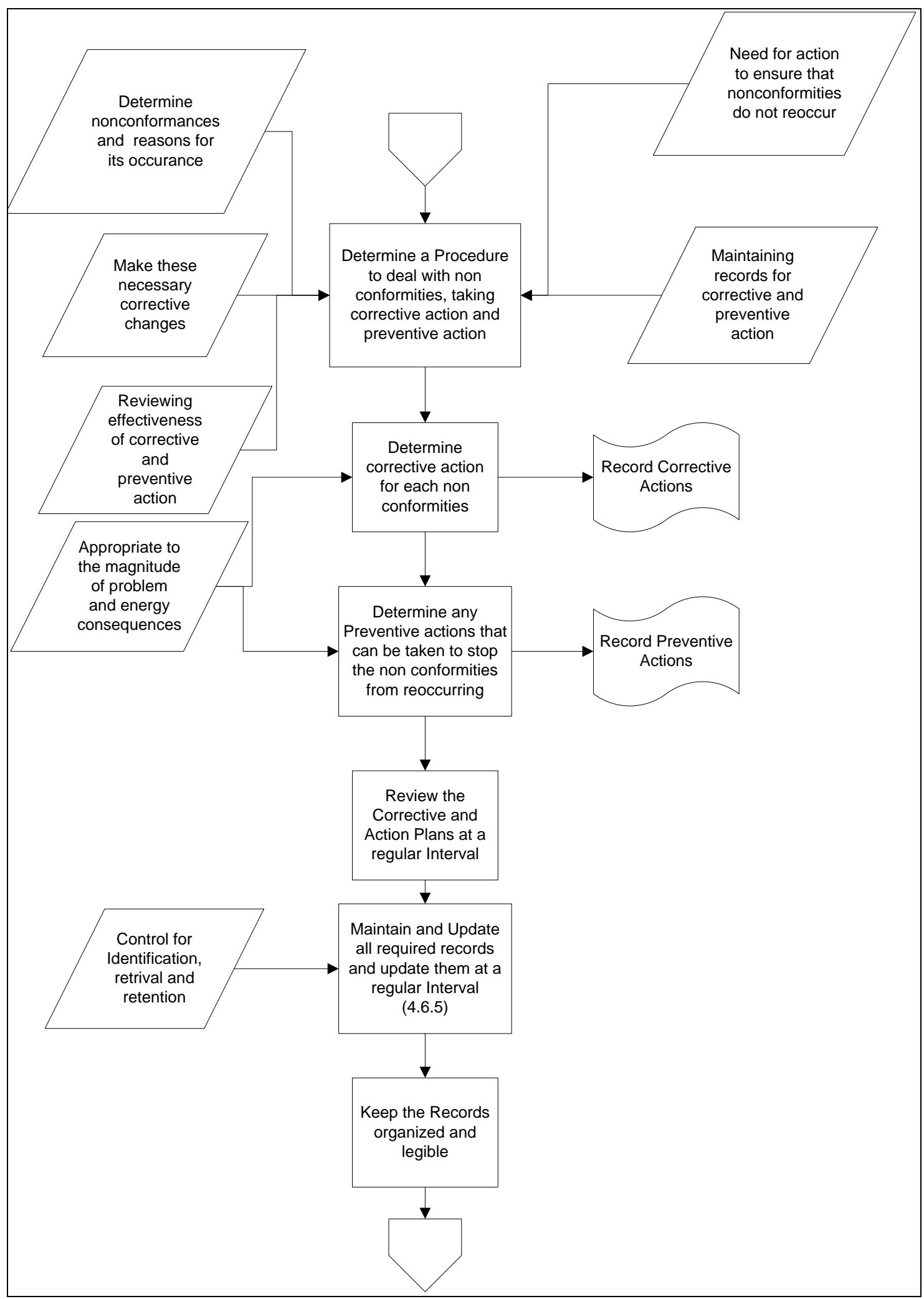

Figure 3.1.16: Nonconformities, correction, corrective and preventive action 


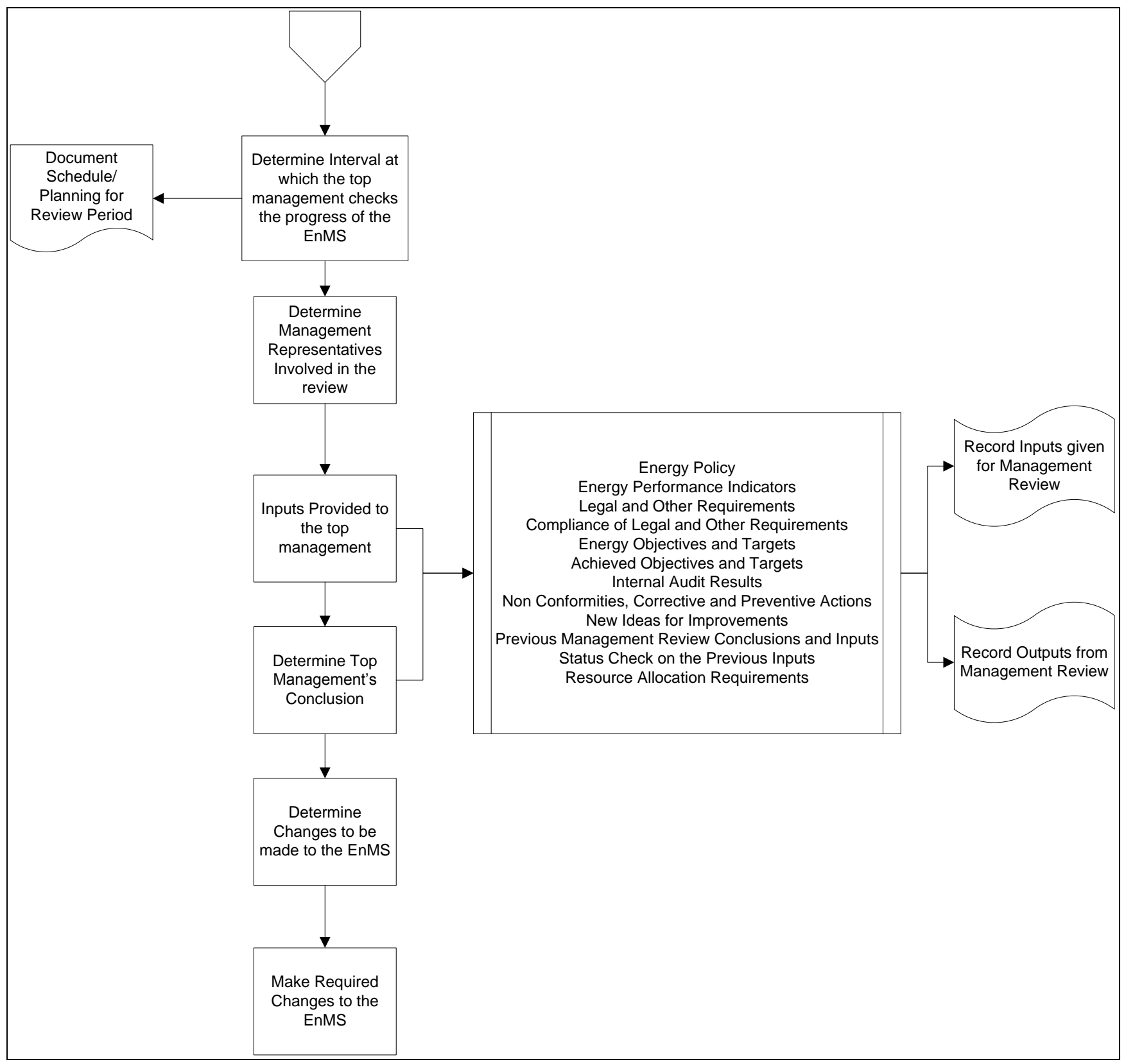

Figure 3.1.17: Management Review 


\subsection{Conclusion}

Flow charts are developed to implement an energy management system via ISO 50001. The main focus of this chapter is to construct a framework to implement an energy management system via ISO 50001. This serves as a guideline for every industry to implement the standard and get certified without the involvement of any external consultant (ISO).

The above flowcharts describe the entire process involved and may be used mostly in developing the software (ISO 50001 Analyzer) which can be used effectively by organizations in implementing an energy management system. The ISO 50001 Analyzer would also help firms to transfer the energy management system to sister plants if required and hence reduce the resources involved to create a new management system. 


\section{Chapter 4}

\section{ISO 50001 Analyzer software}

\section{A.1 About the Software}

The "ISO 50001 Analyzer" software is intended to mainly assist small and medium sized industries in implementing ISO 50001. It can be used by energy manager of an organization or by consultants working as energy managers to introduce ISO 50001 and hence help them identify resources that would be required to implement an energy management system.

The software is designed to take manual inputs from the user and check if requirements as mentioned in the standard are fulfilled. The software also has a database in it which stores all the necessary documents and records created by the organization. This software is linked to the Energy Performance Indicator (EnPI) tool created by the Georgia Tech Research Corporation which helps industries perform regression analysis to create a baseline for each utility. It is very important to use this software as a tool and not as a replacement for the standard itself. It is required that the user have a fair energy background and a minimal understanding of the terms and requirements of the ISO 50001 system to effectively use this software.

\section{Software Development Tool Used}

Java Programming Language is used for development of the software. Java programming language is both a compiler and an interpreter. In Java the code is first translated into an intermediate language using the compiler following which independent codes are interpreted by the interpreter many times. The ISO 50001 Analyzer uses Swing to design window base application in java. Swing supports all types of advanced Graphical User Tnterface components such as JTree and JTable. Microsoft Access database was used in this software to store, search and delete user records using Java's JDBC API (Application Programming Interface). Figure 4.1.A (a) shows the working of Java Programming. 


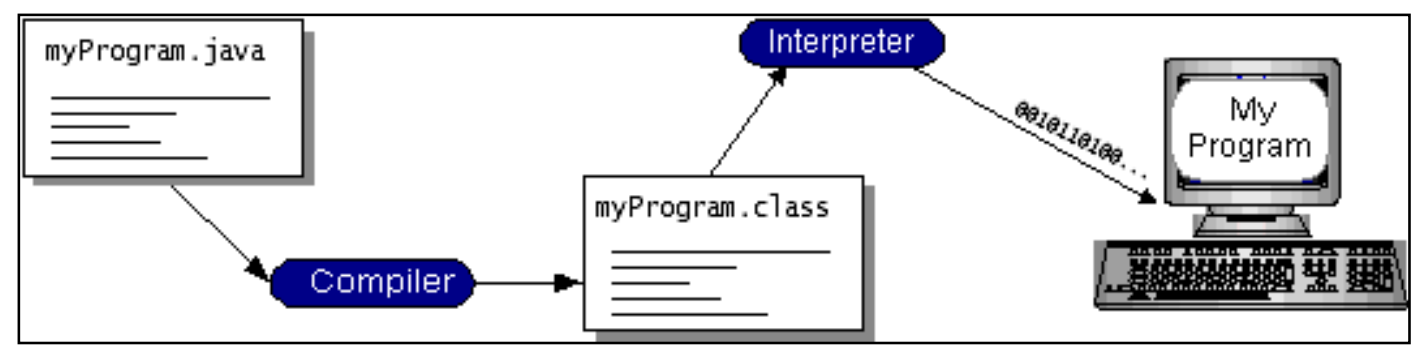

Figure 4.A.1 (a): Working of Java Language

\section{Installation Procedure}

The software works on any 32-bit operating system. The user needs to unzip the software file to a desired drive. Following this the user needs to go to Control panel -> Administrative tools -> Set up data sources (ODBC) -> User DSN -> Add -> Microsoft Access Driver (*.mdb, *.accdb)

-> Database select -> choose iso.accdb file from the drive where the software is saved -> Save. Then, open the file saved in the desired location, double click iso and double click on run, and the software would start.

The software has a feature to store multiple company information data. The data is stored in Microsoft Access. Every row and column in Microsoft Access is coded to store all data entered by the user in the Graphical User Interface (GUI). Every data input by the user can be used in two modes store or retrieve. Additionally every file uploaded in the software is stored in a separate folder (each company) created by the software.

The "ISO 50001 Analyzer" software has been divided into five different modules (Figure 4.A.1 (b)) which are shown below.
1) Company Details
2) Energy Team
3) Energy Data
4) ISO 50001 Standard
5) Document and Record 


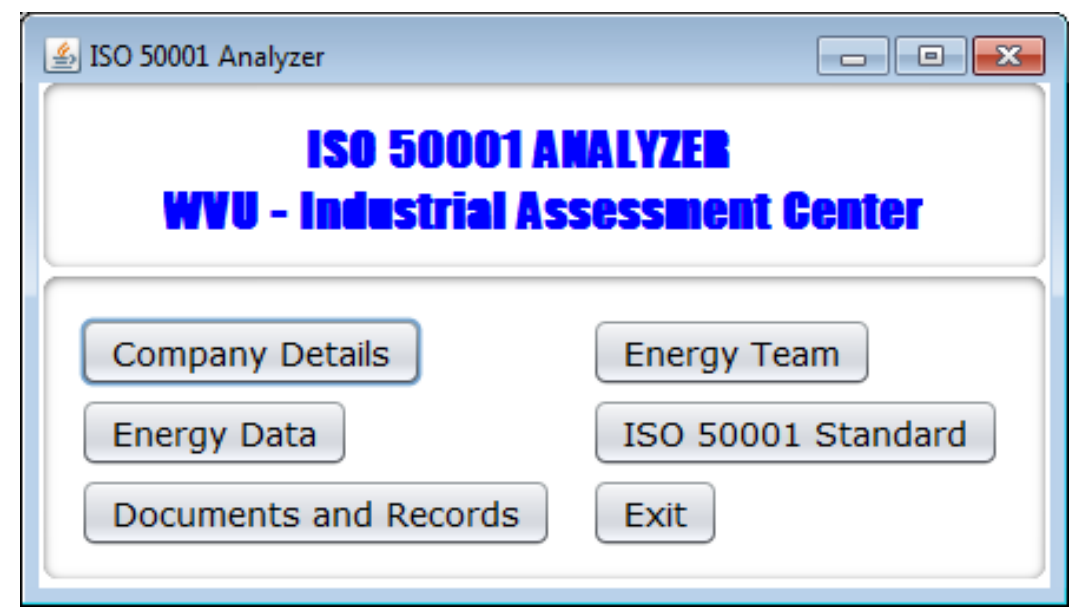

Figure 4.A.1 (b): Software Main Screen

\section{A.2 Company Details}

This module of the software collects the general background information of the organization such as company name, industry type, principal product, SIC code, NAICS code and address. The software is designed to hold data for multiple companies and show information about any selected organization. Figure 4.A.2 below shows the screenshot of the company details module. The view tab in this module shows details of every organization entered by the user.

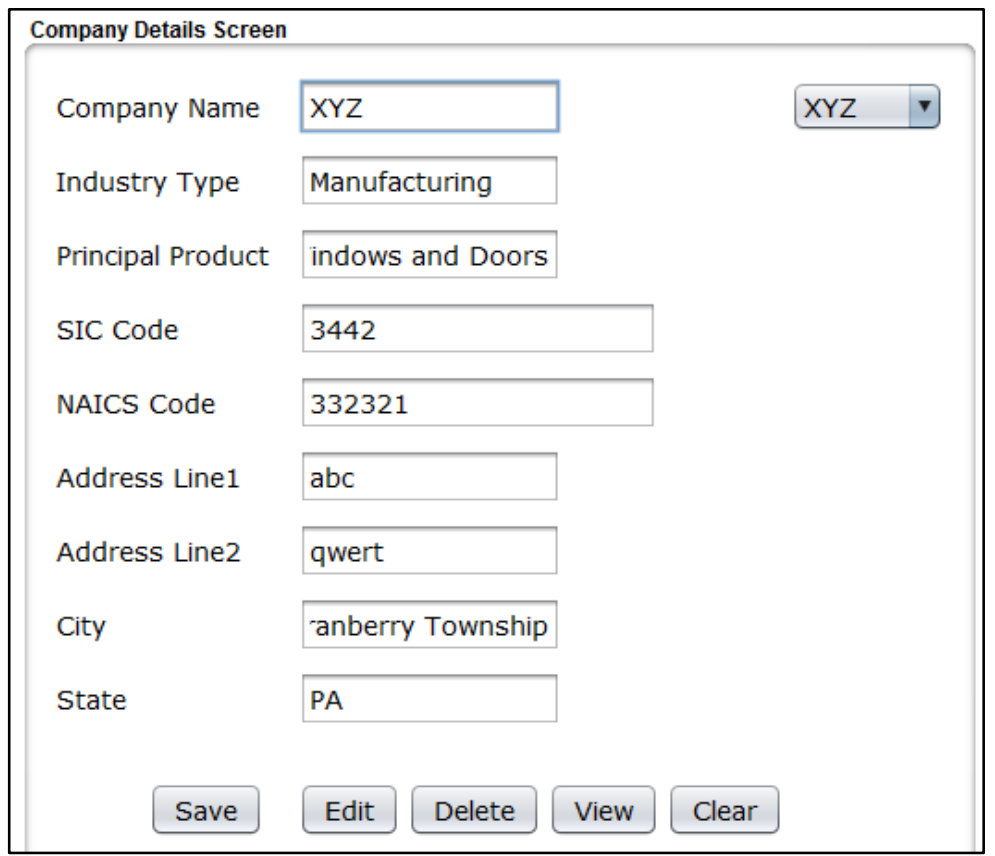

Figure 4.A.2: Company Details Module 


\section{A.3 Energy Team}

The ISO 50001 requires the top management of an organization to appoint a management representative and approve the formation of an energy team. The standard also specifies duties which must be performed by the management representative (ISO 50001 Section 4.2). This section of the software helps in collecting information about the management representative, energy team and other members involved in implementation of this system. The software stores name, division, designation, responsibilities, e-mail ID and contact number. Figure 4.A.3 below shows the energy team module. The view tab in this module shows details of management representative, energy team and other members.

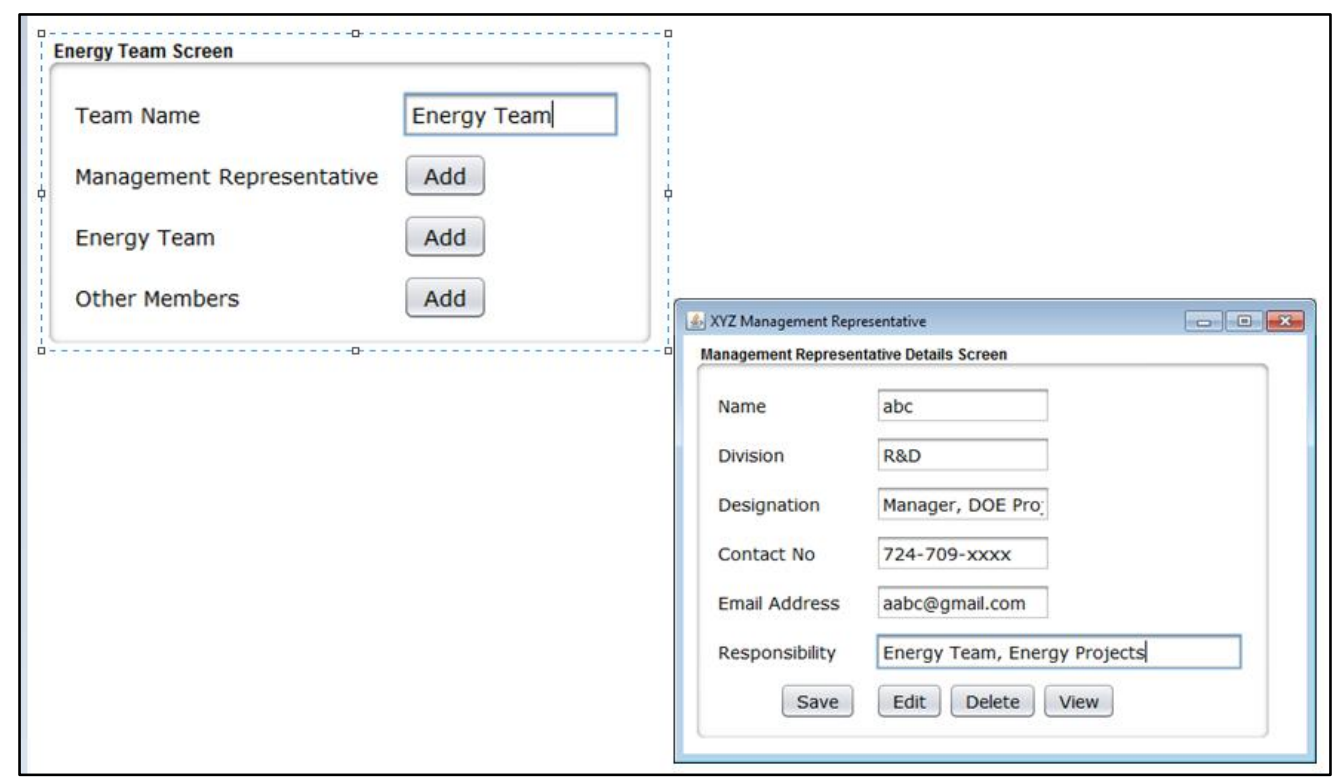

Figure 4.A.3: Energy Team

\section{A.4 Energy Data}

This module requires user to input utility data entering the defined boundary of the organization. The utility data can be of any interval hourly, daily, monthly etc (though monthly data is preferred due to lesser data storage). The user needs to input the data keeping the same interval for all the utilities. Once these data are provided to the software, it calculates the percentage consumption and cost in \$MMBtu for every utility. Superior Energy Performance (SEP) requires users to account for at least $95 \%$ of their annual utility consumption and hence, if one or any combination of utilities sum to less than $5 \%$ of the total consumption, the organization can 
take a decision of eliminating them and this can also be considered for ISO 50001. Figures 4.A.4 (a), (b) show the utility data collection process in the software and calculations performed by the software.

\begin{tabular}{|c|c|c|c|c|c|c|}
\hline Utility Name & Electricity & $\checkmark$ & & & & \\
\hline Name & & & & & & \\
\hline Units & kWh V & & & & & \\
\hline Utility Company & $a b c$ & & & & & \\
\hline Enter Total Rov & & & & & & \\
\hline Consumption Details Ta & & & & & & \\
\hline Date & & Energy Consumption & Energy Consumption(MMBTU) & Cost(\$) & SMMMBTU & \\
\hline $2009-10-01$ & & 2005656 & 6845.3 & 145117 & 21.2 & 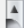 \\
\hline 2009-11-01 & & 1703400 & 5813.7 & 123550 & 21.25 & \\
\hline 2009-12-01 & & 1618692 & 5524.6 & 117615 & 21.29 & \\
\hline 2010-01-01 & & 1765728 & 6026.43 & 128026 & 21.24 & \\
\hline 2010-02-01 & & 1696494 & 5790.13 & 123110 & 21.26 & \\
\hline 2010-03-01 & & 1689240 & 5765.38 & 125091 & 21.7 & \\
\hline 2010-04-01 & & 1585758 & 5412.19 & 118048 & 21.81 & \\
\hline Total & & 22318728 & 76173.8 & 1622448 & & \\
\hline Average & & 1859894 & 6347.82 & 135204 & 21.31 & \\
\hline
\end{tabular}

Figure 4.A.4 (a): Energy Data Collection Screen

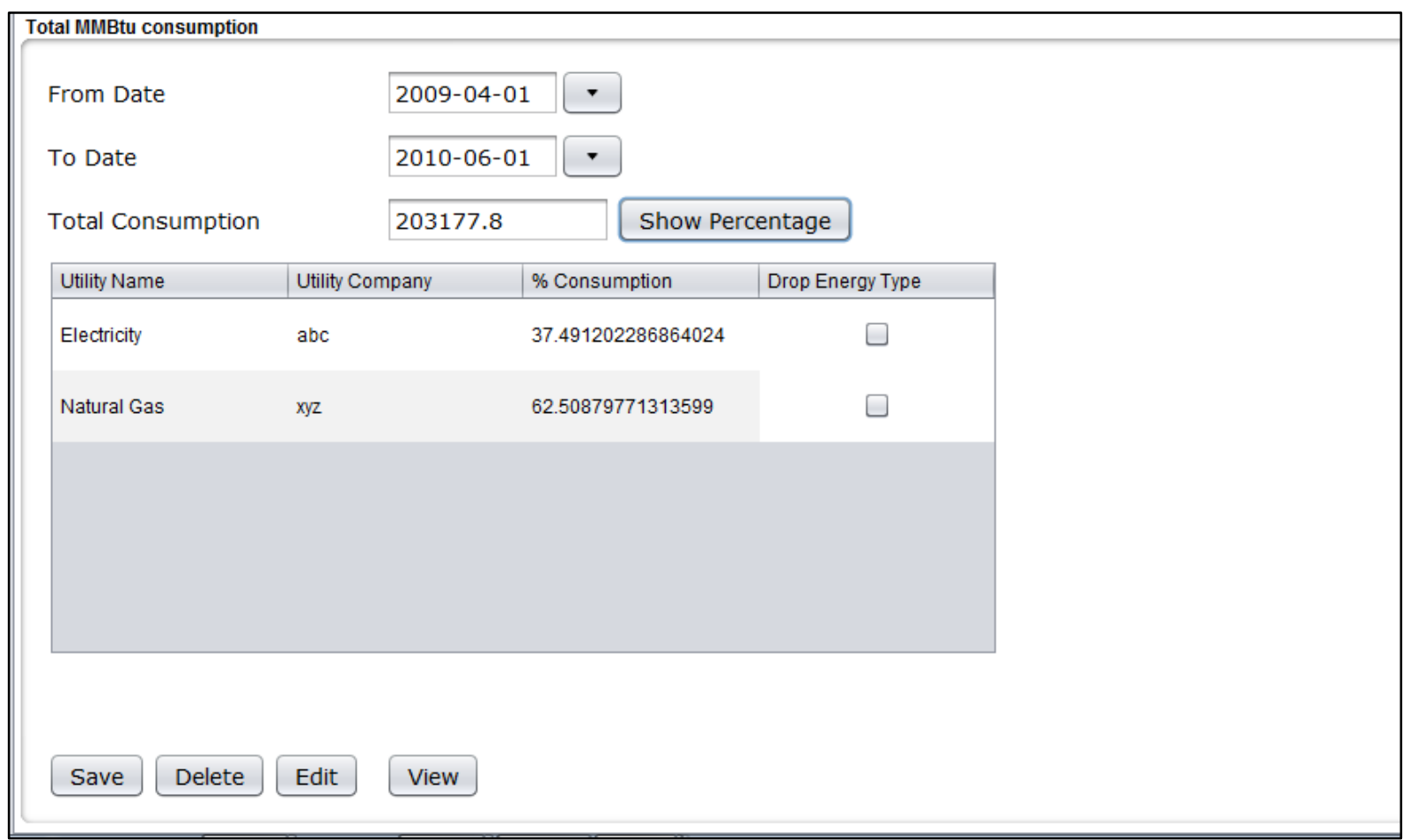

Figure 4.A.4 (b): Energy Data Collection Screen 


\section{B ISO 50001 Standard}

This module (ISO 50001 standard) is divided into 7 different segments as per the ISO 50001:2011. Figure 4.B.1 shows the different sections in this module.

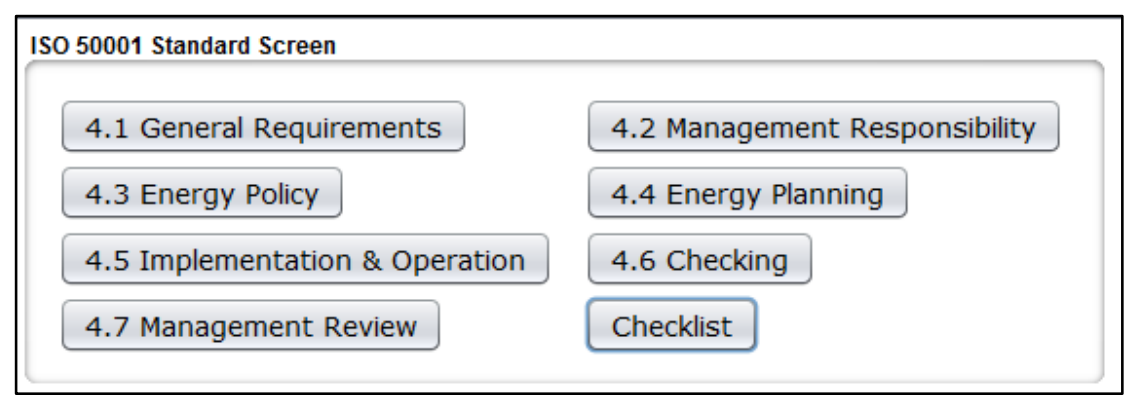

\section{Figure 4.B.1: ISO 50001 Module Main Screen*}

"The checklist is just an additional segment added to the software to help user know requirements in the ISO 50001 standard.

\subsection{General Requirements}

The ISO 50001 standard requires an organization to establish, document, implement and improve an energy management system in accordance with the requirements of the International Standard, define and document the scope and boundaries of the EnMS and determine how it will meet the requirements of this international standard to achieve continual improvement of its energy management system.

The first step in implementation of an energy management system is to define the organization's scope and boundary. It is very important for an organization to set their scope and boundary correctly by assessing energy use throughout the plant, energy efficiency opportunity, employee support and several other considerations. This segment of the software helps the user define their scope and boundary by analyzing if different parts of the plant can be isolated from the EnMS. Figure 4.1.1 shows a screenshot of this software used to set scope and boundary of an organization with 3 buildings A, B and C. The Figure 4.1.1 shows the scenario where the organization wants to remove building $\mathrm{C}$ from its scope without being able to isolate its consumption from the total energy usage. 


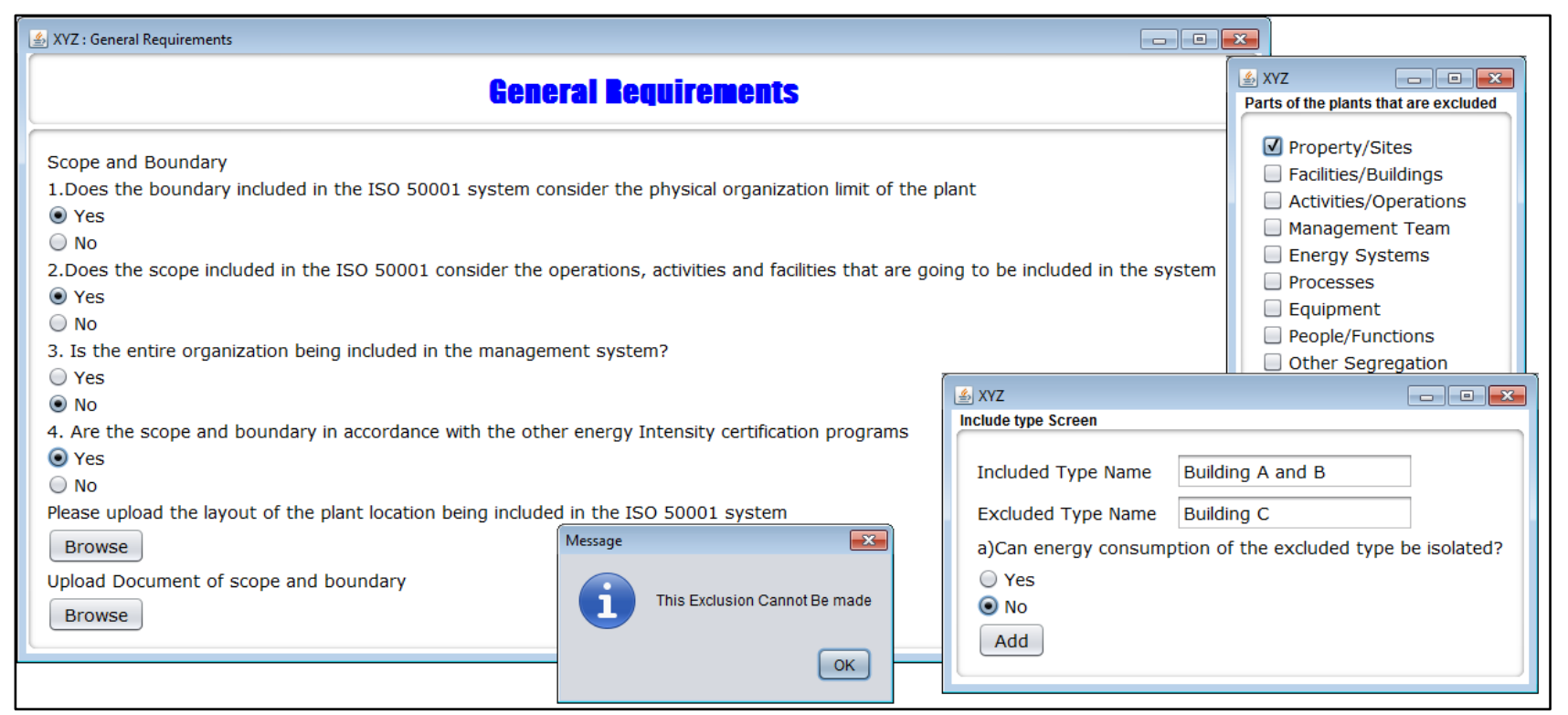

Figure 4.1.1: Screenshot of Scope and Boundary

\subsection{Energy Policy}

An energy policy is a statement made by the top management of the organization to show their commitment towards continuous energy performance. This policy would provide framework for action and setting energy objectives and targets. The policy can be a few sentences to several paragraphs, though preferable to be short, simple and consistent with already existing management systems in place. It must also be appropriate in nature and scale of energy use and consumption by the organization and reflect organization's strategic objectives. This section of the software is divided into two parts which are called as "guide to energy policy" and "post defining energy policy". The guide to energy policy section contains a set of yes/no questions and text boxes which can be used by the users to form their energy policy. The post defining energy policy section which gathers information regarding communication of the energy policy in the organization and updating document.

Figure 4.3.1 (a) shows a screenshot of section 'Guide to build energy policy' where organization does not have a written statement on commitment to continual improvement in energy performance in their energy policy and the software displays a warning screen stating that it is mandatory to have it in the energy policy. 


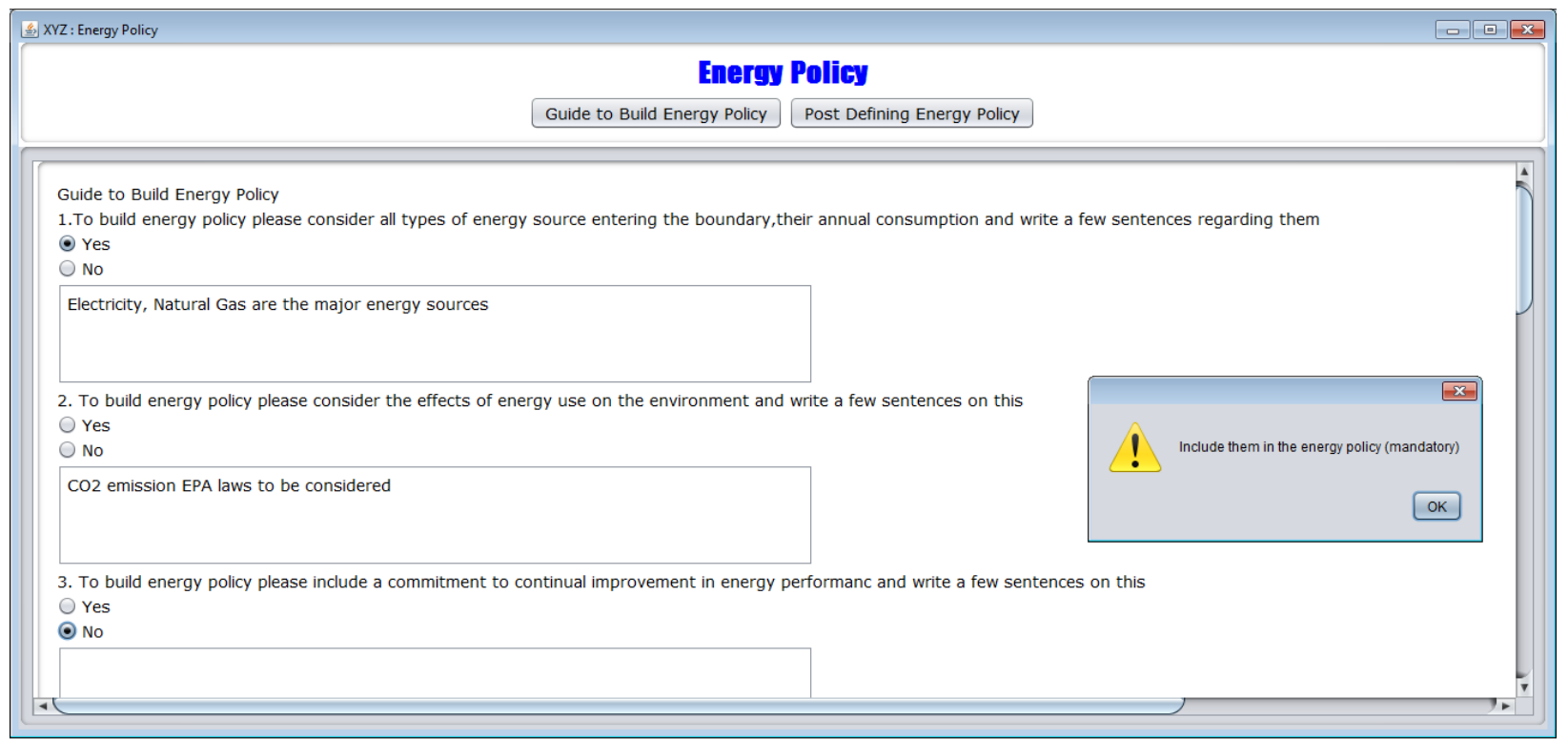

Figure 4.3.1 (a): Screenshot of Section of Guide to Energy Policy

Figure 4.3.1 (b) shows a screenshot of section 'Post Defining Energy Policy' where the organization does not make the energy policy available throughout the organization and the software displays a warning screen stating 'make it available to all levels within an organization'.

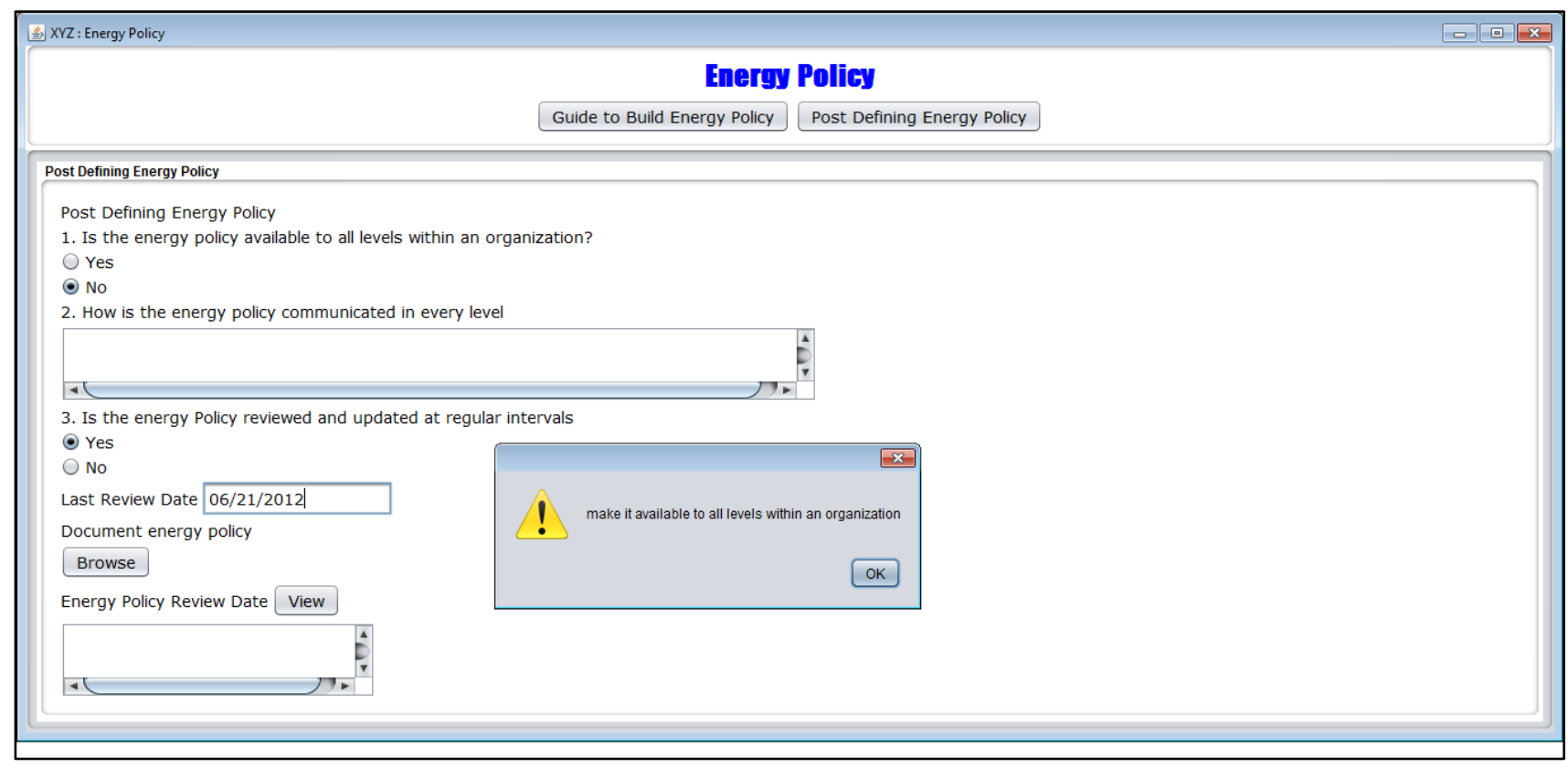

Figure 4.3.1 (b): Screenshot of Post Defining Energy Policy 


\subsection{Energy Planning}

Energy planning is a process which involves reviewing an organization's activities which affect energy performance. This section requires the user to collect several types of data as input to the software such as applicable legal and other requirements, equipment rating and consumption, production data and many more which the user identifies the significant energy users, energy baseline, energy performance indicator, objectives, targets and action plan. The ISO 50001 requires the organization to document and conduct an energy planning process which is stored in 4.4.1 General section of this module.

\subsubsection{Legal Requirements and Other Requirements}

Every organization must identify, implement and have access to applicable legal and other requirements related to its energy use and consumption. They must also be reviewed at an predefined interval. This section of the software is divided into 3 parts which are: general, legal requirements and other requirements. The general section guides users by helping them find the applicable requirement and assigning users to do different tasks. The legal requirement and other requirements have been divided into multiple subgroups depending on the type of requirement. The software is designed to ask user required information about each requirement and check for compliance. If the requirement is not found to be in compliance, the software takes the user to nonconformity screen. Figure 4.4.2 shows the screenshot of an EPA requirement data entered in the legal and other requirements section of the software. 


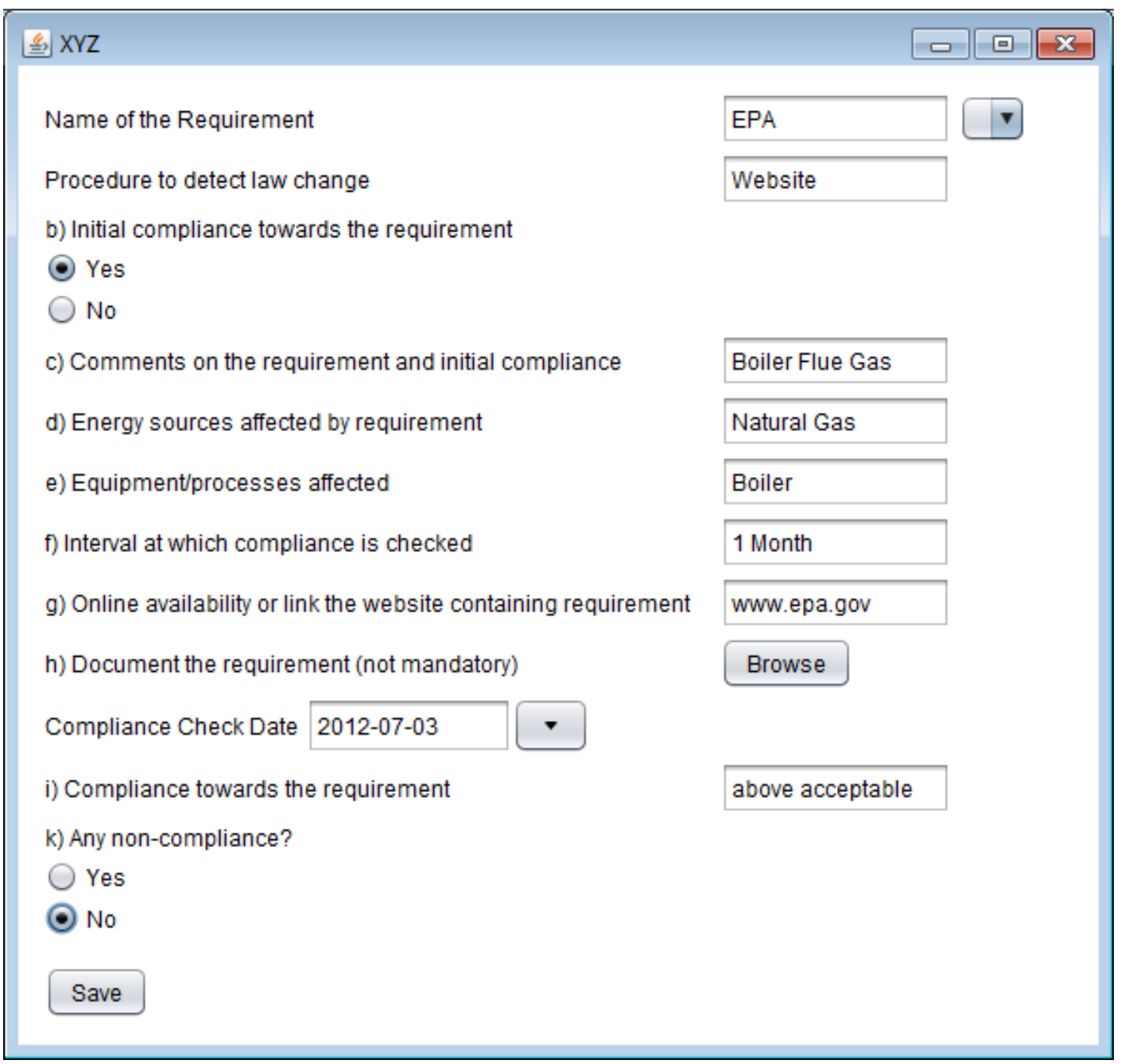

Figure 4.4.2: Screenshot of Legal and Other Requirements

\subsubsection{Energy Review}

The ISO 50001 standard requires an organization to develop an energy review which involves analyzing energy use and consumption based on measurements, identify areas of significant energy use, and identify opportunities to improve energy performance. The user needs to input data related to equipment, significant energy use, variables affecting significant energy use estimated future energy consumption and energy efficiency opportunities. Figure 4.4.3 (a) shows screenshot of energy review. 


\section{Equipment and Plant Type}

This section involves profiling energy use throughout the plant based on equipment type/ area of plant consuming energy. The user needs to input data regarding all equipment/plant area which consume energy as shown in Figure 4.4.3 (b). This helps users assess individual equipment /area which are energy intensive

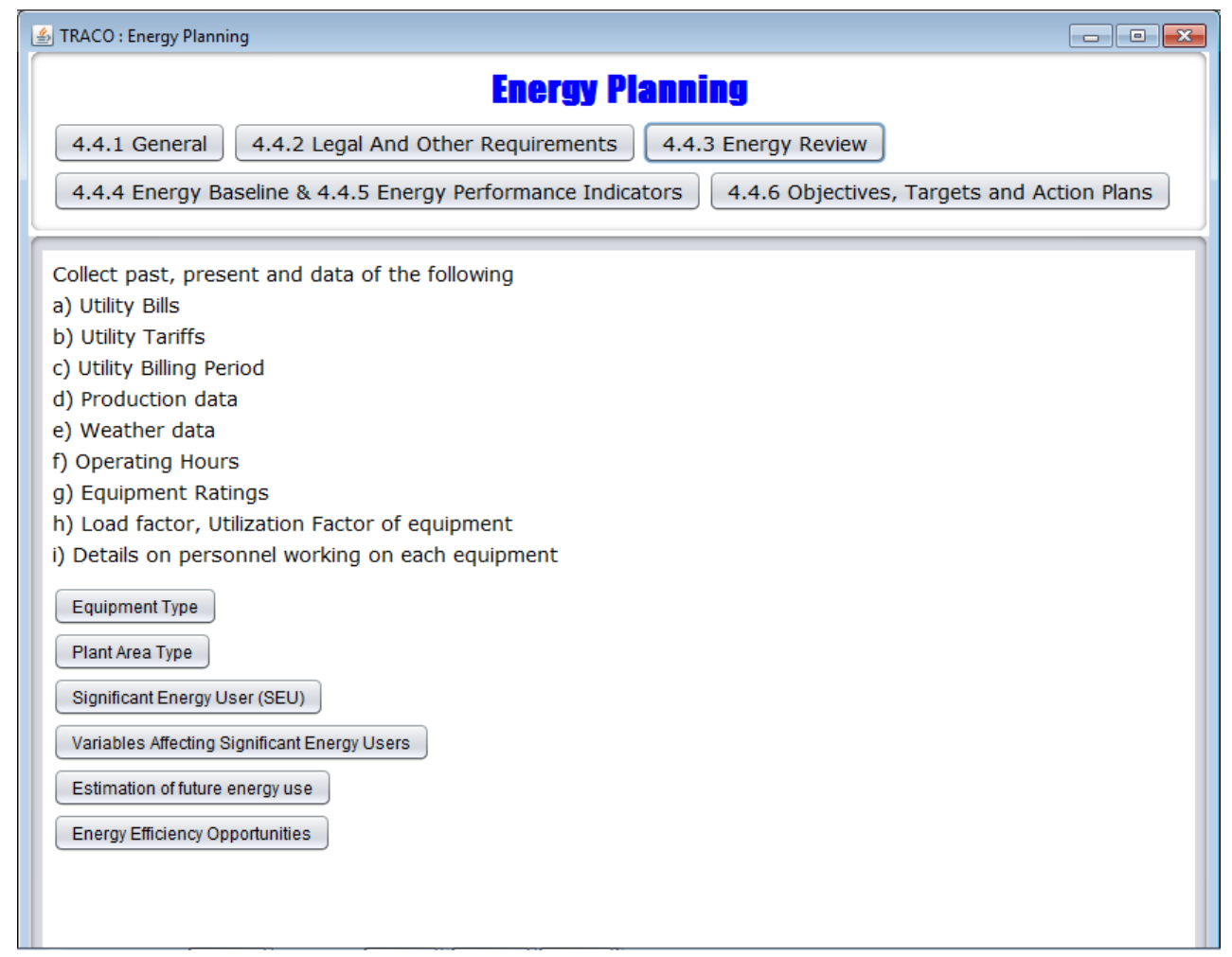

Figure 4.4.3 (a): Screenshot of Energy Review

Significant Energy User (SEU)

Depending upon the output from the previous section, the user can identify and select the significant users. The organization can also select the SEU's based on energy opportunities available, employee competency etc. The user needs to input data regarding the SEU in the software and store them as shown in Figure 4.4.3 (b). 


\begin{tabular}{|c|c|c|c|c|c|c|c|c|c|c|}
\hline 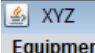 & \multicolumn{8}{|c|}{ Equipment Type } & & \begin{tabular}{|l|l|} 
\\
\end{tabular} \\
\hline & & & & Add & View & Clear & & & & \\
\hline Year & Utility & Equipment Name & Quantity & Rating & & Load Factor & Utilization Factor & Eff & Consumption & Consumption Units \\
\hline 2011 & Natural Gas & Extruder Heater & 1 & 10 & & 70 & 60 & 85 & 32,290 & MMBtu/yr \\
\hline 2011 & Electricity & Compressor & 2 & 450 & & 70 & 70 & 89 & 11,050 & MMEtu/yr \\
\hline 2011 & Natural Gas & Boiler & 1 & 7.5 & & 65 & 90 & 85 & 45,215 & MMEtu/yr \\
\hline 2011 & Electricity & Injection Molding Mch & 4 & 150 & & 80 & 80 & 90 & 9,520 & MMBtu/yr \\
\hline
\end{tabular}

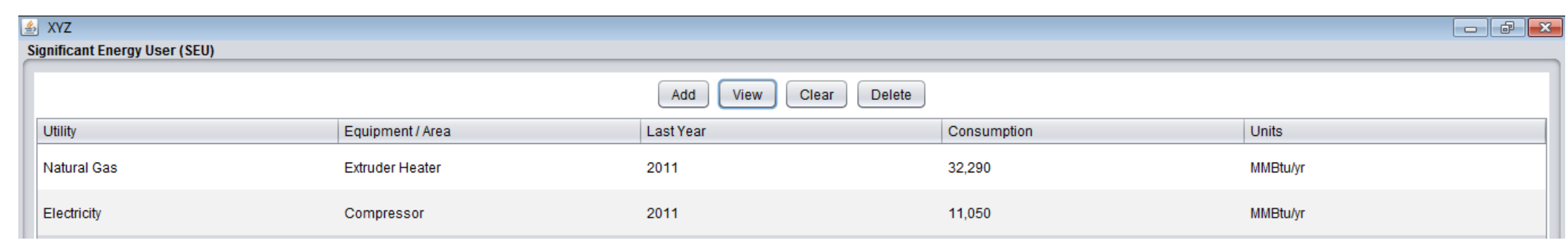

Figure 4.4.3 (b): Screenshot of Energy Review (I)

\section{Variables Affecting Significant Energy Users}

Once the significant energy users are determined, the organization needs to identify variables affecting these users. These variables may be raw material input, operating hours, downtime, temperature etc. Once these are identified, the organization needs to keep a record of all these data. The measurement, monitoring and analysis requirement for these are shown in section 4.6.1. The screenshot of this section is shown in Figure 4.4.3 (c). 


\section{Estimation of future energy use}

The estimation of future energy use can vary from a simple analysis to a very complicated one. ISO 50001 does not prescribe any specific measure or accuracy of estimation of the future use. Hence, a general methodology is used, which involves asking users a time frame for future reference followed by estimated percentage consideration of changes in several factors that can affect energy usage. The summation of all these changes is taken to be change in energy consumption in the defined interval of time and this is shown in Figure 4.4.3 (c).

\section{Energy Efficiency Opportunities}

After all the above steps are performed it is very important for the organization to identify energy efficiency opportunities which can be done by bringing in an energy audit team or by replicating retrofits followed by other organizations. These opportunities can also relate to potential sources of energy, use of renewable energy or alternative energy sources such as waste energy. The screenshot of this section is shown in Figure 4.4.3 (c).

\subsubsection{Energy Baseline and 4.4.5 Energy Performance Indicator (EnPI)}

The ISO 50001 standard requires the organization to establish an energy baseline using the information in the initial energy review done above using a suitable data period. Energy performance changes would be measured against the baseline. Also, the industry needs to identify an energy performance indicator which must be appropriate when compared with the energy baseline. The "EnPI" tool developed by the Georgia Tech Research Corporation has been linked to this ISO 50001 Analyzer software. Hence, the user can access the EnPI tool from this software and set their baseline and energy performance indicator.

\subsubsection{Energy Objectives, Energy Targets and Energy Management Action Plans}

After determining the significant energy users, variables affecting significant energy users and energy efficiency opportunities, the organization should set energy objectives, targets and action plans. The objectives are developed using the organization's policies, goals, strategies and identified opportunities which must be consistent with the energy policy. These energy objectives can be simplified to build small energy targets. The action plans is a "to-do list" which 
must be set to acquire desired results (objectives and targets). The software requires the users to input their objective, target, action plan and store a document containing them. Figure 4.4.5 shows a screenshot of this section.

\begin{tabular}{l}
\hline \begin{tabular}{|l|l|l|}
\hline Xariables Affecting Significant Energy Users \\
\hline SEU Equipment/Area & Cariable Affecting Energy Consumption \\
\hline Extruder Heater & Dos/hr of Glass \\
\hline Extruder Heater & Down Time \\
\hline Compressor & Set Pressure of Air \\
\hline Compressor & Moisture in Air \\
\hline
\end{tabular} \\
\hline
\end{tabular}
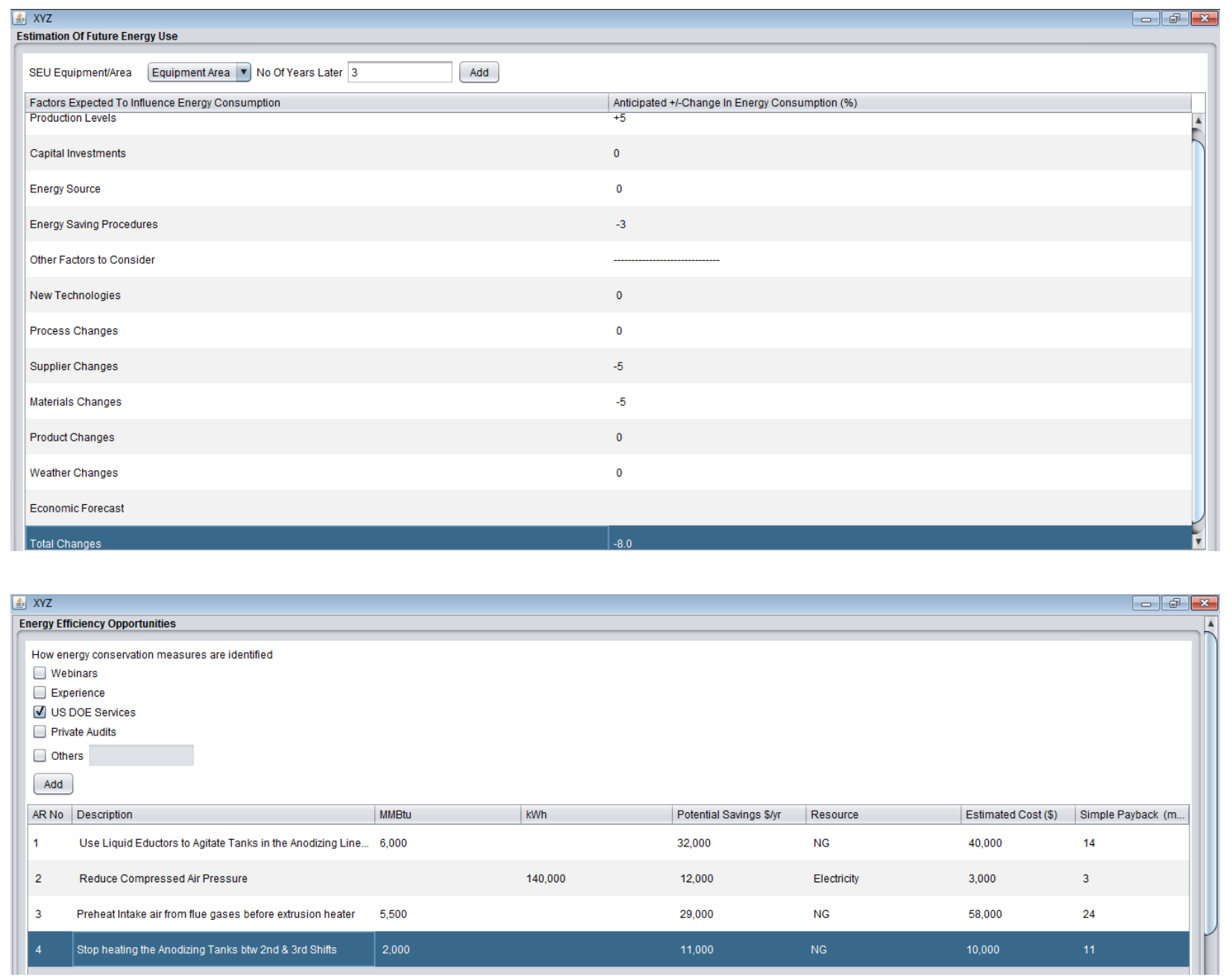

Figure 4.4.3 (b): Screenshot of Energy Review (II) 


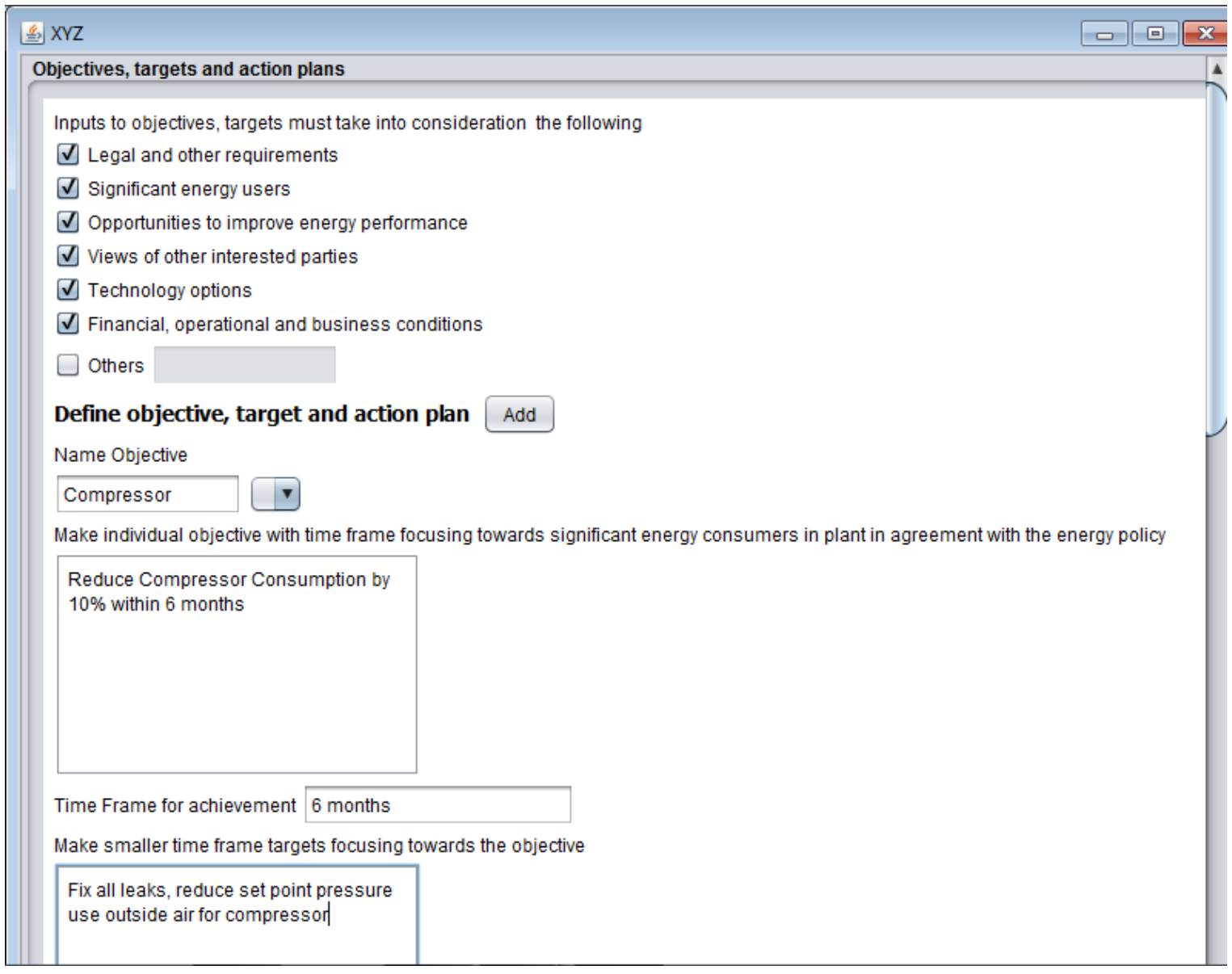

Figure 4.4.5: Screenshot of Energy Objectives, Targets and Action Plan

\subsection{Implementation and Operation}

This is the DO part of the cycle and the main objective of this section is to implement the results obtained from the PLAN part of the cycle. Implementing the outputs from the PLAN section requires competent, trained and aware employees especially ones dealing with the significant energy users followed by good communication methodology established in the organization both internally and externally. Also the organization needs to establish, implement maintain and control documents containing information about the core elements of the EnMS followed by setting criteria for operations on the SEU's, allow energy efficient design consideration to be done during retrofitting or purchasing of newer equipment and develop a procurement criteria of energy services, products and equipment. Figure 4.5.1 shows the screenshot of the Implementation and Operation section of the software. 


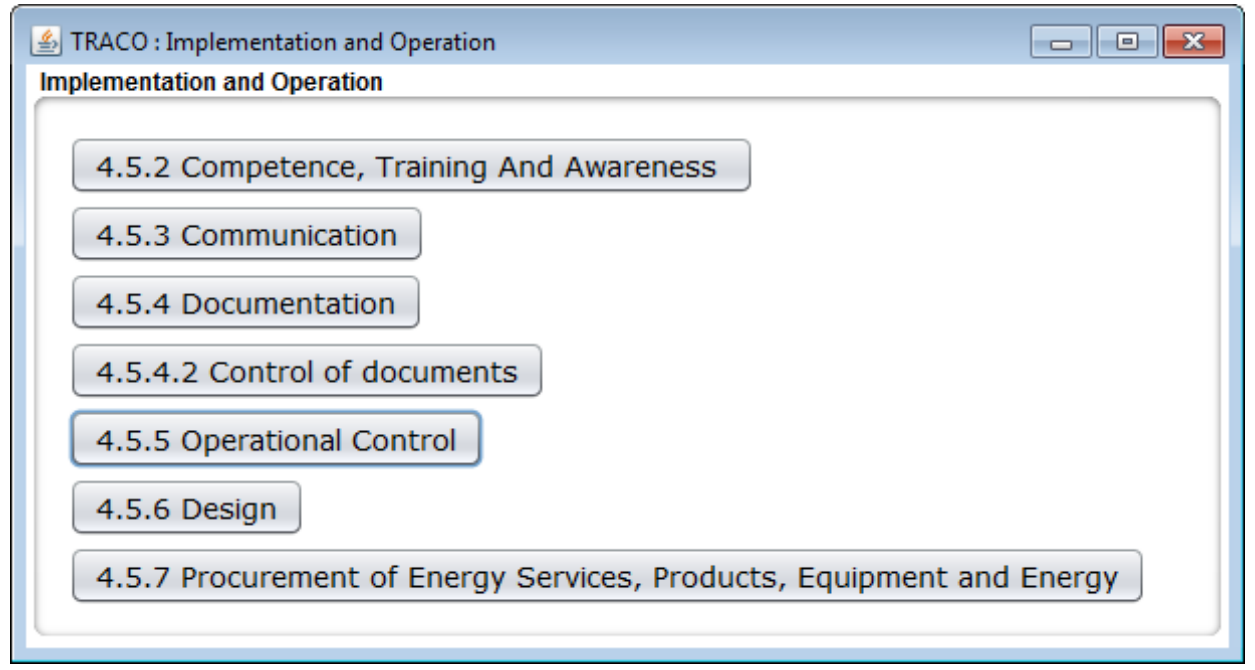

\section{Figure 4.5.1: Software Screenshot of Implementation and Operation}

\subsubsection{Competence, training and awareness}

This part is divided into 3 sub-sections: verification body information, competence and training, awareness.

\section{a) Verification Body Information}

The organization needs to determine the competency requirement for employees working on behalf of the significant energy users on the basis of education, training, skills or experience following which a training plan must be determined for employees who do not meet the minimum competency criteria. This section deals with collecting details about this process and the team determining this requirement.

\section{b) Competency and Training}

As stated above, the ISO 50001 standard requires employees working for or on behalf of the significant energy users to be competent on the basis of appropriate education, training, skills and experience. In this section details on every employee is collected and overall competency level is assigned followed which that employee is assigned two kinds of training needs which are training needs for the control of significant energy user and operation of energy management system. This process is continued for all the employees working on behalf of the SEU's. Figure 4.5.2 (b) shows screenshot of this section. 


\begin{tabular}{|l|}
\hline Significant Energy User \\
\hline Employees working with significant energy users \\
Name \\
Designation \\
Experience Years \\
Experience Rating \\
Educational Background \\
Education Rating \\
Skillset obtained \\
Skill Rating \\
Trainings Attended \\
Training Rating \\
Overall Competency Rating
\end{tabular}

\section{Figure 4.5.2(b): Screenshot of Competency and Training Requirement}

\section{c) Awareness}

This section is similar to the Competency and Training module of the software. Here the employees considered are not just related to the SEU's but the whole organization. It is a general view about the employees and their awareness towards the impact, actual or potential, with respect to energy use and consumption, of their activities and their contribution to the achievement of energy objectives and targets, and the potential consequences of departure from specified procedures, benefits of improved energy performance etc.

\subsubsection{Communication}

The organization may require a communication system to transfer information regarding its energy performance and energy management system internally and externally. The standard requires the organization to establish and implement a methodology for communication which 
allows employees to comment or suggest changes to the EnMS. This section is divided into internal and external communication which helps users collect and record employee information along with their comments and suggestions. Figure 4.5.3 shows the screenshot of this section.

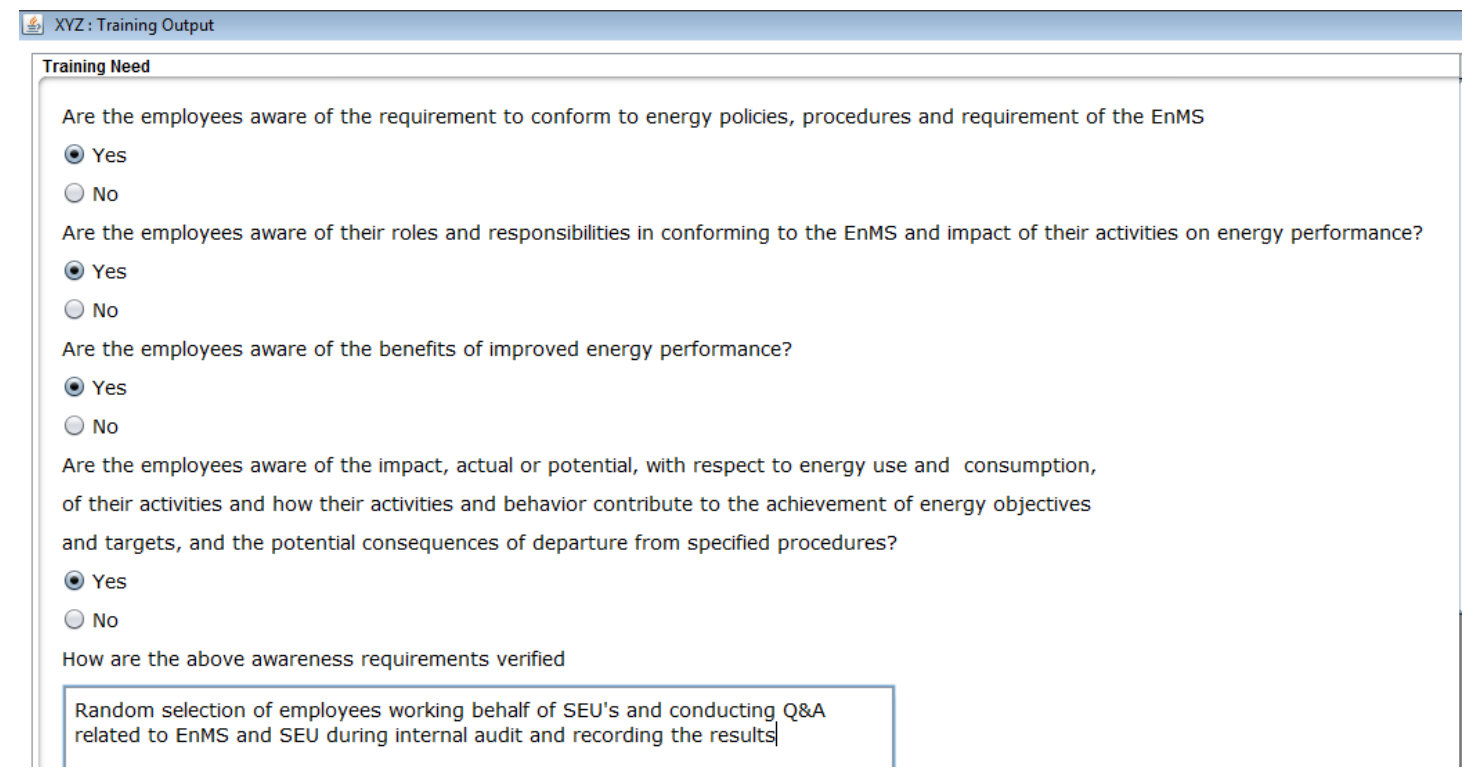

\section{Figure 4.5.2(c): Screenshot of Awareness Requirement}

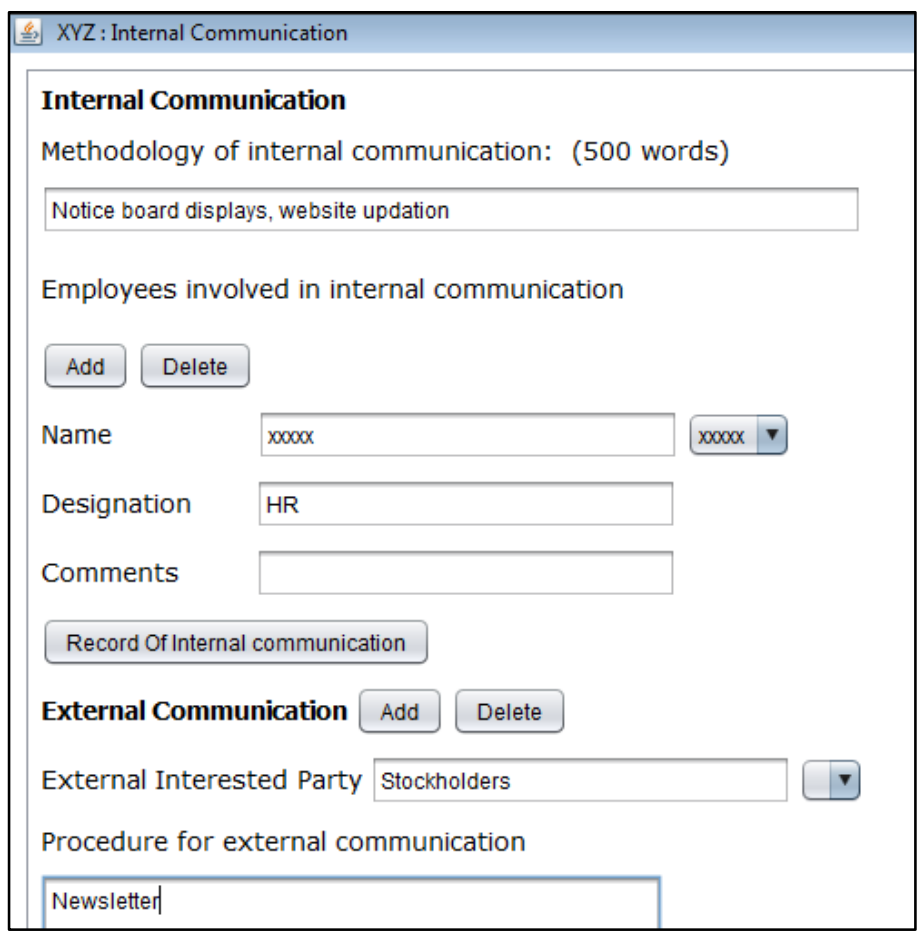

Figure 4.5.3: Screenshot of Communication Section of the Software 


\subsubsection{Documentation}

The Energy Standard requires organization implementing it to maintain information in paper or electronic form which describes the core elements of the EnMS. Unlike other ISO standards which rely heavily on documentation, this standard requires only a few documents which include scope and boundary, energy policy, energy objectives, targets and action plans and other documents determined mandatory by the standard and the organization. These documents required to be controlled which involves an industry to maintain a methodology to approve, review and update documents, identify current and previous revision statuses, assure usage of current documents at the point of use, identification and legibility of document, identification and control of documents of external origin, prevent the use of obsolete documents. These methodologies must then be implemented with best results.

Documents associated with every module of the standard are identified in the software and all the required data including revision number, date, format of the document are collected followed by uploading the document. This process is carried on for all the documents and a list of all the documents with their version numbers and date is viewable. Figures 4.5.4 (a), (b) show the screenshot of document collection process and control of documents. The final module in this software "Documents and Records" has the final collection of all the documents and records and is shown in Figure 4.5 .4 (c)

\begin{tabular}{|l|l|}
\hline Approve documents & Verification by majority energy team members \\
Review and Update Documents & Every Month \\
Current and previous revision statuses are identifiable & Version number upation \\
Current documents are used at the point of use & Check by Energy Team \\
Documents are identifiable and legible & Check by Energy Team \\
Documents of external origin are identified and controlled & Energy Team Meeting \\
Prevent the use of obsolete documents & Energy Team check \\
Save & \\
\hline
\end{tabular}

Figure 4.5.4 (a): Screenshot of Document Approval Process 


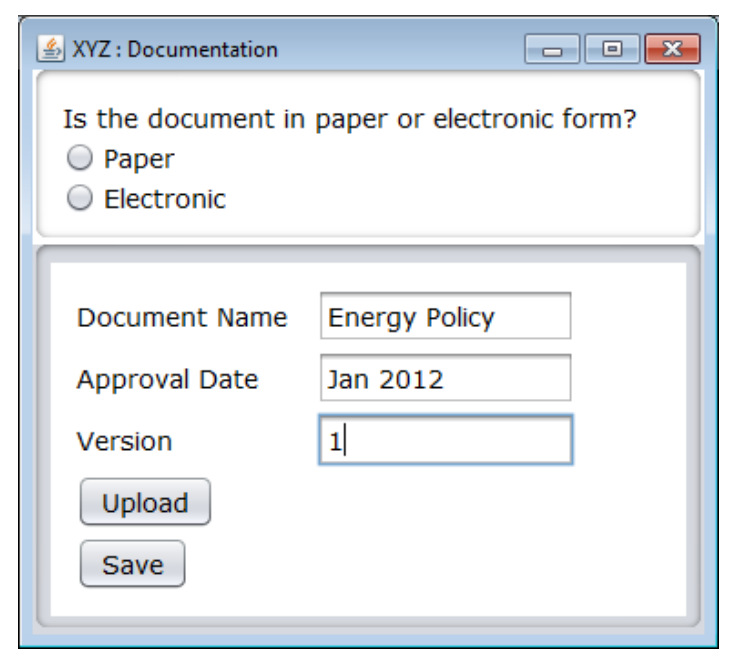

Figure 4.5.4 (b): Screenshot of Document Collection Process

\begin{tabular}{|c|c|c|c|c|}
\hline \multicolumn{4}{|c|}{ XYZ: Documents View } & \multirow[t]{2}{*}{\begin{tabular}{|c|c|} 
& 0 \\
\end{tabular}} \\
\hline \multicolumn{4}{|c|}{ Submit } & \\
\hline Company Name & Document Name & Date & Version & Location \\
\hline $\mathrm{XYZ}$ & Energy Policy & Jan 2012 & 1 & C:IUserslkarthik321Desk... \\
\hline$X Y Z$ & Legal Requirement & Feb 2012 & 1 & C:IUserslkarthik32IDesk... \\
\hline $\mathrm{XYZ}$ & EnPI & March 2012 & 2 & C:IUserslkarthik321Desk... \\
\hline
\end{tabular}

Figure 4.5.4 (c): Documents and Records Module of the Software

\subsubsection{Operational Control}

ISO 50001 requires organization to operate and maintain activities associated with significant energy uses by setting criteria for each of them and operating them in accordance with these criteria. This control criteria needs to be communicated to the personnel working on behalf of the equipment. The software helps users gather and store these operational and maintenance control criteria for every significant energy user. Figure 4.5.5 shows the screenshot of this system. 


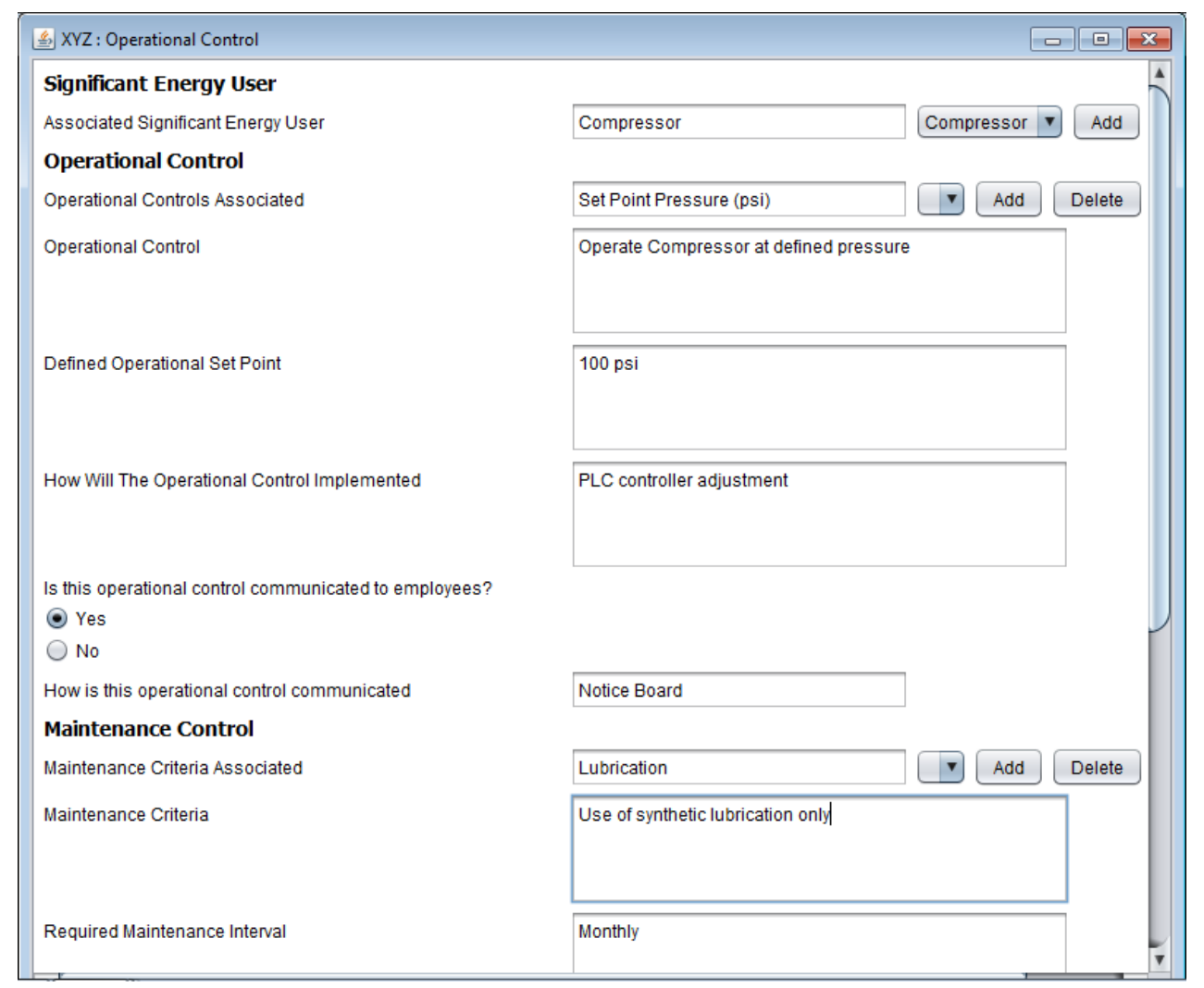

Figure 4.5.5: Screenshot of Operational Control Section of the Software

\subsubsection{Design and 4.5.7 Procurement of Energy Services, Products, Equipment and Energy}

ISO 50001 standard requires organization to consider energy efficiency and controls in design of new, modified and renovated facilities, equipment, systems and processes. The results of this design must be taken into consideration while implementing relevant projects. It is also required that an organization must determine criteria on energy performance while purchasing energy services, product or equipment and this criteria must be informed to the supplier. Additionally, the organization must also set specifications for purchasing energy. This is addressed in the software as shown below in Figures 4.5.6 and 4.5.7. 


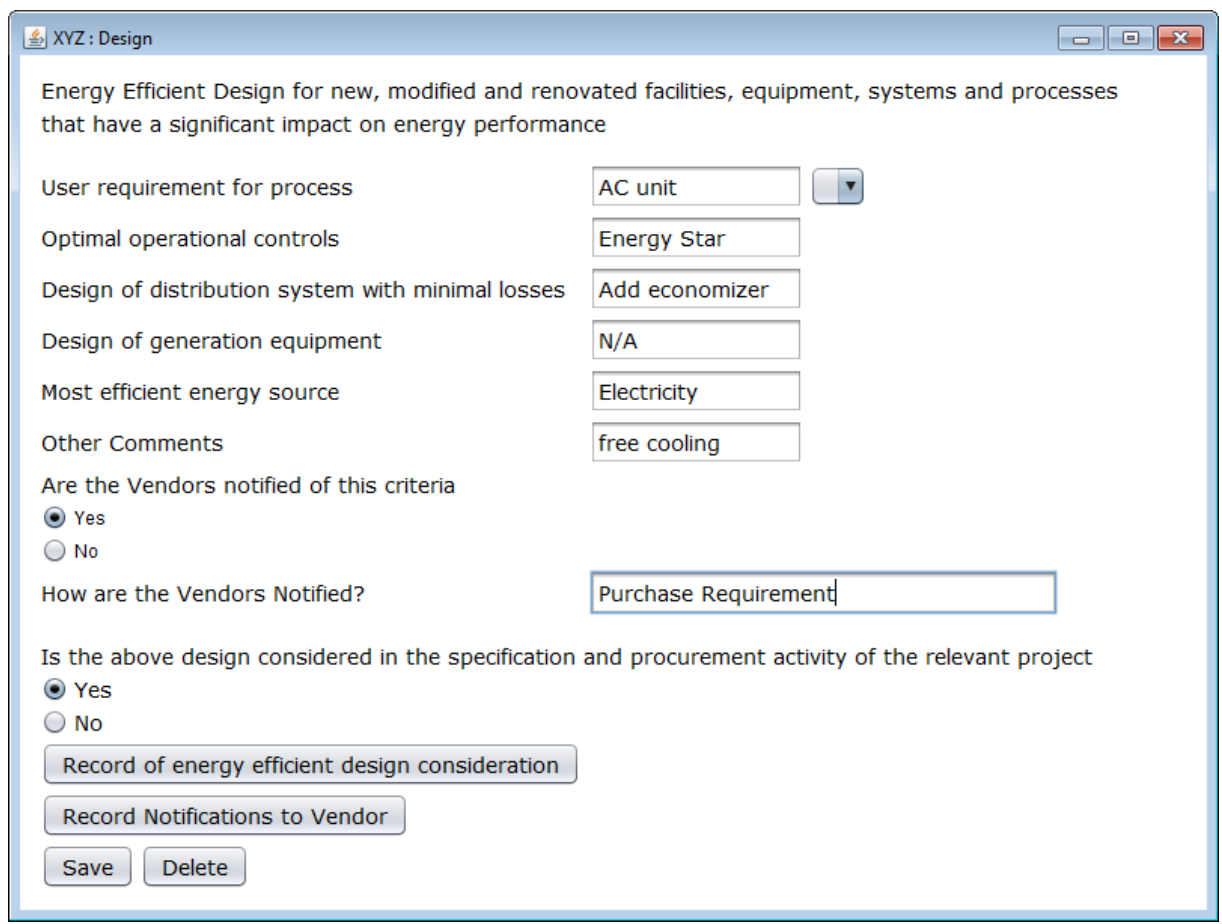

Figure 4.5.6: Screenshot of Design Module

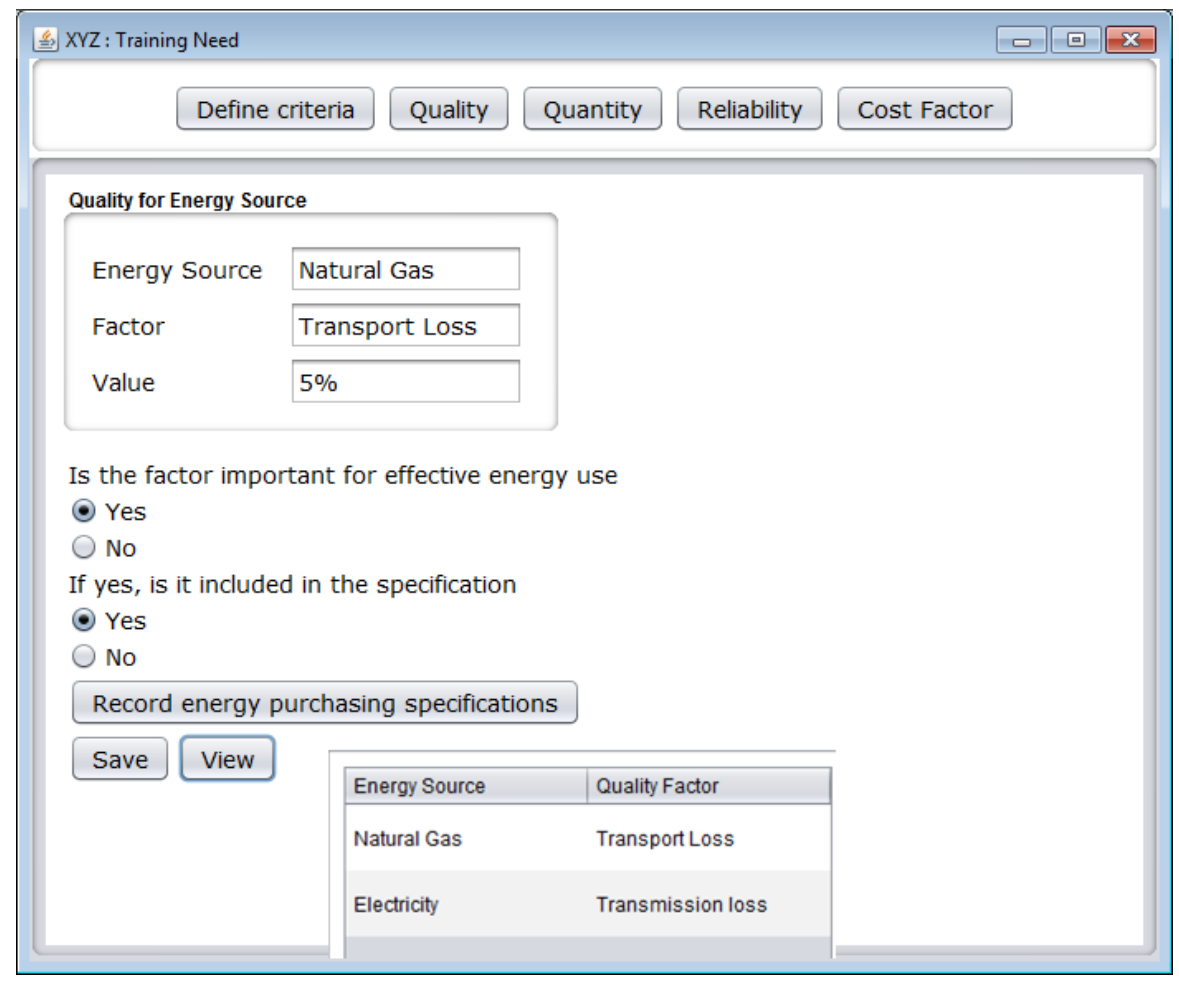

Figure 4.5.7: Screenshot of Procurement of Energy Service, Equipment and Energy Module 


\subsection{Checking}

This section of the standard requires the organization to check if they have implemented their energy management system in accordance with the ISO 50001 standard and verify if they have implemented what they planned and achieved desired results. Checking is divided into several subsections which are monitoring, measurement and analysis, evaluation of legal and other requirements, internal audit, non-conformities, correction, corrective, preventive actions and control of records. Figure 4.6.A shows the different sub-sections in this module.

\begin{tabular}{|l|l|l|} 
4.6.1 Monitoring, measurement and analysis Significant Deviations \\
4.6.2 Evaluation of compliance with legal requirements and other requirements 4.6 .3 Internal audit of the EnMS \\
4.6.4 Nonconformities, correction, corrective action, and preventive action 4.6 .5 Control of records
\end{tabular}

\section{Figure 4.6.A: Checking Performance Screen of the software}

\subsubsection{Monitoring, Measurement and Analysis}

The ISO 50001 standard requires organization's implementing energy management system to determine, monitor, measure and analyze key characteristics which directly alter their energy performance at regular intervals. The standard requires facilities to use calibrated meters while recording data and keep record of calibration. The software collects and stores data on these key characteristics as shown in Figure 4.6.1 (a). Additionally, ISO 50001 requires organization to record, investigate and respond to deviations in energy performance which occur mostly during monitoring and measurement of key characteristics. If critical, these deviations can be moved to nonconformities of the management system as shown in Figure 4.6.1 (b). 


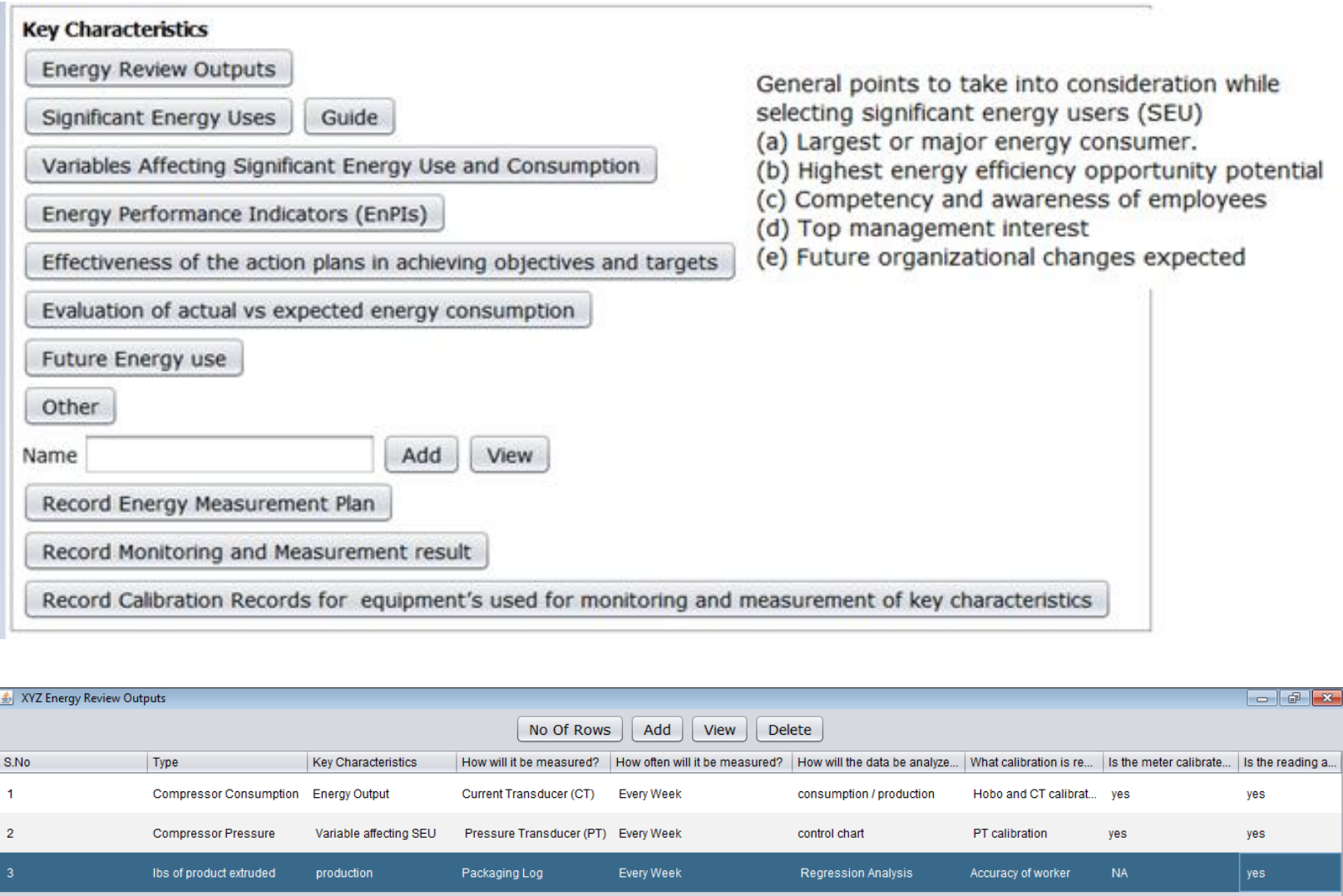

Figure 4.6.1 (a): Monitoring, Measurement and Analysis Screenshot

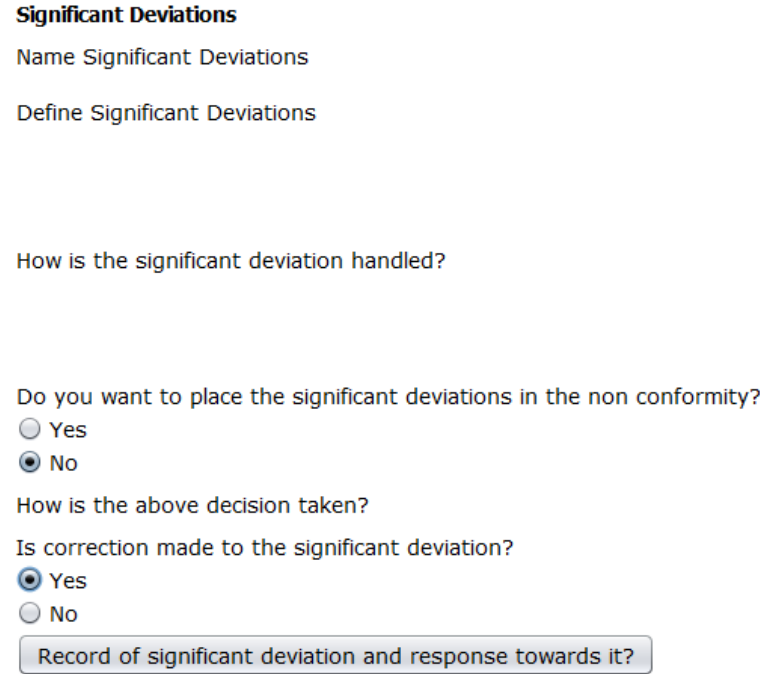

\section{Figure 4.6.1 (b): Significant Deviation Screenshot}




\subsubsection{Internal Audit of the EnMS}

The standard requires every organization to conduct internal audit to check of the EnMS:
a) The Planned arrangement conforms with the requirement in the standard
b) Conforms with energy objectives and targets
c) Is effectively implemented and maintained and improves energy performance

This section of the software is built to collect and store information on the internal audit team and annual internal audit schedule. This scheduling helps industries divide their entire system into multiple elements and plan for audit of each of these elements individually. After the preparation of the entire schedule, the user enters details about every single audit and records details on the audit date and area to be audited. Following the audit, the auditor can record the findings of the audit. This software also allows internal auditors to prepare their own checklist and store them for future use. Figure 4.6.3 shows this section of the software.

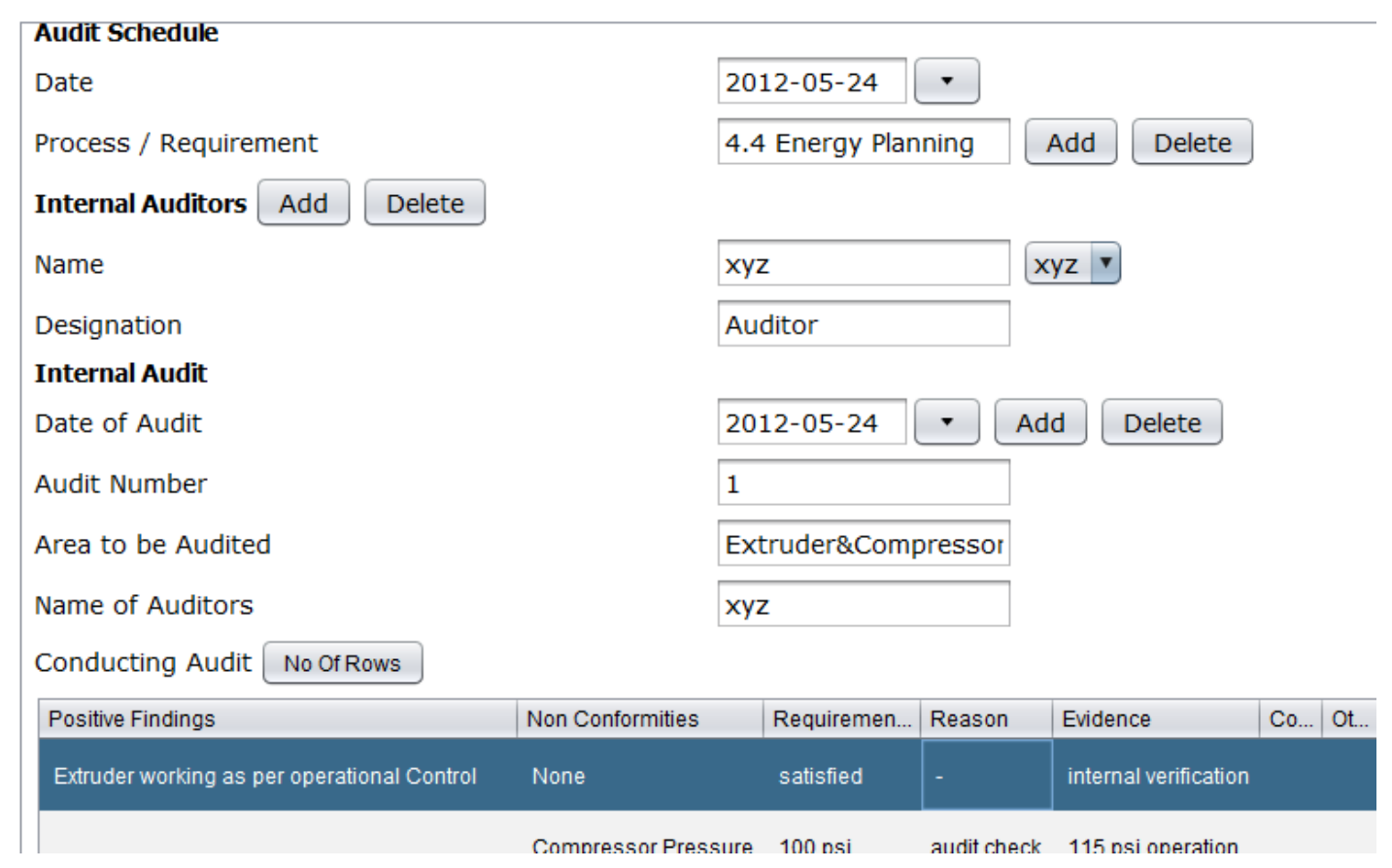

Figure 4.6.3: Internal Audit Section of the Software 


\subsubsection{Nonconformities, correction, corrective action and preventive action}

The ISO 50001 standard requires industries to identify existing and potential nonconformities and take action to eliminate them. An existing nonconformity is one wherein a requirement in the standard is presently not met. A nonconformity which may occur in the future if an action is not taken is called a potential nonconformity. A nonconformity may be generally identified during internal audit, measurement and monitoring activities or by workmen/employees of the industry.

This module in the ISO 50001 software starts with having the user assign employees to lead checking for nonconformity in different parts of the standard. Once a nonconformity is identified, it is defined and assigned to one of the types as shown in the figure below. Then the user needs to identify correction, corrective and preventive action and record them.

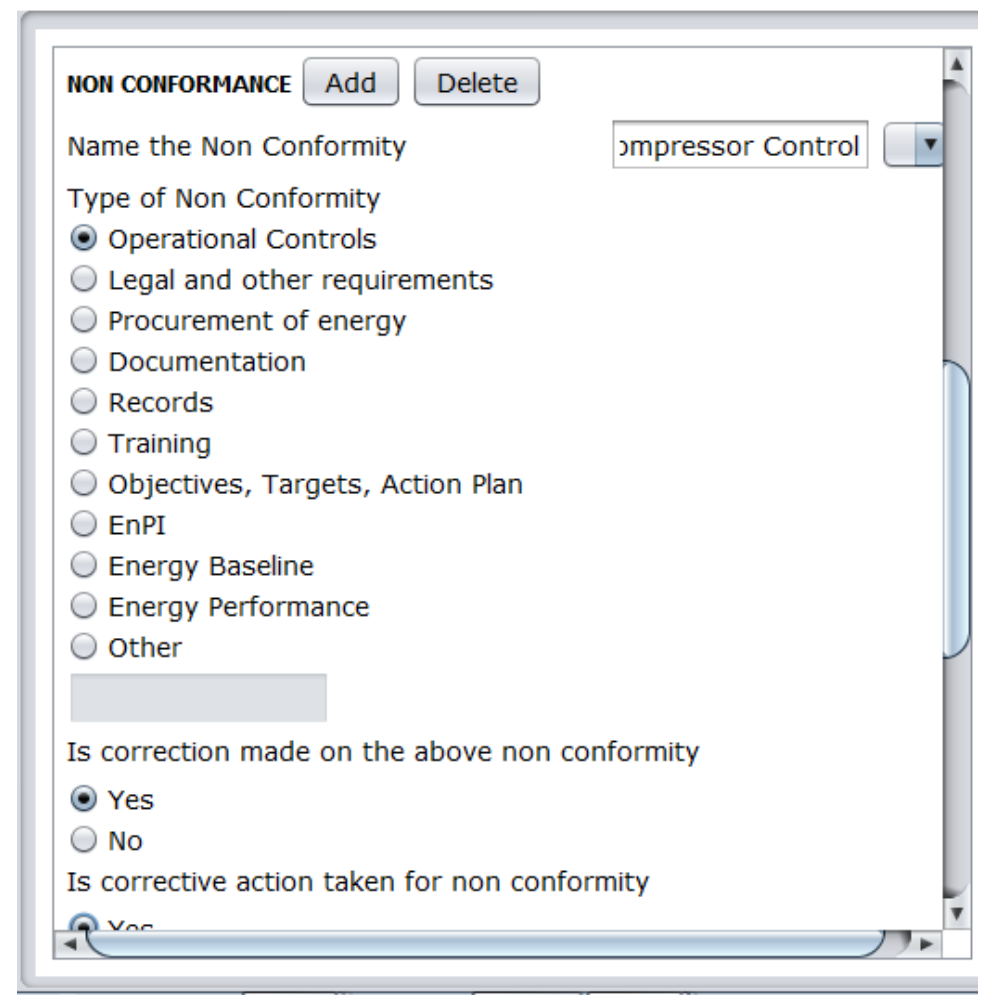

Figure 4.6.4: Nonconformities, Correction, Corrective and Preventive Action Screenshot

\subsubsection{Control of Records}

This section is similar to the "Control of Documents" (4.5.4) part of the software. The only difference being the type of file (records) being handled. As mentioned earlier, the ISO 50001 
requires only very few mandatory documents but requires several records to be maintained, depending on the type and size of the organization. The standard requires the organization to define and implement controls to identification, retrieval and retention of records. This software uploads and stores every record with a specific version number and date. It is very important to use only a single copy of this software to avoid changes in date and version. It is also important to allow limited access to personnel using this software, hence, avoiding multiple copies of similar records. Figure 4.6.5 shows the control of records section of the software.

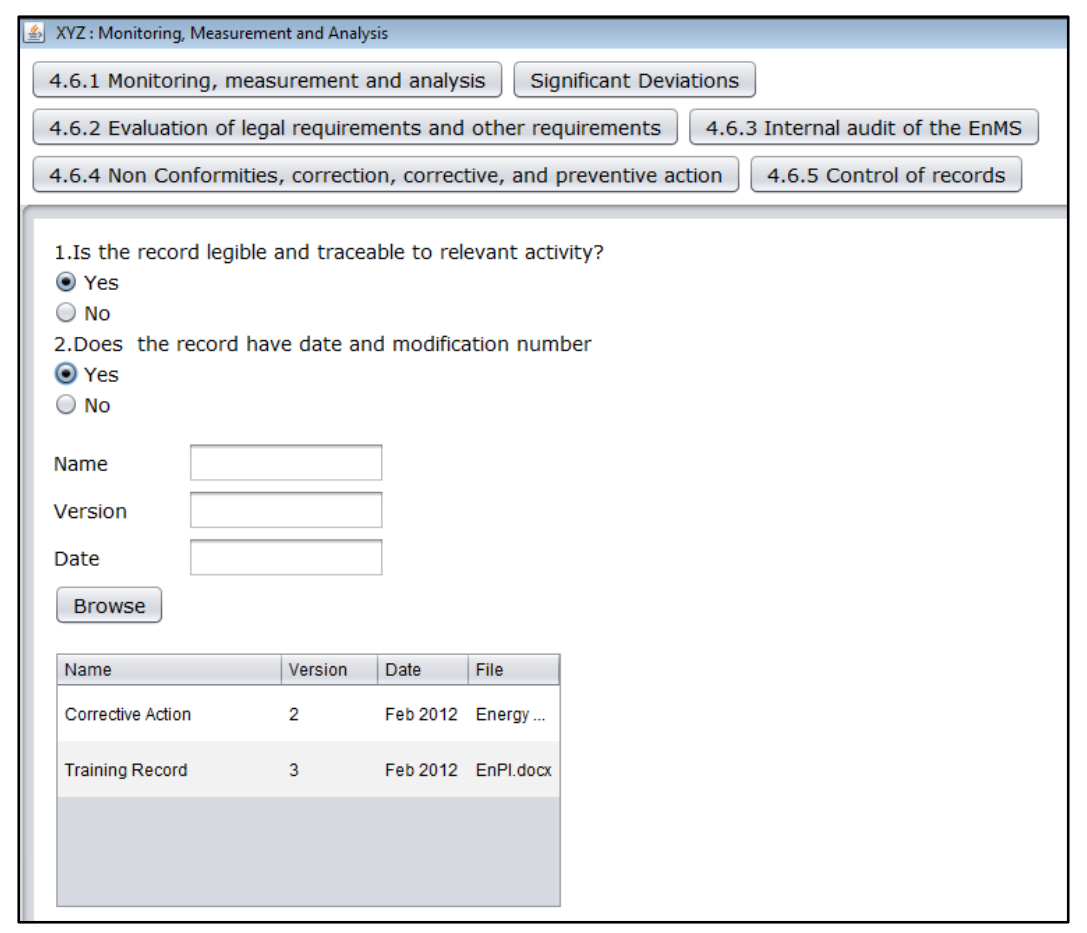

\section{Figure 4.6.5: Screenshot of Control of Records Section of the software}

\subsection{Management Review}

This is the Act part of the PDCA cycle and it involves review, evaluation and follow up actions taken by the top management to change/modify the organization's energy management system to ensure its improvement. The standard requires the management to review the entire scope of the management system. It is not required that all the elements of this system be reviewed at the same time. For best results it is advisable to submit all the important EnMS data as input followed which the top management would review and suggest changes to the system. The changes can include anything from changing policy to modifying document control strategy and 
so on. Once the top management decides to modify some elements of the system, the management representative with the energy team again start planning on strategies and actions to be taken and the whole loop PDCA loop starts again. Figure 4.7.A shows the management review software screen.

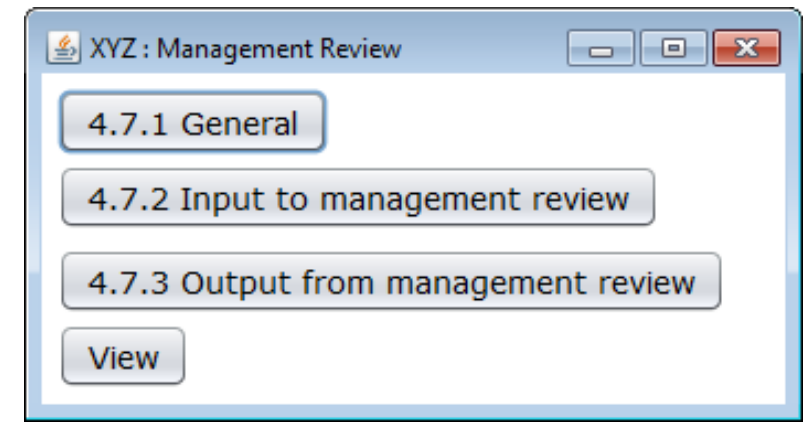

\section{Figure 4.7.A: Management Review screen of the software}

\subsubsection{General}

The general section of this module is built to collect and store information on the top management and annual management review schedule. This scheduling template helps industries to divide their entire system into multiple elements and plan for the review of each of these elements individually. After the preparation of the entire schedule, the user enters details about every single meeting and records details on the meeting date, time, number, attendees (management team, management representative, energy team, other). Figure 4.7.1 shows the management review general screen.

\subsubsection{Input to Management Review and 4.7.3 Output from Management Review}

This section of the software involves collecting details regarding information submitted to the management review team which includes the version of the information submitted. The user also needs to input some documents to show record for inputs submitted.

The management needs to provide the energy team and the management representative with outputs regarding the working of the system, changes in the resource allocation etc. This section collects data regarding the output provided by the review team. Figures 4.7.2 and 4.7.3 show the screenshot of the management review input and output respectively. 


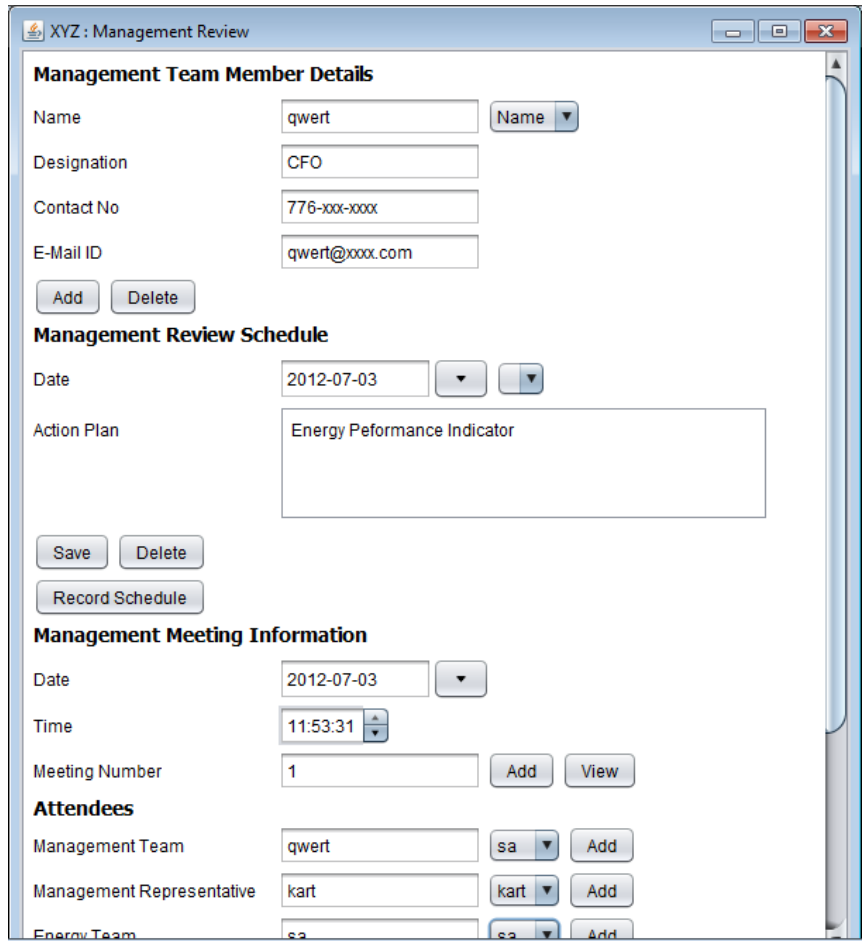

Figure 4.7.1: Management Review General Screenshot

\begin{tabular}{|c|c|c|c|}
\hline \multicolumn{3}{|l|}{ XYZ: Management Review } & 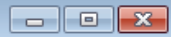 \\
\hline Meeting Number & $\nabla$ & & \\
\hline Input & & & \\
\hline Check List & Status (Yes/No) & Version Submitted & \\
\hline Energy Policy & $\nabla$ & 2 & $\Delta$ \\
\hline Energy Performance (EnPl's) & $\nabla$ & 3 & \\
\hline Compliance to legal and other $\mathrm{r} . .$. & $\nabla$ & 3 & \\
\hline Energy Objectives and target st... & $\nabla$ & 2 & t \\
\hline Audit Results & $\nabla$ & 1 & | \\
\hline Corrective and Preventive action... & $\nabla$ & 3 & | \\
\hline Energy Performance projections & $\nabla$ & 1 & 江 \\
\hline \multicolumn{4}{|l|}{ Record } \\
\hline \multicolumn{4}{|c|}{ Are records of inputs to meeting maintained? } \\
\hline \multicolumn{4}{|l|}{$\bullet$ Yes } \\
\hline \multicolumn{4}{|l|}{$\bigcirc$ No } \\
\hline Upload Other Records & & & \\
\hline
\end{tabular}

Figure 4.7.2: Management Review Input Screenshot 


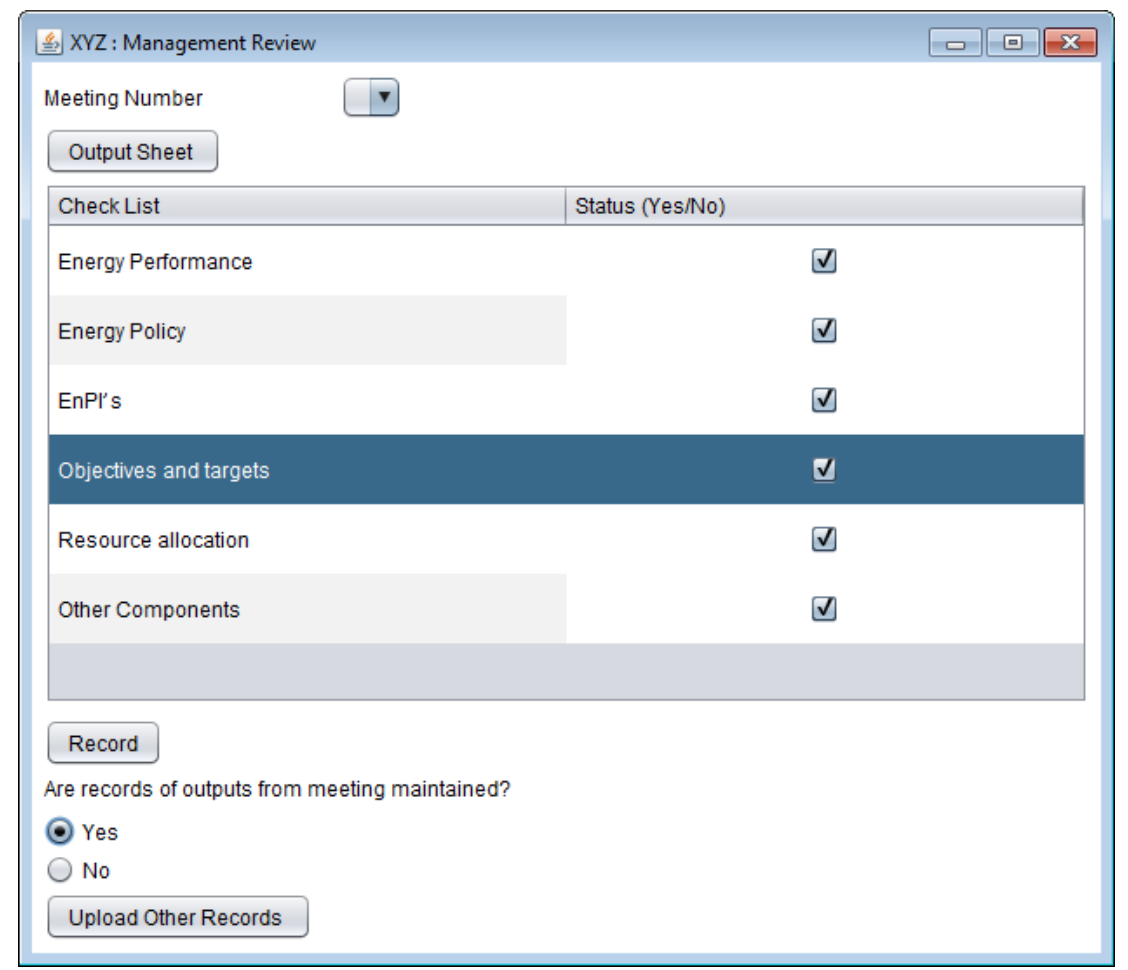

\section{Figure 4.7.3: Management Review Output Screenshot}

\section{Conclusion}

The ISO 50001 Analyzer software has been designed using Java and Microsoft Access. The logical flow for this software has been taken from flowcharts shown in Chapter 3. Additionally this software is linked to the Microsoft Excel tool made by the Georgia Tech Research Corporation called "EnPI Tool" which helps in the calculation of an energy baseline and establishing energy performance indicators. 


\section{Chapter 5}

\section{Key Findings and Future Work}

\subsection{Key Findings}

The ISO 50001 Analyzer software has been developed to help plants implement an energy management system according to ISO 50001and thus reap the benefits of managing energy which include cost reduction, environmental pollution reduction, increased business and many such benefits. This research was intended to overcome the lack of availability of proper framework to implement an energy management system conforming to the ISO 50001 by creating flow charts and ISO 50001 Analyzer software. This software includes a database created using Microsoft Access to store all the information inputted by the user which would be very helpful especially during transfer of the energy management system to a similar plant. Though this software cannot be networked to transfer data, all the data stored can be transferred from one system to other using manual methods. The software is designed using a general logic and hence can be used for any kind of business. Its major focus is to cover all the requirements in the standard and help industries continuously proceed with ease and hence the software does not put excess stress on the process and product being manufactured.

\section{Plan-Do-Check Act Cycle}

The ISO 50001 Analyzer software is designed by following the same organized steps as required in the ISO 50001. It starts from the planning stage defining scope and boundary, developing energy policy, performing energy planning, followed by the do stage implementation and operation, followed by check (checking) and act (management review). The user is again taken to the planning stage if he elects to go there. Also, most sections do not directly get into the requirements and ask for pre-information which leads to cleared approach to perform a task. For example, the internal audit section starts with preparation of schedule followed by selecting internal auditor and only then does the software take the user into the conducting internal audit section where the user enters details on all the findings of the audit. 


\section{ISO 50001 Implementation in Buildings}

ISO 50001 standard is a general standard and can be used in any manufacturing or service industry, buildings, commercial or retail business. Though this software is designed mainly with the intend to help manufacturing industries, it can be used in other organizations too. The software would require modifications majorly in the energy planning section. Since buildings or service industry do not have any tangible product which is manufactured, the energy planning module must be tailored to suit them.

\section{Error Checking, Inconsistency check and Gap Analysis}

The ISO 50001 Analyzer software is primarily a guiding software and does not require major processing of data and hence the present work does not include an error checking feature. Though including error checking for the present work enhances the software, the feature may not be very useful. The present work done does not include inconsistency check and gap analysis, and including them in the software would be very useful for organization using this software. Addition of this feature and other future works suggested would make it a very useful software.

The software does not check if required documents and records are entered but has a general list of documents and records which would be useful for implementation of ISO 50001 standard. During every module of the software the user is asked to record or document the methodology or output. Not every record or document addressed in the software is mandatory and are shown just as a precautionary step. A checklist is added in the ISO 50001 Standard module which provides a list of all the required documents and records. 


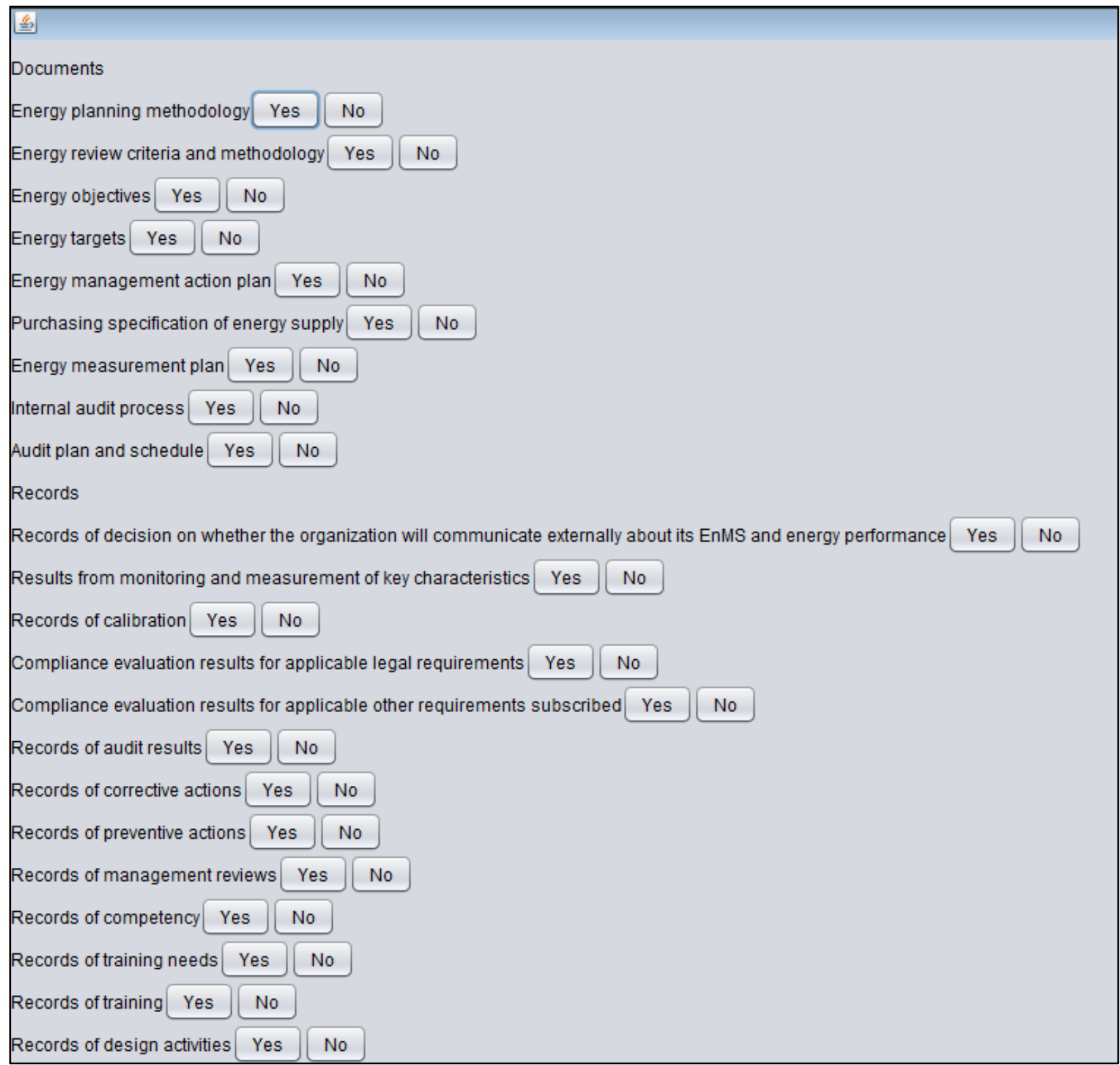

\section{Figure 5.1.1: Checklist showing Document and Record Requirement}

\section{EnPI tool vs Other software tools available in the market}

Though EnPI tool is good for industries to use it is always better to use other regression software tools like SAS, SPSS if available since, EnPI tool has certain drawbacks such as:

a) Does not check for co-linearity between independent variables

b) Does not perform non-linear regression 
c) Does not perform stepwise regression

In the ISO 50001 Analyzer software the user is not required to mandatorily use the EnPI tool for developing energy baseline and it is just an option provided. The user can choose to use different software and record output from the software into the ISO 50001 Analyzer database.

The software was viewed by Mr. Sneh Kumar, Manager, Department of Energy (DOE) Projects, Traco (Alcoa Building and Construction) who stated that the software could be potentially a very helpful tool in planning, guiding and managing the ISO 50001 certification and even for companies that may not require certification, this would be a powerful tool for managing the EnMS implementation. He provided valuable inputs to the software to make it more useful for the industry. Some of the inputs which were addressed in the present work are:
a) Providing user with option of selecting units while entering utility data,
b) Document and record database structure
c) Changing formation of questions.

Other important inputs not included in the present work are text box question elimination, providing a help tool which would help users understand ISO 50001, structural modification of the software to link all the parts of the software in a Plan-Do-Check-Act pattern. These modifications could not be made as including them in the software becomes too cumbersome and beyond the scope of the present work.

\subsection{Future Work}

The present work is a good base tool for organization to use for the implementation of an energy management system in accordance with the ISO 50001. Though the software was developed after designing a detailed logical flow, it still has its own practical limitation. The software requires to be tested in different environments and changes need to be made to the software depending on test outputs. Also performing future work as shown below on this software would lead to an improved and more useful software. Some of the suggested future developments are:

a) Testing the software in different types of manufacturing plants implementing ISO 50001 and improving the software such that every industry could use it. 
b) Addition of knowledgebase from other organizations which would help industries with similar product/process lines view the general working of other organization's management system.

c) Addition of a system to take into consideration any existing management system or practices being followed presently by the organization.

d) Use of intra-net in the software to give multiple access to the software within an organization.

e) Addition of enhanced energy review would complement this software and would assist the implementation of the ISO 50001 to a much simpler level.

f) Addition of gap analysis feature would help organization implementing ISO 50001 to have a clear picture of requirements needing additional resources.

Addition of some of these features would add additional value to the software and hence make the software easily marketable. 


\section{References}

1. Administration, US Energy Information. DOE/EIA-0484 International Energy Outlook 2010 Highlights. Statistics and Analysis, US Energy Information Administration, May 25, 2010.

2. Wikipedia. World energy consumption.

http://en.wikipedia.org/wiki/World_energy_consumption (accessed April 9, 2011).

3. Industrial Sector Energy Consumption.

http://www.eia.doe.gov/totalenergy/data/annual/\#consumption (accessed April 17, 2011).

4. Lazzarin, R; Noro, M. Local or District Heating by Natural Gas: Which is Better from Energetic, Environmental and Economic Point of View?, Applied Thermal Engineering, 2006: 244-250.

5. Turner, Wayne; Capehart, LB; Kennedy, Williams. Guide to Energy Management. The Fairmont Press, Inc 2008.

6. Patrik, Thollander; Ottosson, Mikael. Energy Management Practices in Swedish EnergyIntensive Industries. Journal of Cleaner Production, 2010: 1125-1133.

7. Philip, Fearnside. Greenhouse-Gas Emissions from Amazonian Hydroelectric Reservoirs: The Example of Brazil's Tucuruí Dam as Compared to Fossil Fuel Alternatives. Environmental Conservation. 2002: 64-75.

8. Chapman, Duane; Tyralle, Duanne; Timothy, Mount. Electricity Demand Growth and the Energy Crisis. Science. 1972: 703-705.

9. Rajkumar, Selvaraj. Plant Wide Energy Assessment Using a Systems Approach. MS Thesis. Morgantown. West Virginia University. 2003.

10. Brown, Micheal; Key, Ginny. Revisions to ANSI/MSE 2000. The Energy Management System Standard, Strategic Planning for Energy and the Environment, 2006: 47-55.

11. Ferland, Kathey, et al. Results from the Texas Pilot Project on Manufacturing Plant Energy Efficiency Certification. ACEEE Summer Study on Energy Efficiency in Industry. 2009: 42-53. 
12. Scheihing, Paul. Energy Management Standard. Webcast, US DOE, 2009.

13. European Energy Management. EN 16001. http://www.bsigroup.com/en/Assessment-andcertification-services/management-systems/Standards-and-Schemes/EN-16001-EnergyManagement/ (accessed May 8, 2011).

14. Pondolfo, Daiane. Implementing an Energy Management System. MS Thesis. Politecnico Di Milano, $2009-2010$.

15. Tsim, YC; Yeung, VWS; Leung, Edgar. An Adaptation to ISO 9001:2000 for Certified Organizations. Managerial Auditing Journal. Vol. 17 Iss 5:245 - 250

16. Biazzo, Stefano; Bernardi, Giovanni. Process Management Practices and Quality Systems Standards: Risks and Opportunities of the New ISO 9001 Certification. Business Process Management Journal. 2003: 149-169.

17. Morrow, David; Rondinelli, Dennis. Adopting Corporate Environmental Management Systems:: Motivations and Results of ISO 14001 and EMAS Certification. European Management Journal. 2002: 159-171.

18. Rondinelli, Dennis; Vastag, Gyula. Panacea, Common Sense, or Just a Label: The Value of ISO 14001 Environmental Management Systems. European Management Journal. 2000: 499510.

19. Cheol, Park; et al. Energy Consumption Reduction Technology in Manufacturing- A Selective Review of Policies, Standards and Research. International Journal of Precision Engineering and Manufacturing. 2009: 151-173.

20. Pinero, Edwin. Energy Management System Standard ISO 50001. ISO Workshop. 2010.

21. Energy Management Systems-Requirements with Guidance. DIS, ISO, 2010.

22. Kissock, Kelly; Eger, Carl. Measuring Industrial Energy Savings. Applied Energy. 2008: 347-361.

23. Superior Energy Performance. http://www.superiorenergyperformance.net/ (accessed May 12, 2011). 
24. Scheihing, Paul; et al. Superior Energy Performance: A Roadmap for Continual Energy Performance Improvement. ACEEE Study on Energy Efficiency in Industry. 2009: 33-41.

25. Scheihing, Paul. Save Energy Now: A Resource for Success. Webcast, US DOE, 2009

26. Dusan, Gordic; et al. Development of Energy Management System - Case Study of Serbian Car Manufacturer. Energy Conversion and Management. 2010: 2783-2790.

27. Gorp, Van. Enterprising Energy Management. Power \& Energy Journal. IEEE. 2004: 59- 63.

28. Gorp, Van. Using Key Performance Indicators to Manage Energy Costs. Strategic Planning for Energy and the Environment. Vol 25 No 2: 9-25

29. Capehert, LB. Energy Balancing-Making Financial Decisions. Strategic Planning for Energy and the Environment. Vol 21 No 3: 58-80

30. Wu, Bin; Ponte, Sadina. Institutionalizing Energy Efficiency within the Manufacturing Industry; a Computer Aided Framework for ISO 50001. 2nd International Conference on Environment and Industrial Innovation. 2012: 29-33

31. Tarasovskiy, GV; Syusyukin, AI; Yeremeyeva, GI. Energy Management System Difficulties in Development and Implementation.

www.gce.ru/files/groupgce/Energy\%20Management\%20System.pdf

32. Lammers, N; Kissock, Kelly. Measuring Progress with Normalized Energy Intensity. SAE Int. J. Mater. Manuf.2011: 460-467

33. Enerit. ISO 50001 Software http://enerit.com/ (accessed July 30, 2012). 